\title{
IV „Ein Kasten in nordisch-arabisch-ägyptischem Stil“": Thorvaldsens Museum
}

\section{Die Rückkehr des Nationalhelden}

Bevor Thorvaldsen 1838 endgültig nach Dänemark zurückkehrte, hatte er bereits im Sommer 1819 eine Reise von Rom nach Kopenhagen unternommen, die in einem regelrechten Triumphzug resultierte. ${ }^{1}$ Mit diesem Besuch in seiner Heimatstadt löste der Bildhauer ein über Jahre immer wieder aufgeschobenes Versprechen ein. Bereits Anfang 1805 hatte Abildgaard seinen Zögling in einem vertraulichen Brief gefragt, ob er plane, Rom jemals wieder zu verlassen und nach Kopenhagen heimzukehren. ${ }^{2}$ Gleichzeitig bot er Thorvaldsen an, die Professur des betagten Bildhauers Weidenhaupt an der Kopenhagener Kunstakademie nach dessen Ableben für ihn freizuhalten. ${ }^{3}$ Nachdem Weidenhaupt im April 1805 verstorben war, wurde Thorvaldsen im Juni desselben Jahres trotz Abwesenheit als Professor für Bildhauerei berufen. ${ }^{4}$ Im Laufe der Zeit scheinen sich die Ansprüche der Dänen relativiert zu haben. So äußerte der Baron Schubart am 28. Februar 1812 Thorvaldsen gegenüber den Wunsch seiner Landsleute, dieser möge für ein Jahr nach Dänemark zurückkehren. ${ }^{5}$ Allerdings seien sowohl der Kronprinz Christian Frederik als auch der Architekt Hansen, die zentrale Funktionen innerhalb der Kunstakademie ausübten, „liberal genug, um einzusehen, dass Sie, um ein großer und berühmter Künstler zu bleiben, in Rom arbeiten und leben müssen, und nicht in Dänemark, wo Ihr Genius Sie bald verlassen würde“.6

1 Siehe dazu auch die Kap. I.2 und III.2.

2 Nicolai Abildgaard an Bertel Thorvaldsen, 31. Januar 1805, TMA, Ref. ml 1805, nr. 1. Siehe auch Thiele 1852 -1856, Bd. 1, 123; Jørnæs 2011, 59.

3 Thiele $1852-1856$, Bd. 1, 123.

4 Christian VII. von Dänemark an Bertel Thorvaldsen, 7. Juni 1805, TMA, Ref. m29 II, nr. 1. Siehe auch Thiele 1852 -1856, Bd. 1, 129; Kronberg Frederiksen 2014b; Miss 2016, 5. Am 28. März 1833 wurde Thorvaldsen zudem ebenfalls in Abwesenheit zum Direktor der Kopenhagener Kunstakademie gewählt und hatte diese Position bis zu seinem Tod am 24. März 1844 inne; siehe dazu TMA, Ref. m18 1833, nr. 35 und Ref. m29 II, nr. 55.

5 Herman Schubart an Bertel Thorvaldsen, 28. Feburar 1812, TMA, Ref. m3 1812, nr. 11.

6 Ebd.: „Prindsen saavel som Hansen ere liberale nok til at indsee, at for at vedblive med at være en stor og berømt Kunstner, maae De arbeyde og leve i Rom, og ikke i Dannemark hvor Deres Genius snart ville 
Nach Thorvaldsens Besuch in Kopenhagen in den Jahren 1819/1820 dauerte es fast zwei Jahrzehnte bis zu seiner nächsten Reise in die Heimat, die zugleich seine Rückkehr dorthin war. Im Folgenden wird die als Nationalfest gefeierte Heimkehr des Bildhauers im Herbst 1838 beleuchtet. Die langjährige Stilisierung Thorvaldsens zum dänischen Nationalhelden kulminierte in den Festlichkeiten zu seiner Rückkehr, die dem Pomp anlässlich eines Herrschereinzuges ähnelten. Der Grund für Thorvaldsens Heimkehr war die Errichtung des von ihm selbst initiierten Museums, das am Ende auch seine Grabstätte enthalten sollte. Thorvaldsens Museum/Mausoleum war nicht nur der beispiellose Höhepunkt von Visualisierungen des Künstlerkults um ihn, sondern zugleich das wichtigste Instrument zur Verwandlung seiner diesseitigen celebrity in posthumen Ruhm.

\section{Von der Peripherie ins Zentrum und zurück}

Die oben zitierte Äußerung Schubarts macht deutlich, dass man sich in Dänemark der Notwendigkeit eines Aufenthalts in der Kunstmetropole Rom oder nach Möglichkeit einer Übersiedelung dorthin für eine erfolgreiche Künstlerlaufbahn durchaus bewusst war. Denn der durch die Tradition der Grand Tour angeregte Fremdenverkehr des europäischen und zunehmend auch amerikanischen Bildungsbürgertums ermöglichte in Rom einen florierenden Kunstmarkt. Demgegenüber war Dänemark im frühen 19. Jahrhundert nicht nur geografisch, sondern auch kulturell eine periphere Region im damaligen Europa, obschon die Jahrzehnte zwischen 1800 und 1850 heute als das Goldene Zeitalter der dänischen Kunst gelten. Die kulturell periphere Situation in Skandinavien zeigt sich auch darin, dass die meisten dänischen Künstler jener Zeit Reisen in die Zentren Rom und etwas später Paris unternahmen, was sich in ihren Werken deutlich niederschlug. Man kann in Bezug auf Dänemark zu Thorvaldsens Lebzeiten folglich kaum von einem „Wert künstlerischer Peripherie“ sprechen, wie dies Jan Białostocki mit Blick auf andere kulturelle Randgebiete getan hat und der spätestens seit der künstlerischen Avantgarde nicht nur an Bedeutung gewann, sondern gleichsam zu einem Teil künstlerischen Selbstverständnisses wurde. $^{7}$

Kopenhagen bot zu Beginn des 19. Jahrhunderts weder die Voraussetzungen für ein Antikenstudium noch Aussichten auf prestigeträchtige Aufträge für Bildhauer. ${ }^{8}$ So schrieb Abildgaard bereits am 4. Oktober 1801 an Thorvaldsen, dass die Bildhauer in Dänemark einzig Grabsteine anfertigten. ${ }^{9}$ In ähnlicher Weise bemerkte auch Fernow zwei Jahre spä-

forlade Dem; [...].“ Siehe auch Thiele 1852-1856, Bd. 1, 216. Der dänische Kronprinz Christian Frederik war damals Präsident der Kopenhagener Kunstakademie, während Hansen die Professur für Architektur bekleidete.

8 Wittstock 1975, 37 - 39; Jørnæs 1989c, 27; Jørnæs 1990a, 19; Bogh 2006, 284; Bencard 2009.

9 Nicolai Abildgaard an Bertel Thorvaldsen, 4. Oktober 1801, TMA, Ref. ml 1802, nr. 5. Siehe auch Jørnæs 1990a, 19; Bencard 2009. 
ter, kurz nach der Entstehung der Jason-Statue, dass Thorvaldsen, wäre er in Dänemark geblieben, „in seinem Vaterlande unerkannt, genötigt gewesen wäre durch Arbeiten unter seiner Sphäre kümmerlich seinen Unterhalt zu erwerben “. ${ }^{10}$ Neergaard war 1814 der Meinung, dass die Bildhauer aus dem Norden „immer ihre schönsten Arbeiten in Italien“ gemacht hätten und Thorvaldsen daher besser in Rom bleiben sollte. ${ }^{11}$ Im Gegensatz zu Rom als dem Kunstzentrum der Zeit galt Kopenhagen als kulturelle Peripherie, wie etwa Harro Harring in seinen 1828 publizierten Reiseberichten festgestellt hat: „Copenhagen ist für den bildenden Künstler in sofern ein undankbarer Ort, da es abgeschnitten von der übrigen Kunstwelt, das Leben der Künstler beschränkt. "12 Infolgedessen erhoffte sich Steinheim 1842, dass Kopenhagen nach Fertigstellung von Thorvaldsens Museum „das Ziel der Wanderungen gebildeter Reisenden werde, und daß von Süden her nach dem nordischen Tempel der bildenden Kunst gewallfahrt werde “.13 In den Augen der Zeitgenossen wurde dies schließlich erreicht - gemäß Otto gelangte die Kunst überhaupt erst durch Thorvaldsen in die dänische Hauptstadt, wodurch diese quasi von der Peripherie zu einem Zentrum geworden sei. ${ }^{14}$

Auch der Bildhauer selbst war sich der Notwendigkeit der geografischen Mobilität von der kulturellen Peripherie ins Kunstzentrum bewusst. Auf eine entsprechende Aussage von Thorvaldsen antwortend, schrieb der Bildhauer Franz Woltreck am 2. August 1837 an den Dänen: „Ich sage Sie haben Recht nicht von Rom weg zu gehen, oft, ja sehr oft gedenke ich Ihrer, wenn Sie mir sagten der Künstler muß in Rom leben, und wenn er nur troken Brodt zu essen hat. "'15 Auch gegenüber Andersen, der Thorvaldsen von einem vernichtenden Urteil über eines seiner Gedichte berichtet hatte, soll Thorvaldsen gemeint haben: „Ja ja, ich kenne die zu Hause! [M]ir wäre es nicht besser ergangen, wenn ich dageblieben wäre! Ich hätte vielleicht nicht einmal Modell sitzen dürfen!"16 1838 suchte sich Andersen ins Gedächtnis des nun endgültig in Dänemark erwarteten Thorvaldsen zurückzurufen, indem er ihm in einem Brief über sein drei Jahre zuvor veröffentlichtes Buch Der Improvisator berichtete und für die einstmalige Ermunterung dankte. ${ }^{17}$ Bezeichnenderweise handelte es sich bei diesem Werk um den ersten dänischen Bildungsroman, durch den sich die Bedeutung geografischer Mobilität beziehungsweise von Peripherie

10 Carl Ludwig Fernow an Karl August Böttiger, 1. Juli 1803, zit. nach Wittstock 1975, 280, auch 44.

11 Neergaard 1814, 576.

12 Harring 1828, 78. Siehe auch Drees 1991, 123.

13 Salomon Ludwig Steinheim, Ende Oktober 1842, TMA, Ref. m30 II, nr. 78a (dieser Text wurde außerdem anonym in der Zeitschrift Telegraph für Deutschland, 188, November 1842, 749 - 752, publiziert).

14 Otto 1869, 667; auch Just Mathias Thiele, Rede am Stiftungstag der Kopenhagener Kunstakademie, 31. März 1844, zit. bei Thiele 1852 - 1856, Bd. 3, 187.

15 Franz Woltreck an Bertel Thorvaldsen, 2. August 1837, TMA, Ref. m21 1837, nr. 43.

16 Zit. nach Andersen 1961, 169.

17 Hans Christian Andersen an Bertel Thorvaldsen, 10. Mai 1838, TMA, Ref. m22 1838, nr. 35. Siehe auch Johansson 1994, $194-195$. 
und Zentrum für eine erfolgreiche Künstlerlaufbahn wie ein roter Faden zieht. ${ }^{18}$ Der entscheidende Stellenwert von Thorvaldsens Übersiedelung nach Rom für seine Künstlerbiografie manifestierte sich schließlich darin, dass er den 8. März, seinen Ankunftstag in der Ewigen Stadt 1797, alljährlich als seinen zweiten Geburtstag feierte. ${ }^{19}$ Nach seiner Ankunft in Rom änderte er ferner seinen Vornamen von Bertel zu Alberto, wobei das korrekte italienische Äquivalent zu seinem dänischen Namen Bartolomeo gewesen wäre. ${ }^{20}$

Ebenfalls im Zusammenhang mit den Gegenpolen von Zentrum und Peripherie ist schließlich die sich simultan zu den Vergleichen Thorvaldsens mit Phidias häufende Betonung seiner nordischen Herkunft bezeichnend. Dieser Kontrast zwischen Süden und Norden, Italien und Dänemark (oder Island), Rom und Kopenhagen wurde in unzähligen Quellen hervorgehoben. Für den vorliegenden Kontext ist er interessant, weil er offensichtlich Thorvaldsens Leistung besonders hervorheben sollte: Wie Peter Davidson in seinem kulturgeschichtlichen Porträt The Idea of North festgehalten hat, wird die Vorstellung vom Norden durch Gedanken an abgelegene, klimatisch raue, kulturell brache und zuweilen mystische Orte geprägt. ${ }^{21}$ Dies gilt gerade auch für Skandinavien im 19. Jahrhundert: Die Vorstellung von Island vereinte sämtliche Ideen des äußersten Nordens in sich, was durch die Wiederentdeckung und wissenschaftliche Aufarbeitung der altnordischen Mythologie noch verstärkt wurde. ${ }^{22}$ Durch die Betonung von Thorvaldsens isländischer Abstammung - also seiner (angeblichen) Herkunft fern von Kultur und einem für künstlerisches Schaffen zuträglichen Klima - musste seine Entwicklung zu einem der erfolgreichsten und berühmtesten Bildhauer im damaligen Kunstzentrum Rom umso erstaunlicher erscheinen. ${ }^{23}$ Zugleich bildete seine skandinavische Herkunft ein verbindendes Element unter seinen dänischen Landsleuten und die Grundlage für seine beispiellose Verehrung als Künstlergenie, seine Stilisierung zum Nationalhelden und die celebrity-Kultur in der Heimat.

19 Siehe bspw. Thiele 1852 - 1856, Bd. 1, 46; Atkinson 1873, 54; Helsted 1973, 20; Schoch 1991, 17. Siehe auch Kap. I.1. Auch für Johann Wolfgang von Goethe und John Gibson ist überliefert, dass sie das Datum ihrer Ankunft in Rom als zweiten Geburtstag feierten; siehe dazu Atkinson 1873, 54.

20 Das erste Zeugnis dafür scheint ein vermutlich noch im März 1797, also unmittelbar nach Thorvaldsens Ankunft in Rom, verfasster Briefentwurf des Bildhauers an Jørgen West zu sein; TMA, Ref. C818v. Siehe auch „Alberto eller Bertel“ 2008 (hier findet sich außerdem eine Liste sämtlicher Schreibweisen von Thorvaldsens Namen).

21 Davidson 2016, bes. 11-12.

22 Siehe auch Jørnæs 2011, 12.

23 Siehe in ähnlichem Zusammenhang auch Mildenberger 1991, 196. 


\section{Thorvaldsens Ankunft in Kopenhagen}

Nachdem er über vier Jahrzehnte in Rom gewirkt hatte, erreichte Thorvaldsen am 17. September 1838 seine Geburtsstadt Kopenhagen. ${ }^{24}$ Seine definitive Heimkehr wurde als Nationalfeiertag und der Bildhauer selbst als Nationalheld zelebriert. Der pompöse Empfang durch seine Landsleute wurde in verschiedenen bildlichen Darstellungen und schriftlichen Zeugnissen festgehalten und ausgeschmückt. Ein 1839 entstandenes Gemälde von Eckersberg zeigt Thorvaldsens Ankunft in einem Ruderboot mit dem Kapitän Dahlerup, weiteren Reisenden und Matrosen der Fregatte Rota, unter denen man den Bildhauer am privilegierten Sitzplatz und den weißen Haaren erkennt (Taf. VIII). ${ }^{25}$ Die Rota, die Thorvaldsen auf einer rund einen Monat dauernden Fahrt von Italien nach Dänemark gebracht hatte, liegt im Hintergrund des Gemäldes vor Anker. Bevor diese und andere Visualisierungen von Thorvaldsens Heimkehr näher betrachtet werden, soll ein am 18. September 1838 in der Tageszeitung Kjøbenhavnsposten publizierter Artikel beleuchtet werden. Es handelt sich dabei um den ersten und detailliertesten Bericht über die Ankunft des Bildhauers in Kopenhagen:

Kjøbenhavnsposten erscheint erst heute, weil die Schriftsetzer gestern beim Zollhaus [Toldboden] waren. Denn die alltägliche Ordnung der Dinge wurde unterbrochen, und Kopenhagen war beim Zollhaus oder auf der Reede, und das große nationale Fest, das gefeiert wurde, war in Wahrheit eines der reizendsten und bedeutsamsten Ereignisse, von denen die Stadt Kopenhagen jemals Zeugin gewesen ist. [...] ein ermüdendes Warten und strömender Regen hatten nicht im Entferntesten die Begeisterung gemildert, mit der die Kopenhagener nach draußen eilten, um dem höchst verdienstvollen Künstler, ihrem mit Ehren bekrönten Landsmann einen jubelnden Empfang darzubringen. [...] In einer beinahe unüberschaubaren Reihe folgte nun Boot an Boot, viele davon mit Laub und Blumengirlanden geschmückt, und fast alle mit festlichen Flaggen, die auf das Fest des Tages anspielende Embleme führten. [...] Als sich dieser Zug, umringt von einer großen Menge Privatbooten, unter dem anhaltenden Spiel der verschiedenen Musikchöre, um die Fregatte versammelt hatte, gingen Freund und Thiele mit einem in pompejianischer Art dekorierten Boot an Bord, und als darauf Thorvaldsen erschien, wurde er mit enthusiastischem Jubel empfangen. ${ }^{26}$

Siehe auch Kat. Köln 1977, 345; Kat. Nürnberg/Schleswig 1991, 699. Zu Dahlerups eigenen Erinnerungen an seine Fahrt von Italien nach Kopenhagen siehe Dahlerup 1909.

Kjøbenhavnsposten, 12:256, 17. September 1838 [erschienen am 18. September 1838], 1031-1032: „Københavnsposten udkommer først i Dag, fordi Sætterne igaar vare paa Toldboden. Den daglige Tingenes Orden var nemlig suspenderet, og Kjøbenhavn var paa Toldboden eller paa Rheden, og den store nationale Fest, som der blev feiret, var i Sandhed et af de yndigste og betydningsfuldeste Optrin, hvortil Staden Kjøbenhavn nogensinde har været Vidne. [...] en trættende Venten og øsende Regn ikke i fjerneste Maade havde lunknet den Begejstring, med hvilken Kjøbenhavnerne ilede ud for at bringe den høitfortjente Konstner, den hæderkronede Landsmand et jublende Velkommen. [...] I en næsten uoverseelig Række fulgte nu Baad paa Baad, flere smykkede med Løv og Blomsterguirlander, og næsten alle med festlige Flag, der førte Emblemer sigtende til Dagens Høitid. [...] Da disse Tog, omringede af en stor Mængde Privatbaade, under vedvarende Spil af de forskjellige Musikchor, havde samlet sig om Fregatten, gik Freund og Thiele, med en paa pompeiansk Maade decoreret Baad ombord, og da derpaa Thor- 
Aus diesem Artikel geht die zentrale Bedeutung von Thorvaldsens Rückkehr nach Kopenhagen für das dänische Selbstverständnis hervor. Dies zeigt sich auch darin, dass die Zeitung anlässlich dieses Ereignisses ihren Betrieb unterbrochen hatte. Dem Bericht in Kjøbenhavnsposten entsprechen auch die visuellen Darstellungen von Thorvaldsens Ankunft. So betont etwa Eckersbergs Gemälde die Masse an Schaulustigen auf Booten, die dasjenige der Reisenden umgeben und den Bildhauer feierlich begrüßen. Besonders prominent erscheint dabei das Boot der Dichter im rechten Vordergrund. Am Schiffsmast hält sich Andersen fest und schwingt seinen Hut. Der inzwischen erfolgreiche Dichter hat selbst einen ausführlichen Bericht über die Ankunft seines bewunderten Landsmannes hinterlassen:

Es war ein Nationalfest. Boote, mit Blumen und Fahnen geschmückt, schaukelten zwischen Langelinie und Trekroner auf dem Wasser. [... Dies kann man noch auf dem gemalten Fries am Thorvaldsen-Museum angedeutet sehen; in dem Dichterboot dort erkennt man Oehlenschläger, Heiberg, Hertz und Grundtvig; ich stehe auf der Ruderducht, halte mich am Mast fest und schwenke den Hut. - Am Ankunftstage war nebliges Wetter, und man erblickte das Schiff erst, als es ganz nahe bei der Stadt war. Die Signale ertönten, Leute strömten zum Zollschuppen; und die eingeladenen Dichter, die von Heiberg zusammengerufen worden waren, der damals der Führende und Ausschlaggebende war, standen bei ihren Booten, die am Larsens Platz lagen, aber Oehlenschläger und Heiberg selbst waren noch nicht gekommen, die Poeten warteten, die Böllerschüsse ertönten vom Fahrzeug, das schon Anker warf; ich erkannte, daß Thorvaldsen bereits an Land gestiegen sein würde, bevor wir kämen; schon trug der Wind die Liederklänge zu uns herüber, der festliche Empfang hatte angefangen, ich wollte mit dabei sein und sagte daher zu den anderen: ,Wir wollen losrudern! - ,Ohne Oehlenschläger und Heiberg?' riefen die anderen aus. - ,Die kommen ja nicht, und alles ist schnell vorbei!' [...] die anderen kamen nun mit mir, und wir waren gerade dort draußen, als Thorvaldsen auf das Ufer zuhielt. Heiberg und Oehlenschläger trafen wir dort draußen in einem Boot, das sie sich genommen hatten; nun kamen sie zu uns an Bord. ${ }^{27}$

Eckersbergs Darstellung wurde erst im Jahr nach Thorvaldsens Rückkehr fertiggestellt. Bei diesem Werk handelt es sich um die vom Bildhauer selbst in Auftrag gegebene, vergrößerte Replik eines Gemäldes von 1838, das sich in Privatbesitz befindet. ${ }^{28}$ Möglicherweise war es Thorvaldsen wichtig, dass in seinem Museum dereinst ein Gemälde eines namhaften Künstlers von seiner triumphalen Rückkehr zeugen werde. Ferner sind in der Grafischen Sammlung des Kopenhagener Statens Museum for Kunst zwei - wenige Tage

valdsen kom frem, blev han modtagen med enthusiastisk Jubel.“ Siehe auch Müller, S. 1893, 269; Jørnæs 2011, $213-214$.

27 Andersen 1961, 262-263. Für weitere ausführliche Beschreibungen von Thorvaldsens Ankunft in Kopenhagen siehe Thiele 1831-1850, Bd. 4, 38 -55; Thiele 1852-1856, Bd. 3, 5-26; Barfod 1844, 183-224; auch Andersen 1845, 56-57; Repholtz 1911, 21 -22; Schultz 1938. Der von Andersen erwähnte gemalte Fries an Thorvaldsens Museum wird im Kap. IV.2 besprochen.

28 Fischer, E. 1991, 211 - 212; auch Schultz 1938, 32 - 34; Kat. Köln 1977, 345; Kat. Nürnberg/Schleswig 1991, 698-699. 
nach diesem Ereignis entstandene - Zeichnungen von Eckersberg erhalten, der bei der Ankunft des Bildhauers persönlich anwesend war. ${ }^{29}$

\section{Unter Mitwirkung höherer Mächte}

Im Hintergrund fast aller Darstellungen von Thorvaldsens Ankunft in Kopenhagen, so auch bei Eckersberg, wölbt sich ein Regenbogen über dem Øresund. Gemäß den Augenzeugenberichten war der 17. September 1838 ein regnerischer Tag, doch als die Fregatte Rota mit Thorvaldsen an Bord vor Kopenhagen erschien, seien die Wolken aufgebrochen und ein Regenbogen habe sich gebildet. ${ }^{30}$ Mag dies stimmen oder nicht: Im Zusammenhang mit dem beispiellosen Kult um den Bildhauer ist der Regenbogen durchaus auf einer symbolischen Ebene zu sehen. So brachte Andersen ihn mit Thorvaldsens ,Triumphzug als Künstler in Verbindung und nannte das Naturschauspiel eine „Ehrenpforte für Alexander" ${ }^{31}$ Damit verwies der Dichter auf Thorvaldsens berühmten Relieffries Einzug Alexanders des Großen in Babylon von 1812, der im Kapitel I.2 besprochen wurde, und verglich den Bildhauer direkt mit dem antiken Herrscher.

Auf einer anderen Ebene standen der Wetterumschwung und der Regenbogen für höhere Mächte, wenn Letzterer in der Zeitung Kjøbenhavnsposten als ,jenes uralte Symbol des Bundes“ bezeichnet wurde. ${ }^{32}$ Gemeint war damit der Regenbogen als Zeichen des Bundes zwischen Gott und den Menschen, mit dem die biblische Sintflut und die Irrfahrt der Arche Noah ein glückliches Ende fanden. Ohnehin sollen höhere Mächte Thorvaldsens Reise begleitet und sich bereits bei seiner Ankunft in Helsingør am Tag zuvor in Form von Nordlichtern gezeigt haben. ${ }^{33}$ Andersen schrieb dazu:

Seit langem sahen wir nicht so schöne Nordlichte, als im Herbst 1838. Rothe und blaue Flammen wirbelten am Horizonte; Islands helle Nächte waren zu unsern grünen Inseln herabgestiegen; es war, als ob Thorwaldsens Voreltern, in Glanz der Nordlichte gehüllt, zum Gruß ihres Abkömmlings herniederschwebten. ${ }^{34}$

Auch Thiele verband dieses Phänomen mit Thorvaldsens isländischer Abstammung und der nordischen Götterwelt:

Inv.-Nr. KKS18751 und KKSgb4223. Siehe auch Schultz 1938, 29 - 34; Fischer, E. 1991, bes. 211. 1843, 49; Andersen 1845, 56; Thiele 1831-1850, Bd. 4, 40; Thiele 1852-1856, Bd. 3, 8-9; Dahlerup 1909, 218; Thiele 1917, 67; Andersen 1961, 263.

31 Andersen 1845, 56; Andersen 1961, 263.

32 Kjøbenhavnsposten, 12:256, 17.September 1838 [erschienen am 18.September 1838], 1031: „[...] og en smuk Regnbue, hiin Pagtens ældgamle Symbol, kom tilsyne. “ Siehe auch Jørnæs 2011, 213.

33 Thiele 1831-1850, Bd. 4, 38-39; Thiele 1852-1856, Bd. 3, 5-6; auch Dahlerup 1909, 218; Schultz 1938, 20 - 23; Fischer, E. 1991, 211.

34 Andersen 1845, 55. 
Da brachte auch die Himmelssphäre des Norden[s] ihrem großen Sohn einen festlichen Gruß; von dem fernen Horizonte sendete Gott Thor sein schönstes Strahlenlicht aus, und das Meer fing es in seinem dunkeln Spiegel auf - Thorvaldsen stand umstrahlt von den herrlichsten Nordlichtern! ${ }^{35}$

Zugleich war Thiele um die Glaubwürdigkeit seiner Beschreibungen bemüht und zog als ,Beweis Eckersbergs Gemälde bei, auf dem der Regenbogen deutlich zu sehen ist. ${ }^{36} \mathrm{Zu}$ dem untermauerte er seinen Wahrheitsanspruch mit der Begründung, dass Thorvaldsens Leben von zahlreichen solcher „kleinen Wunder" geprägt gewesen sei. ${ }^{37}$ So hätten „Grüße aus dem fernen Pole in knisternden Nordlichtern" den Bildhauer bereits bei dessen Besuch in der Heimat im Sommer 1819 empfangen. ${ }^{38}$ Als sozusagen objektiven, wissenschaftlichen Beleg dafür, dass es sich bei seinem Bericht nicht um „schwulstigen Tand und Erdichtung" handle, führte Thiele eine entsprechende Mitteilung des bei Thorvaldsens Ankunft 1838 auf einem Wachtschiff in Helsingør anwesenden Admirals Christian Christopher Zahrtmann vom 14. Januar 1852 an. ${ }^{39}$ Dieser erinnerte sich darin an die Wetterverhältnisse bei der Einfahrt der Fregatte Rota in den Øresund und bestätigte die Erscheinung der „stärksten und schönsten Nordlichter, die ich jemals erblickt habe“ ${ }^{40}$

\section{Triumphzug durch Kopenhagen}

Häufiger als alle anderen Momente von Thorvaldsens Rückkehr wurde sein tosender Empfang an Land bei der Zollstelle Toldboden dargestellt, der in der Zeitung Kjøbenhavnsposten in folgenden Worten beschrieben ist:

Am Zollhaus begrüßte der konferensraad Hansen als erster der Professoren der Kunstakademie deren großen Meister [...], und nachdem er [Thorvaldsen] die wartende Kutsche bestiegen hatte, wurden die Pferde losgebunden, und der Wagen bewegte sich in der größten Ordnung und Regelmäßigkeit durch die Amaliegade über den Amalienborg Palast zu Schloss Charlottenborg, begleitet von unaufhörlichen Vivats, die sich besonders zu stürmischem Jubel erhoben, als der Zug den Königspalast passierte. Nicht bloss die Fenster der Häuser, an denen der Triumphzug vorbeiging, waren mit Menschen gefüllt, sondern Wagen, Treppen und dergleichen waren mit Pyramiden von Zuschauern bedeckt. ${ }^{41}$

Thiele 1852 - 1856, Bd. 3, 6. Siehe auch Thiele 1831-1850, Bd. 4, 38 - 39.

Thiele $1852-1856$, Bd. 3, 9-11; auch Thiele 1831-1850, Bd. 4, 40 und 43.

Thiele $1852-1856$, Bd. 3, 6.

Ebd.

Ebd., 6-7.

Zit. nach ebd., 7.

Kjøbenhavnsposten, 12:256, 17.September 1838 [erschienen am 18. September 1838], 1032: „Paa Toldboden modtog Conferentsraad hansen i Spidsen for Konstacademiets øvrige Professorer deres store Mester, [...] og da han var stegen i den Vogn, som der ventede ham, vare i et Nu Hestene spændte fra og i den største Orden og Regelmæssighed bevægede Vognen sig gjennem Amaliegaden, over Amalienborg til Charlottenborg, ledsaget af uophørlige Vivats, der især hævede sig til stormende Jubel idet Toget passerede forbi Kongens Palais. Ikke blot Vinduerne i de Huse, forbi hvilke Triumphtoget gik, vare opfyldte 


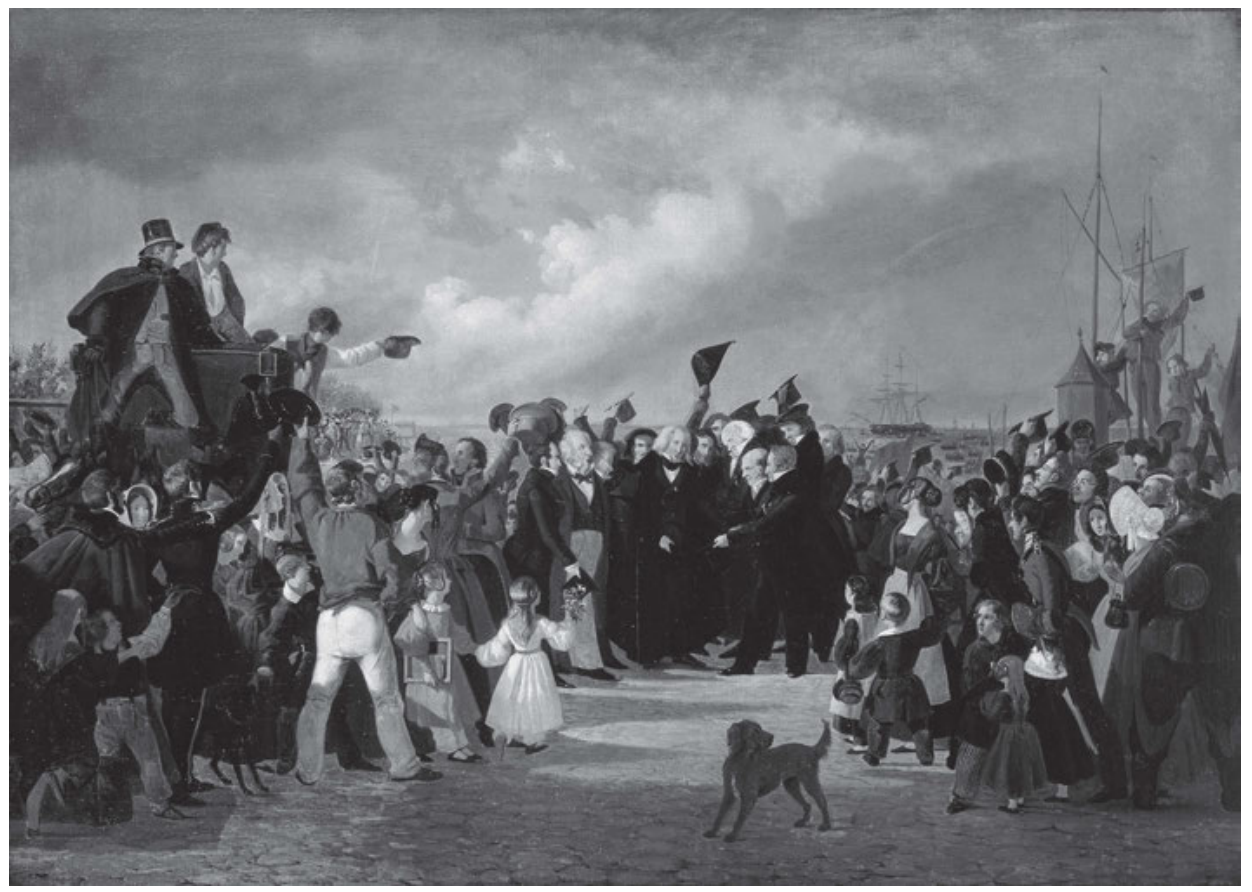

91_Fritz Westphal, Der Empfang von Bertel Thorvaldsen bei der Zollstelle Toldboden in Kopenhagen am 17. September 1838, 1839-1841, Öl auf Leinwand, 71,5 × $100 \mathrm{~cm}$, Kopenhagen, Thorvaldsens Museum (Inv.-Nr. B453)

Entsprechend diesem Bericht zeigt Fritz Westphals Gemälde von 1839 - 1841 für den Kopenhagener Kunstverein, wie der Bildhauer bei der Zollstelle in Begleitung des am weißen Haar und der Halbglatze erkennbaren Architekten Hansen und weiterer Zeitgenossen durch die jubelnde Menge schreitet, während im rechten Hintergrund die Fregatte Rota auszumachen ist (Abb. 91)..$^{42}$ Durch die Wiedergabe von Menschen jeder Gesellschaftsschicht und jeden Alters veranschaulicht Westphals Gemälde einen Aspekt, der für den Thorvaldsen-Kult in Dänemark von zentraler Bedeutung war: Sowohl die Heimkehr des Bildhauers als auch die Errichtung seines Museums sollten Ereignisse von nationaler Dimension sein, an denen sämtliche Bürger Dänemarks Anteil hatten. Da-

med Mennesker, men Vogne, Trapper og deslige vare bedækkede med Pyramider af Tilskuere." Siehe auch Müller, S. 1893, 270; Jørnæs 2011, 214.

42 Zu diesem Gemälde siehe Schultz 1938, 41 - 43; Fischer, E. 1991, 212; Jørnæs 1992, 14. Westphals Gemälde befand sich später im Privatbesitz und wurde 1986 von Thorvaldsens Museum erworben. Eine mit Bleistift und Wasserfarbe angefertigte Skizze zu diesem Bild befindet sich im Nationalhistorischen Museum auf Schloss Frederiksborg in Hillerød; Abb. bei Schultz 1938, 40. 


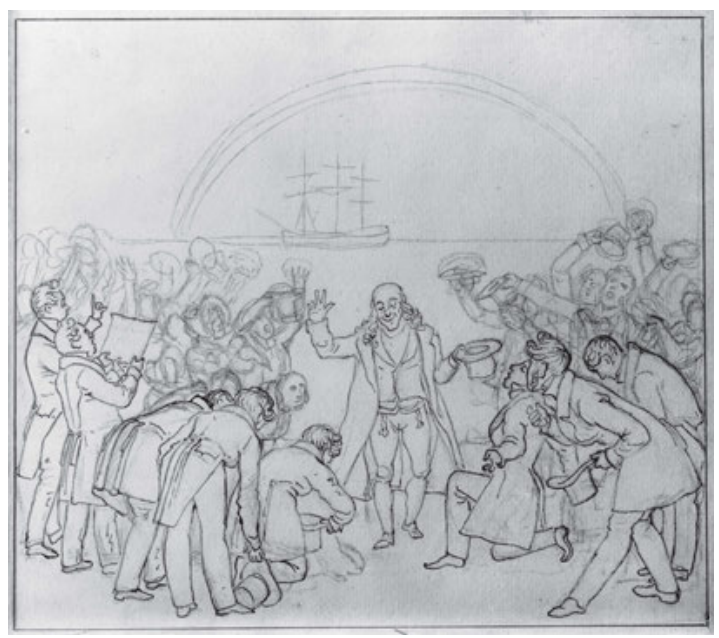

92_Christen Købke, Bertel Thorvaldsens Heimkehr, um 1838, Bleistift und Tusche auf Papier, $95 \times 133 \mathrm{~mm}$, Hillerød, Det Nationalhistoriske Museum på Frederiksborg Slot (Inv.-Nr. 4811)

durch wurde wiederum der symbolische Gehalt jener Ereignisse gestärkt, der Eingang ins kollektive Gedächtnis finden und zum dänischen Selbstverständnis der Zeit beitragen sollte.

In den Bildern von Thorvaldsens Ankunft in Kopenhagen wirkt die bis in die Antike zurückreichende Ikonografie von Herrschereinzügen nach. ${ }^{43}$ Im Unterschied zu tatsächlichen Adventus-Darstellungen erscheint der Protagonist hier jedoch weder hoch zu Ross, noch sind Kopenhagens Straßen von ephemerer Architektur und tableaux vivants gesäumt, wie sie Herrschereinzüge besonders in der Frühen Neuzeit begleiteten. Dennoch wird Thorvaldsen, der über Jahrzehnte mit zahlreichen Ritterorden ausgezeichnet worden war, in den Visualisierungen seiner triumphalen Rückkehr erneut - diesmal auf symbolischer Ebene - geadelt. Den Vergleich zwischen dem Bildhauer und Herrschern haben bereits Thorvaldsens Zeitgenossen gezogen, wie beispielsweise mit Blick auf den Alexanderzug deutlich wurde. ${ }^{44}$ Dementsprechend schrieb der Autor Louis de Loménie in den 1840 er Jahren unter dem Pseudonym Un homme de rien, dass ein „König, der nach gewonnener Schlacht in seine Heimatstadt zurückkehrt, kein lebendigeres Aufsehen erregt, als das Aufsehen, das durch die Neuigkeit der Ankunft des dänischen Künstlers erregt wurde“. ${ }^{45}$ Der Ballettmeister August Bournonville bezeichnete Thorvaldsen derweil als einen „Helden, der gekämpft und gesiegt hatte“ und als einen „König im Reich des Geistes 
93 Christoffer Wilhelm Eckersberg (zugeschrieben), Bertel Thorvaldsens Heimkehr, um 1838, Bleistift auf Papier, $170 \times 230 \mathrm{~mm}$, Kopenhagen, Det Kongelige Bibliotek

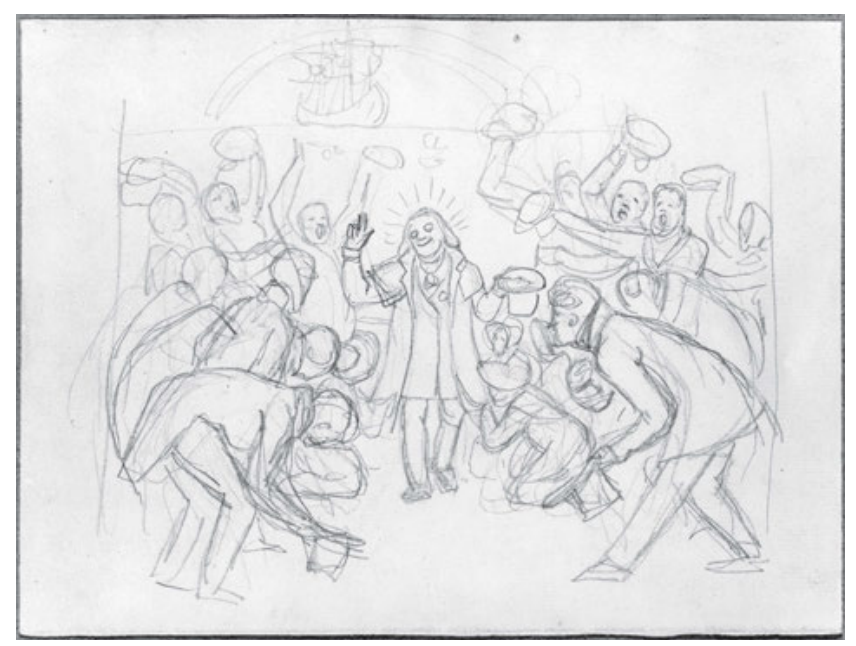

und der Schönheit“ “ ${ }^{46}$ Und gemäß dem Schriftsteller Holst übertrafen die tosende BegrüBung Thorvaldsens durch seine Landsleute und dessen „triumphaler Einzug" gar jeden noch so feierlichen Empfang für einen König oder Helden. ${ }^{47}$ Darin spiegelt sich zum einen Thorvaldsens Status als internationale Berühmtheit wider, zum anderen - mit dem ersten Punkt eng verknüpft - die Stilisierung des Bildhauers zum dänischen Nationalhelden.

Die grenzenlose Verehrung von Thorvaldsen durch seine Zeitgenossen, die auch bei Westphal deutlich gezeigt wird, ist in zwei Karikaturzeichnungen der Ankunft des Bildhauers an der Zollstelle auf die Spitze getrieben: Sowohl Christen Købke als auch Eckersberg (zugeschrieben) skizzierten Zuschauer, die vor Thorvaldsen in die Knie sinken, den Saum seines Mantels küssen, sich verbeugen oder ausgelassen ihre Hüte schwingen (Abb. 92 und 93). ${ }^{48}$ Der Bildhauer selbst hat in beiden Zeichnungen ebenfalls den Hut abgenommen und geht lächelnd durch die Menge. Seine rechte Hand hat er zu einem Segnungsgestus geformt, während in der Eckersberg zugeschriebenen Zeichnung ein strahlender Nimbus seinen Kopf umgibt. Wie nah gerade letzteres Bild an der damaligen, stark verherrlichenden Vorstellung über Thorvaldsen war, veranschaulicht besonders ein Satz in Andersens Bericht über den Empfang für den Bildhauer: „Für alle lag um Thorvaldsen

Bournonville 1865, 220: „[...] han [Thorvaldsen] var jo en Helt, der havde kæmpet og seiret, en Konge i Aandens og Skjønhedens Rige.“ Siehe auch Jørnæs 1992, 14. Bournonville schrieb 1839 anlässlich von Thorvaldsens Rückkehr aus Italien das erfolgreiche Ballett Das Fest in Albano (dän. Festen i Albano), das mit Unterbrüchen bis Ende 1919 am Königlichen Theater in Kopenhagen aufgeführt werden sollte; McAndrew/Jürgensen 2002, 408.

47 Holst 1865/1866, 28: „Jamais roi n’a été ainsi reçu par son peuple, jamais héros n’a fait une entrée triomphale aussi brillante.“

$48 \mathrm{Zu}$ diesen beiden Karikaturen, jedoch ohne Künstlerzuschreibungen, siehe auch Schultz 1938, 43 - 45. 
ein Nimbus, der mich scheu zurückhielt. ${ }^{{ }^{49} 9}$ Solche - bei Købke und Eckersberg (zugeschrieben) jedoch deutlich karikierten - christomorphen Züge wie der Segnungsgestus, der Nimbus und die Berührung des Mantelsaums sind im Zusammenhang mit dem romantischen Künstlerkult zu sehen, der in den beiden Zeichnungen folglich ebenfalls zur Satire wird. ${ }^{50}$

Nach dem Empfang des in die Heimat zurückgekehrten Bildhauers an der Zollstelle zogen die Anwesenden ihren verehrten Landsmann in einem Wagen mit ihrer eigener Kraft - die Pferde waren ausgespannt worden - durch die Stadt zu Schloss Charlottenborg, dem Sitz der Kunstakademie, wo Thorvaldsen eine Wohnung und ein Atelier hatte. ${ }^{51}$ Auf dem Platz vor Charlottenborg, dem Kongens Nytorv, versammelten sich die Schaulustigen. Auch hier wurde Thorvaldsen feierlich, ja königlich begrüßt: „Am Kongens Nytorv wartete die Menschenmenge, bis Thorvaldsen auf dem Balkon von Charlottenborg

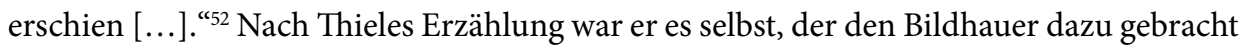
hatte, auf den Balkon zu treten:

\begin{abstract}
Als er an meinem Arm gelehnt, sich der Balkonthüre näherte, um in dem nächsten Augenblick vor die jubelnde Menschenmenge hinzutreten, sagte er mit seinem schelmischen Lächeln: ,Das ist ja ganz wie wenn der Papst den Segen austheilt! - Und mit diesen an mich gerichteten Worten entblößte er sein Haupt und trat ehrerbietig vor die jubelnde Volksmenge, und er stand dort in der That ganz wie der Papst auf St. Peter in Rom. ${ }^{53}$
\end{abstract}

Die Szene, wie der Bildhauer auf den Balkon tritt und den Hut zur Begrüßung der kaum überblickbaren Menschenmenge abgenommen hat, wurde von Christian Carl Peters in einer kleinen Tuschezeichnung festgehalten (Abb. 94). Thieles quasi-sakralisierende Beschreibung dieses Ereignisses veranschaulicht einmal mehr seine zentrale Rolle bei der Pflege des Kults um Thorvaldsen. Ferner wurde der Bildhauer durch seine Begrüßung des Volkes vom Balkon aus - einer bis in die Gegenwart anhaltenden Tradition der Königshäuser - erneut mit einem Herrscher assoziiert.

In den Tagen und Wochen nach Thorvaldsens Rückkehr folgten weitere Festlichkeiten zu seinen Ehren. ${ }^{54}$ Unter anderem wurde eine von Christen Christensen bereits 1835 entworfene Medaille geprägt, mit der noch heute junge Absolventen der Kopenhagener

49 Andersen 1961, 264.

50 Siehe auch Bjarne Jørnæs, in: Helsted 1973, 14.

51 Andersen 1961, 263; auch Olsen, F. C. 1843, 49; Bjarne Jørnæs, in: Helsted 1973, 15.

52 Kjøbenhavnsposten, 12:256, 17. September 1838 [erschienen am 18. September 1838], 1032: „Paa Kongens Nytorv forblev Massen, indtil Thorvaldsen kom frem paa Altanen paa Charlottenborg, [...]. “Siehe auch Müller, S. 1893, 270; Jørnæs 2011, 215.

53 Thiele 1852 -1856, Bd. 3, 12. Siehe auch Thiele 1831-1850, Bd. 4, 44-45; Trier 1903, 174-177; Thiele 1917, 70.

54 Für Ausführungen dazu siehe Andersen 1845, 58 - 59; Thiele 1831-1850, Bd. 4, 48 - 55; Thiele 1852 - 1856, Bd. 3, $15-26$. 
94_Christian Carl Peters, Bertel Thorvaldsen auf dem Balkon von Schloss Charlottenborg, 1838, Tinte und Bleistift auf Papier, Maße und Verbleib unbekannt

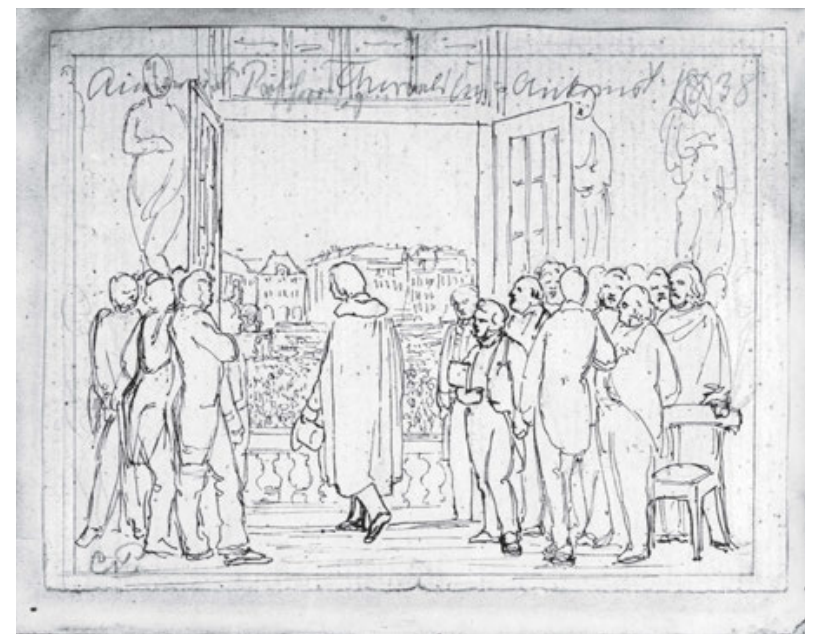

Kunstakademie ausgezeichnet werden..$^{55}$ Die Vorderseite der Medaille zeigt ein vom Alexanderzug umgebenes Profilporträt Thorvaldsens, die Rückseite eine allegorische Darstellung der Schenkung von Thorvaldsens Werken an seine Heimatstadt sowie dem Rand entlanglaufend ausgewählte Skulpturen des Bildhauers. Am 21. November 1838 wurde der Bildhauer schließlich zu Kopenhagens erstem und nach wie vor einzigem Ehrenbürger ernannt. ${ }^{56}$

\section{Erste Ideen zu einem Museum für Thorvaldsen}

Wie eingangs angedeutet, erfüllte sich für die Dänen mit Thorvaldsens Rückkehr eine jahrzehntelang gehegte Hoffnung. Denn wie schon seinen ersten Besuch in Dänemark 1819/1820 hatte Thorvaldsen auch diese Reise mehrmals verschoben. ${ }^{57}$ Den entscheidenden Anstoß für seine endgültige Heimkehr gab die Idee eines Museums für den Bildhauer. Bereits im April 1818 hatte der Kronprinz Christian Frederik bei Thorvaldsen Gipsabgüsse von sämtlichen seiner Werke bestellt. ${ }^{58}$ In einem wenige Tage später verfassten Brief wurden diesbezüglich die Abgüsse nach Jason (1803), Adonis (1808), Mars und Amor (1810)

Kopenhagen, Thorvaldsens Museum (Inv.-Nr. F13). Siehe dazu bspw. Thiele 1831-1850, Bd. 4, 48; Thiele 1852 - 1856, Bd. 3, 15 -16; Kat. Köln 1977, 349; Jørnæs 2011, 217. Als erster Künstler wurde 1838 der Maler Rørbye mit der Thorvaldsen-Medaille ausgezeichnet; siehe dazu Kat. Köln 1977, 349. TMA, Ref. N36. Siehe dazu ausführlich Ravn 1938b; auch Schultz 1938, 12; Jørnæs 2011, 218; Miss 2016, 5. Davon berichtete Wagner zwischen April und September 1838 in verschiedenen Briefen an Ludwig I. von Bayern, zit. bei von Urlichs 1887, 31-32. mission fra Prinds Cristian at bestille hos Dem en Copie i Gips - af alle De[re]s Arbeider, saavel store som smaae [...]." Siehe auch Thiele 1852-1856, Bd. 1, 309-310; Kronberg Frederiksen 2017. 
sowie Hebe (1816) ausdrücklich genannt, wohingegen bereits für Dänemark bestimmte Marmorversionen wie der Taufstein für Brahetrolleborg sowie die für Christiansborg bestellten Reliefs Herkules und Hebe (1808), Hygieia und Äskulap (1808), Minerva und Prometheus (1807 - 1808), Nemesis und Jupiter (1810) und der Alexanderzug (1812) ausgenommen waren. ${ }^{59}$ Zweifellos in unmittelbarem Zusammenhang mit dieser Bestellung des dänischen Königshauses formulierte der Kritiker Hjort noch im selben Monat erstmals die Idee einer Thorvaldsen-Sammlung in Kopenhagen. ${ }^{60}$ Damals ging es in erster Linie um den von verschiedenen Zeitgenossen geäußerten Wunsch nach einer „Sammlung von Abgüssen nach allen Werken des Künstlers, die zweifellos nach Hause in Dänemarks Hauptstadt gehört und deren Wirkung von unschätzbarem Nutzen besonders auf die studierende Jugend sein wird“.61 Der Auftrag für das Königshaus wurde zwischen 1818 und 1833 ausgeführt und in mehreren Transporten nach Dänemark verschifft. ${ }^{62}$ Die Sammlung dürfte jedoch nach der Eröffnung von Thorvaldsens Museum 1848 obsolet geworden sein, denn sie wurde in der zweiten Hälfte des 19. Jahrhunderts aufgelöst.

Auffallend ist, dass das Streben nach einer Thorvaldsen-Sammlung in Kopenhagen aus einem neuen nationalen Selbstverständnis der Dänen erwuchs und zugleich an dieses appellierte. Dementsprechend formulierte Hjort seine Vorstellung über die zu errichtende Sammlung als ein kollektives Unternehmen von nationaler Bedeutung:

Eine große Vereinigung von vielen Individuen der verschiedenen Stände, die einstimmig den Willen und den Wunsch des Volkes aussprächen, das wäre am schmeichelhaftesten für den Künstler und am angenehmsten für das nationale Gefühl..$^{63}$

Im selben Jahr schrieb die Dichterin Brun an den Grafen Christian Ditlev Reventlow über das Vorhaben einer Thorvaldsen-Sammlung in Kopenhagen: „Allein es kommt darauf an, die Sache so national zu machen, dass jeder die kleinste Gabe als willkommen ansehe!“64 Es schien außerdem Einigkeit darüber zu bestehen, dass die Dänen mit der Umsetzung einer Thorvaldsen-Sammlung nicht nur ihren berühmten Landmann, sondern mehr noch sich selbst ehren würden. ${ }^{65}$

59 Christian VIII. von Dänemark an Bertel Thorvaldsen, 7. April 1818, TMA, Ref. m5 1818, nr. 21. Siehe auch Kronberg Frederiksen 2017.

60 Hjort 1818. Siehe auch Trier 1903, 231; Bramsen 1959, 49; Miss 1991, 346; Miss 1998, 16.

61 Hjort 1818, 10: „[...] Samling af Afstøbninger af alle Kunstnerens Værker, hvilken unægtelig hører hjemme i Danmarks Hovedstad, og hvis Virkning vilde være af uberegnelig Nytte, især paa den studerende Ungdom [...].“ Siehe auch Miss 1991, 347; Jørnæs 2011, 130; Grandesso 2015, 171.

62 Für eine Rekonstruktion der gelieferten Werke und einen Katalog derselben siehe Kronberg Frederiksen 2017.

63 Hjort 1818, 9-10: „En stor Forening imellem mange Individuer af de forskjællige Klasser, som kunde udtale det eenstemmige Folks Mening og Længsel, vilde være meest smigrende for Kunstneren, og behageligst for den nationale Følelse.“ Deutsche Übersetzung nach Miss 1991, 347.

64 Brun 2006, 183.

65 Siehe bspw. Jacobsen 1820, 100; Brun 2006, 183. 
Es waren indessen nicht nur Thorvaldsens Zeitgenossen, die mit dem Gedanken an ein Museum spielten, sondern spätestens seit der zweiten Hälfte der 1820er Jahre auch der Bildhauer selbst. Darauf deutet dessen Vorhaben hin, auf eigene Kosten die Bronzestatue einer lebensgroßen Viktoria auf einer Biga oder Quadriga zu schaffen. ${ }^{66}$ Laut Thiele war es in Rom kein Geheimnis, dass Thorvaldsens Idee hinter dieser Skulpturengruppe die Dekoration eines eigenen Museums war. ${ }^{67}$ Im Hinblick auf die Gründung eines Museums überlegte sich Thorvaldsen 1827 zudem, den Renaissance-Palazzo Giraud im römischen Borgo-Bezirk zu kaufen. ${ }^{68}$ Im Jahr darauf äußerte der Bildhauer gegenüber dem Grafen Rantzau erstmals das Anliegen, dass ein Museum für ihn in seiner Heimatstadt Kopenhagen eingerichtet würde. ${ }^{69}$ Rantzau sprach daraufhin beim dänischen König Frederik VI. vor, der die Idee eines Museums für Thorvaldsen begrüßte und unterstützte. ${ }^{70}$ Als Zeichen seiner Anerkennung schlug der König den Bildhauer am 1. August 1829 zum Kommandeur des Dannebrog-Ordens. ${ }^{11}$

\section{Thorvaldsens Schenkung und testamentarische Bestimmungen}

Im Anschluss an jene frühen Ideen verfügte Thorvaldsen am 8 . August 1830 testamentarisch die Schenkung seiner Sammlungen - bestehend aus Gemälden, Zeichnungen, Grafiken, Antiken, Gipsabgüssen, Medaillen und Büchern - an die Stadt Kopenhagen. ${ }^{72}$ Bereits in diesem Testament drückte Thorvaldsen seinen Willen aus,

daß diese Kunstsachen ein Museum für sich ausmachen, welches meinen Namen tragen und welches weder mit fremden Sammlungen vergrößert, noch unter irgend welchem Vorwand getheilt werden oder irgend einer Verkleinerung unterliegen darf. ${ }^{73}$

Bertel Thorvaldsen an Johan Gunder Adler, 9. Dezember 1826, RA, J.G. Adlers privatarkiv, Breve fra andre (Transkript im TMA); Bertel Thorvaldsen an Christian Frederik von Dänemark (später Christian VIII.), 4. Februar 1827, dritter und fünfter Entwurf, TMA, Ref. m28, nr. 98 und Ref. m28, nr. 96. Der abgeschickte Brief befindet sich im RA, Kongehusarkivet (Transkript im TMA). Siehe auch Thiele 1831 -1850, Bd. 3, 9; Thiele 1852 - 1856, Bd. 2, 180; Miss 1991, 347; Miss 1998, 16.

67 Thiele $1852-1856$, Bd. 2, 184.

68 Ebd., 182 - 183; Bruun, C./Fenger 1892, 3; Helsted 1982b, 61; Jørgensen 1984, 237; Miss 1991, 347; Jørnæs 2011, 181; auch Trier 1903, 231.

69 Thiele 1852-1856, Bd. 2, 186; Miss 1991, 347; Kronberg Frederiksen 2014b.

70 Conrad Rantzau an Bertel Thorvaldsen, 20. April 1828, TMA, Ref. m14 1829, nr. 58; Thiele 1831-1850, Bd. 3, 10 -11; Thiele 1852 - 1856, Bd. 2, 186 und 206; Miss 1991, 347; Lange, B. 2002, 21.

71 TMA, Ref. m29 II, nr. 43; Thiele 1852-1856, Bd. 2, 207.

72 Ravn 1938a, 44; Miss 1991, 347; Bätschmann 1997, 90; Jørnæs 2011, 184. Zu Thorvaldsens Testamenten siehe ausführlich Ravn 1938a.

73 Bertel Thorvaldsen, Testament vom 8. August 1830, TMA, Ref. m29 I, nr. 6, §2: „Det er min Villie, at disse Konstsager udgiøre et Museum for sig selv, som fører mit Navn, og som hverken maa forøges med fremmede Samlinger, eller under hvilketsomhelst Paaskud deles eller lide nogen Formindskelse. “ Deutsche Übersetzung nach Thiele $1852-1856$, Bd. 2, 236. 
Was das Gebäude betraf, so sollte „[v]on der Stadt Kopenhagen [...] zu diesem Museum ein passendes besonderes Local angewiesen werden, bei welchem Rücksicht auf Sicherheit gegen Feuersgefahr zu nehmen ist " ${ }^{74}$ Ferner bestimmte Thorvaldsen, dass die Besucherinnen und Besucher mit Ausnahme von Künstlern einen Eintrittspreis zahlen sollten, um davon eine Aufsichtsperson zu entlohnen. ${ }^{75}$ Schließlich legte Thorvaldsen fest, dass seine Tochter Elisa eine jährliche Rente aus den Zinsen seines auf der dänischen Nationalbank anzulegenden Vermögens erhalten sollte. ${ }^{76}$ Im Todesfall ohne Nachkommen oder nach dem Aussterben derselben sollten diese Zinsen hingegen zum Ankauf von Arbeiten dänischer Künstler verwendet werden, „um in solcher Weise die Kunst zu fördern und zugleich die Galerie in dem von mir errichteten Museum zu vergrößern “ ${ }^{77}$ In diesem ersten Testament fällt auf, dass Thorvaldsen nur über seine selbst angelegten Sammlungen, nicht aber über den Verbleib seiner eigenen Werke entschied. Noch nicht, muss angemerkt werden, denn er fügte explizit an, dass er sich mit jener Frage zu einem späteren Zeitpunkt befassen würde. ${ }^{78}$

Høyen deutete Thorvaldsens Entscheidung, seinen Nachlass der Stadt Kopenhagen zu vererben und in seine Heimatstadt zurückzukehren, als Ausdruck von Vaterlandsliebe. ${ }^{79}$ Verfolgt man jedoch die Vorgeschichte von Thorvaldsens Museum genauer, erhärtet sich der Eindruck, dass der Bildhauer zwar Kopenhagen als Bestimmungsort seiner Sammlungen bevorzugte, zugleich aber verschiedene Möglichkeiten ausloten wollte. Die Existenz jenes ersten Testaments scheint denn auch nur einem engen Kreis bekannt gewesen zu sein. ${ }^{80}$ Dafür spricht die Tatsache, dass das Ringen um den dänischen Bildhauer besonders von Seiten des bayerischen Königs Ludwig I. bis mindestens 1835 anhielt. Man hoffte in München zum einen, dass Thorvaldsen den Ruf an die dortige Kunstakademie annehmen und in die bayerische Hauptstadt ziehen, zum anderen dass er die Original-

74 Bertel Thorvaldsen, Testament vom 8. August 1830, TMA, Ref. m29 I, nr. 6, §3: „Af Staden Kiøbenhavn bør anvises til dette Museum et passende særskilt Locale, hvorved maa tages Hensyn paa Sikkerhed imod Ildsvaade.“ Deutsche Übersetzung nach Thiele 1852-1856, Bd. 2, 236.

75 Ebd., $₫ 4$ : „For at besee Museet, bør fastsættes en liden Indgangspriis, og de derved indkomne Penge anvendes til at lønne en Opsynsmand. Konstnere erlægge Intet.“ Siehe auch Thiele 1852 - 1856, Bd. 2, 236. Ravn 1948, 16 -18, schreibt hingegen, dass der Zutritt zum Museum bis 1880 gratis gewesen sei.

76 Ebd., $§ 5$ : „Betalingssummen for de af Danmark hos mig bestilte Arbeider, tilligemed hvad jeg efterlader mig i Penge efter min Død, skal urokkeligen hensættes i Nationalbanken i Kiøbenhavn, og alene Renterne tilfalde min Datter: Elisa Sophia Charlotta og hendes Afkom. “ Siehe auch Thiele 1852-1856, Bd. 2, 237.

77 Ebd., $\$ 6$ : „Dersom min Datter skulde afgaae ved Døden, uden at efterlade noget Afkom, eller i Tilfælde, at hendes Afkom i Tiden uddøde, da er det min Villie, at ovennævnte Rentepenge anvendes til Bestillinger hos danske Konstnere, for saaledes at fremme Konsten og tillige forøge Galeriet i det af mig oprettede Museum. “Deutsche Übersetzung nach Thiele 1852-1856, Bd. 2, 237.

78 Ebd., $\$ 7$ : „Med Hensyn til de i mine Studier henstaaende Arbeider, skal følge en nøiere Detaille.“ Siehe auch Thiele 1852-1856, Bd. 2, 237; Miss 1991, 347.

79 Høyen 1837, 7.

80 Siehe auch Jørnæs 2011, 186. 
modelle seiner Werke Ludwig I. hinterlassen würde. ${ }^{81}$ Kurzum: Der bayerische König wollte den gefeierten Bildhauer „besitzen“, wie er es selbst formuliert hatte. ${ }^{82}$

Gleichzeitig - und, wie sich bald zeigen sollte, mit mehr Erfolg - hatte der württembergische Konsul Karl von Kolb einen Teil von Thorvaldsens Nachlass für Stuttgart beansprucht. ${ }^{83}$ Auch hinter diesem Bestreben stand die Idee eines Museums für den Bildhauer, das ein „Wallfahrtsort [...] für die Künstler des Nordens und Südens“ werden sollte. ${ }^{84}$ Thorvaldsen, der Kolb im März 1837 eine Liste mit Objekten für den württembergischen König Wilhelm I. überreicht hatte, versuchte Wagner indessen mit der Erklärung zu besänftigen, dies „seien blos Gypse [...], die er habe vernichten wollen“. ${ }^{85}$ Kurz vor seiner Abreise nach Kopenhagen stellte Thorvaldsen dem bayerischen König „alles was doppelt vorhanden oder wovon schon ein in Marmor ausgeführtes Werk in Dänemark vorhanden sei“ in Aussicht. ${ }^{86}$ Außerdem versprach er Wagner, diesbezüglich eine schriftliche Verfügung zu verfassen. Doch Wagner, der sich von Thorvaldsen und dem Kult um ihn noch nie hatte beeindrucken lassen, traute jenem Versprechen nicht: „Allein wer kann sich darauf verlassen, um so weniger aber, da er zum Schreiben fast nicht zu bringen ist. " 87 Wagners Zweifel sollten sich bewahrheiten, als bei Thorvaldsens Tod keine Verfügung existierte, wonach Ludwig I. bei der Nachlassverteilung berücksichtigt werden würde. Derweil hatte sich Kolb nach Thorvaldsens Abreise von Rom Gipsmodelle in dessen Werkstätten gesichert, worüber Wagner dem bayerischen König in mehreren Briefen mit offensichtlicher Bitterkeit berichtete. ${ }^{88}$ So habe Kolb laut Wagner den Erhalt der Abgüsse „erschlichen“ und holte diese bei einer „Plünderung“ in Thorvaldsens Atelier ab. ${ }^{89}$ In der Tat besaß Stuttgart ab den 1850er Jahren die größte Sammlung von Gipsabgüssen nach

81 Miss 1991, 347; auch Thiele 1852-1856, Bd. 2, 237 - 238 und 298-300; Gohr 1977b, 90 - 91; Jørgensen 1984, 237; Bott, G. 1993, 368; Miss 1998, 16 und 22 -23. Zu Ludwigs I. Bemühungen um Thorvaldsen siehe auch die Kap. II.1 und III.1.

82 Ludwig I. von Bayern an Bertel Thorvaldsen, 21. November 1830, TMA, Ref. m15 1830, nr. 155. Siehe auch Thiele $1852-1856$, Bd. 2, 238.

83 Siehe bspw. Georg von Reinbeck an Bertel Thorvaldsen, 4. Mai 1838, TMA, Ref. m22 1838, nr. 30; Thiele 1831-1850, Bd. 3, 147; Thiele 1852-1856, Bd. 2, 317-321. Zu den Bestrebungen aus Stuttgart siehe auch Bott, G. 1993, 368 - 369; Jørnæs 2011, 195 - 198.

84 Verein für Schiller's Denkmal (Georg von Reinbeck) an Bertel Thorvaldsen, 28. Mai 1839, TMA, Ref. m23 1839, nr. 5. Siehe auch Thiele 1852 - 1856, Bd. 3, 88; Bott, G. 1993, 369.

85 Bertel Thorvaldsen an Wilhelm I. von Württemberg, 25. März 1837, Kopenhagen, Landsarkivet for Sjælland, Landsover- samt Hof- og Stadsretten, Københavns Skiftekommission, Eksekutorboer 1790 -1919, pk. 445, nr. 78 (Transkript im TMA); Johann Martin von Wagner an Ludwig I. von Bayern, 4. Juni 1838, zit. nach von Urlichs 1887, 31.

86 Johann Martin von Wagner an Ludwig I. von Bayern, 2. Juli 1838, zit. nach von Urlichs 1887, 32. Auf diese Zusicherung wurde auch im Kap. III.1 verwiesen.

87 Johann Martin von Wagner an Ludwig I. von Bayern, 14. September 1838, zit. nach von Urlichs 1887, 32.

88 Zit. bei von Urlichs 1887, $32-33$.

89 Johann Martin von Wagner an Ludwig I. von Bayern, 8. Dezember 1838, zit. nach von Urlichs 1887, 33. 
Thorvaldsens Skulpturen außerhalb Kopenhagens. Die dortige Abgusssammlung, die auch die Werke des Dänen beherbergte, wurde jedoch im Zweiten Weltkrieg fast vollständig zerstört. ${ }^{90}$

Erst am 18. März 1837 bestätigte Thorvaldsen, sowohl seine Sammlungen als auch seine Werke der Stadt Kopenhagen für das geplante Museum zu schenken. ${ }^{91}$ Am 24. August desselben Jahres setzte Thorvaldsen auf der Grundlage seiner 1830 verfassten Nachlassurkunde ein weiteres Testament auf. ${ }^{92}$ Die für den vorliegenden Kontext nennenswerteste Ergänzung in dieser donatio mortis causa ist Thorvaldsens Bestimmung, dass die bei seinem Tod unvollendeten Arbeiten auf Kosten seines Vermögens und unter der Aufsicht von Freund und Galli für das zu errichtende Museum fertiggestellt werden sollten. ${ }^{93}$

Nachdem Thorvaldsen bereits in seinem ersten Testament bestimmt hatte, dass seine Sammlungen weder geteilt noch verkleinert werden dürften, untersagte er im späteren Dokument jegliche Veränderung seiner Sammlungen sowie deren Vermischung mit anderen Sammlungen..$^{94}$ Ausgenommen von dieser Bestimmung war jedoch die Vergrößerung seiner Sammlungen durch posthume Ankäufe, was sowohl aus seinen Testamenten als auch aus dem heutigen Bestand des Museums hervorgeht. Dementsprechend verfügte er in seinem Testament vom 24. August 1837, dass das Museum „nie aufhören darf, meinen Namen zu tragen, da es durch mein Vermögen vermehrt wird“.95 Schließlich präzisierte er die Aufgaben der vom Eintrittsgeld zu finanzierenden Aufsichtsperson, wonach diese sowohl für die Konservierung als auch für die Reinhaltung der Objekte und des Museums zuständig sein sollte. ${ }^{96}$

90 Bott, G. 1993, 369-370.

91 Bertel Thorvaldsen an Jonas Collin, 18. März 1837, TMA, Thorvaldsens Museums Oprettelse, 35. Siehe auch Thiele 1852 -1856, Bd. 2, 325; Bott, G. 1981, 346; Jørgensen 1984, 237; Miss 1991, 348.

92 Bertel Thorvaldsen, Testament vom 24. August 1837, Kopie im TMA, Ref. m29 III, nr. 5. Gemäß Thiele 1852 - 1856, Bd. 2, 340, datiert das Dokument vom 10. April 1838. Dieses Datum bezieht sich jedoch ausschließlich auf einen Brief von Thorvaldsen an Collin, dem er die Kopie jenes Schenkungsbriefs beilegte; $\mathrm{KB}$, Collins brevsamling XXIVb (Transkript im TMA).

93 Bertel Thorvaldsen, Testament vom 24. August 1837, Kopie im TMA, Ref. m29 III, nr. s5, §3a: „Che quelle statue e quei bassoriliievi che in tempo della mia morte si ritrovassero incomplete debbano a spese della mia eredità portarsi a compimento ed esecuzione per opera del Sig.r Professor Freund e del Sig.r Pietro Galli mio scolare onde questi lavori compiuti vadano quindi uniti e compresi nel legato e donazione sopraesposta e coi stessi pezzi e condizioni.“ Siehe auch Thiele 1831-1850, Bd. 4, 36; Thiele 1852-1856, Bd. 2, 341 .

94 Ebd., $\$ 1$ : „Che tutti gli oggetti sopra designati debbano formare un solo e particolare Museo portante il mio nome di maniera che non possa mai venir confuso con altre raccolte qualsivogliano ed in conseguenza neppure possa venire diminuito, diviso, o permutato sotto qualunque pretesto o causa. "Siehe auch Thiele $1852-1856$, Bd. 2, 341.

95 Ebd., $₫ 4 \mathrm{a}:$ „[...] che non cesserà di portare il mio nome perché aumentato colle mie sostanze [...].“ Deutsche Übersetzung nach Thiele 1852-1856, Bd. 2, 344.

96 Ebd., $\$ 4 \mathrm{a}:$ „[...] il custode dalla Città nominato per la conservazione, e pulizia degli oggetti, e del Museo." Siehe auch Thiele 1852-1856, Bd. 2, 341. 
Nachdem Thorvaldsen im Spätsommer des folgenden Jahres von Rom über Livorno nach Kopenhagen gereist war, verfasste er am 5. Dezember 1838 ein erneutes Vermächtnis. Dieses basiert im Wesentlichen auf dem Testament vom 24. August 1837 und einer Erklärung bezüglich der Rente für seine Tochter Elisa vom 25. Juli 1838. ${ }^{97}$ Ergänzt hat Thorvaldsen jedoch den wirkungsvollen und gerade für den vorliegenden Kontext bedeutsamen Vorbehalt, im Fall von Schwierigkeiten bei der Suche nach einem passenden Gebäude sein Vermächtnis hinsichtlich der noch in Rom befindlichen Werke zurückzuziehen. ${ }^{98}$

\section{Ein geplantes Nationaldenkmal}

Die Frage nach dem Standort des Museums war eines der meistdiskutierten Themen im Zusammenhang mit dem Nachlass des Bildhauers. Von zentraler Bedeutung war diesbezüglich ein Architekturwettbewerb, den der Kopenhagener Kunstverein 1833 ausgeschrieben hatte. Dabei ging es um Vorschläge für die Verwendung des Baugrundes der unvollendeten Marmorkirche in Kopenhagen. ${ }^{99}$ Deren Bau war 1749 durch den Architekten Nicolai Eigtved begonnen und nach dessen Ableben von Nicolas-Henri Jardin weitergeführt worden. Nach dem Tod von König Frederik V., der dieses monumentale Projekt finanziert hatte, stagnierten die Bauarbeiten seit 1770 und sollten erst ab 1878 wiederaufgenommen werden. Die Kirche in unmittelbarer Nähe zur heutigen Amalienborg-Anlage wurde 1894 durch Ferdinand Meldahl vollendet. ${ }^{100}$

Als Gewinner des genannten Wettbewerbs ging Hetsch hervor. Sein Entwurf zeigt einen Pantheon-ähnlichen Rundbau und trägt das Motto „Die Werke der Kunst sind die Ehre des Vaterlandes“ (Abb. 95).101 Dieser Leitsatz veranschaulicht, dass der Kunstverein keineswegs zu Projekten für Kirchenbauten aufrief. Im Gegenteil: Man schien sich in Kopenhagen einig zu sein, dass das Ziel dieses Wettbewerbs in einem Museum für Thorvaldsens Werke bestand. Dementsprechend bestätigte der Vorsitzende des Kunstvereins und königliche Berater (konferensråd) Collin in einem Brief vom 15. November 1834 an Thorvaldsen, jene Ausschreibung sei „der erste Schritt, um ein Musæum Thorvaldsenia-

97 Zur Erklärung bezüglich Elisas Rente siehe TMA, Thorvaldsens Museums Oprettelse, 84k. Dieses Dokument wird zudem in Thorvaldsens Testament vom 5. Dezember 1838 erwähnt. Siehe dazu auch Ravn 1938a, $53-56$.

98 Bertel Thorvaldsen, Testament vom 5. Dezember 1838, TMA, Thorvaldsens Museums Oprettelse, 84, $\$ 1 \mathrm{c}$, „[...] at jeg forbeholder mig, dersom der skulde møde Vanskeligheder med at faae bemeldte Locale i Stand, at forandre min Disposition over den Deel af ovennævnte Kunstgienstande, som er i Rom, hvorimod den Deel deraf, som er ankommen, eller endnu maatte ankomme til Danmark, er og forbliver Staden Kiøbenhavns Eiendom.“ Siehe auch Thiele 1831-1850, Bd. 4, 59-60; Thiele 1852-1856, Bd. 3, 35.

99 Thiele 1852 - 1856, Bd. 2, 294; Bruun, C./Fenger 1892, 6; Oppermann 1930, 105; Jørgensen 1984, 238 ; Kat. Nürnberg/Schleswig 1991, 702; Miss 1991, 348.

100 Johannsen 1987 , bes. $467-469$ und $677-685$.

101 Kat. Nürnberg/Schleswig 1991, $702-703$. 


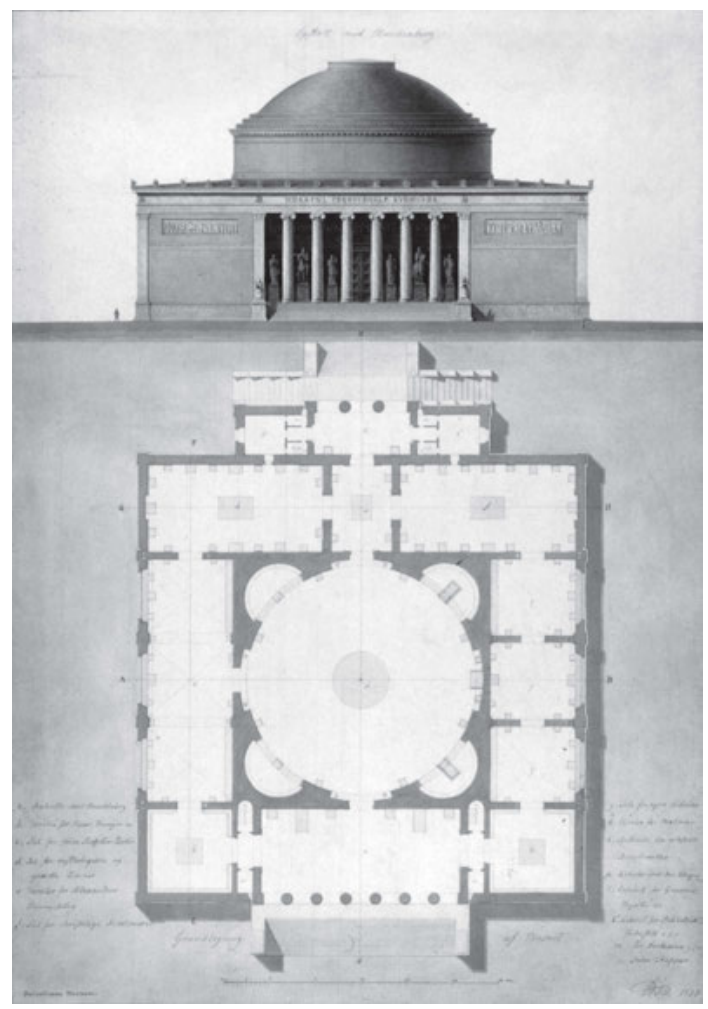

95_Gustav Friedrich Hetsch, Aufriss und Plan für ein Skulpturenmuseum, 1834, Feder- und Bleistiftzeichnung laviert auf Papier, $648 \times 490 \mathrm{~mm}$, Kopenhagen,

Danmarks Kunstbibliotek

num zustande zu bringen “102 Diese Idee wird umso deutlicher, wenn man die Zeichnungen von Collins Neffen Bindesbøll für denselben Wettbewerb betrachtet, die in jedem Raum konkrete Werke von Thorvaldsen zeigen (Abb. 96). ${ }^{103}$ Letzten Endes kam es aber nicht zur Realisierung eines Museums für Thorvaldsen auf dem Grundstück der Marmorkirche.

Bereits Ende 1836, noch vor der Niederschrift von Thorvaldsens zweitem Testament, wurde in Kopenhagen das Komitee zur Errichtung von Thorvaldsens Museum (Comitteen for Oprettelsen af Thorvaldsens Museum) gegründet, um das Geld zu dessen Finanzierung

102 Jonas Collin an Bertel Thorvaldsen, 15.11.1834, TMA, Ref. m19 1834, nr. 68: „Seer De nu, gode Etatsraad, det er det første Skridt til at faae et musæum Thorvaldsenianum i Stand. "Siehe auch Thiele $1852-1856$, Bd. 2, 294; Oppermann 1930, 105; Ravn 1938a, 48; Kat. Nürnberg/Schleswig 1991, 703; Miss 1991, 348. Collin war nicht nur der Vorsitzende des Kunstvereins, sondern auch einer der Protagonisten bei der Sensibilisierung seiner Landsleute für Thorvaldsens Werk und bei der Propagierung eines Museums für diesen; siehe dazu bspw. Thiele 1852-1856, Bd. 2, 294; Thule Kristensen 2013, 62 - 63.

103 Von dieser Einsendung sind nur Vorzeichnungen erhalten; Bramsen 1959, 50. 


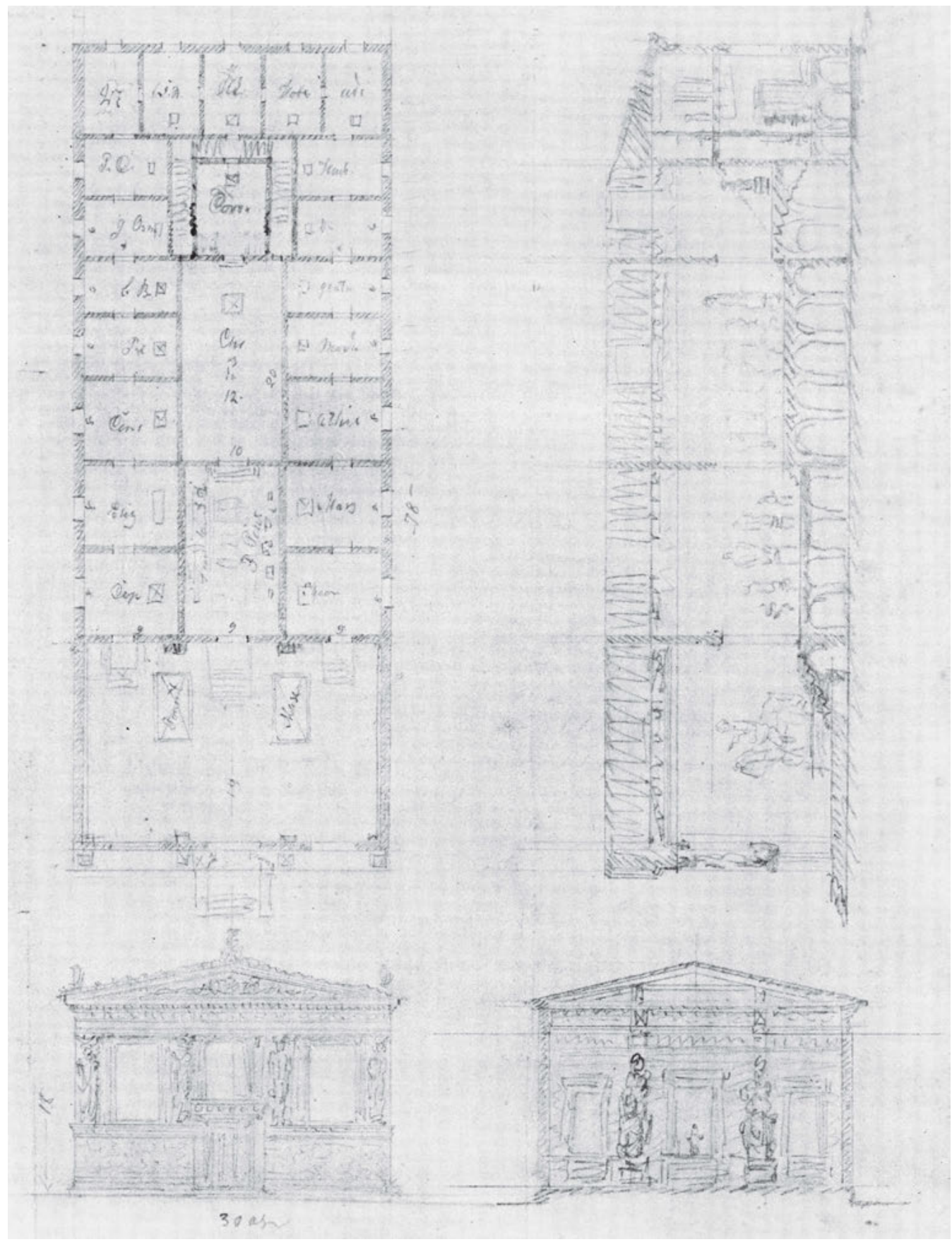

96__Gustav Friedrich Hetsch nach Gottlieb Bindesbøll, Entwurf zu einem Museum für Thorvaldsen, 24. Februar 1834, Bleistift auf Papier, $326 \times 306$ mm, Kopenhagen, Danmarks Kunstbibliotek 
zu sammeln. ${ }^{104}$ Die Gründungsmitglieder dieses Komitees waren neben Collin der Kunsthistoriker Høyen, der Theologe Clausen, der Botaniker Schouw sowie der Bildhauer und Thorvaldsen-Schüler Freund. Das Komitee zählte noch andere Mitglieder, darunter Thiele sowie mit Bissen einen weiteren Schüler Thorvaldsens. Im Januar 1837 brachte das Komitee ein Flugblatt mit einem Spendenaufruf für ein Thorvaldsen-Museum in ganz Dänemark in Umlauf und publizierte die Geldsammlung zusätzlich in der Wochenzeitung Dansk Folkeblad. ${ }^{105}$ Der dänische celebrity-Kult um Thorvaldsen erreichte dadurch einen Höhepunkt. Das zu realisierende Museum für Thorvaldsen wurde im erwähnten Flugblatt als „ein würdiges nationales Denkmal“ bezeichnet. ${ }^{106}$ Was sich schon bei Hjort 1818 und in Hetschs Einsendung zum Architekturwettbewerb 1833 abgezeichnet hatte, wurde somit in der Art der Finanzierung des geplanten Museums offensichtlich: Die Gründung eines Museums für Thorvaldsen wurde als ein Unterfangen von nationaler Bedeutung betrachtet. ${ }^{107}$ Dementsprechend wurde in jeder Phase dieses Prozesses an den dänischen Nationalstolz appelliert.

Diesbezüglich ist eine genauere Betrachtung des Aufrufs des Komitees zur Errichtung von Thorvaldsens Museum aufschlussreich: So wurden alle Gesellschaftsschichten zur finanziellen Unterstützung des Projekts aufgefordert, denn „die Opfer [finanzielle Beiträge], welche die Kräfte Einzelner übersteigen, oder für eine Classe der Gesellschaft abschreckend erscheinen möchten, können ohne Schwierigkeit gebracht werden, wenn alle Stände sich dazu vereinigen. “108 Folglich war „für die Größe des Beitrags keine Gränze gesetzt", weder nach oben noch nach unten. ${ }^{109}$ Denn es handelte sich bei dem Vorhaben um ,ein Werk, welches seine kräftigste Aufforderung hat in der Ehre der Nation, und erst dann seine volle Bedeutung gewinnt, wenn es der Nation gehört “. ${ }^{110}$ Dieselbe Bestimmung des künftigen Museums als Nationaldenkmal geht auch aus einer kleinen, sich ebenfalls explizit an alle sozialen Schichten richtenden Begleitschrift von Høyen hervor, welcher schon die Texte für die Spendenaufrufe des Komitees verfasst hatte. ${ }^{111}$ Innerhalb nur eines halben Jahres kamen 61.300 dänische Reichstaler für die Errichtung eines Thorvaldsen-

104 Miss 1991, 348; auch Kat. Kopenhagen 1974, 31 - 32. Thiele 1852 - 1856, Bd. 2, 325 - 326 und 232, schreibt fälschlicherweise, dass sich genanntes Komitee Anfang 1837 gebildet habe.

105 Komitee zur Errichtung von Thorvaldsens Museum (Comitteen for Oprettelsen af Thorvaldsens Museum), 10. Januar 1837, TMA, Thorvaldsens Museums Oprettelse, 26; Dansk Folkeblad, 2:51, 27. Januar 1837, 203 - 204; auch Miss 1991, 352.

106 Komitee zur Errichtung von Thorvaldsens Museum (Comitteen for Oprettelsen af Thorvaldsens Museum), 10. Januar 1837, TMA, Thorvaldsens Museums Oprettelse, 26.

107 Siehe auch Schleiden 1890, 91; Jørgensen 1970, 7 - 9; Jørgensen 1972b, 24 - 25; Kat. Kopenhagen 1974, 32, Anm. 56, und 33; Gohr 1977b, 90; Miss 1991, 352; Christensen 1998, 149 - 150.

108 Komitee zur Errichtung von Thorvaldsens Museum (Comitteen for Oprettelsen af Thorvaldsens Museum), 10. Januar 1837, TMA, Thorvaldsens Museums Oprettelse, 26.

109 Ebd.

110 Ebd. Siehe auch Miss 1991, 352.

111 Høyen 1837 , bes. $33-34$. 
Museums zusammen, wobei Thiele in seinen Biografien über den Bildhauer die genannte Zeitspanne auf einen einzigen Monat verkürzt und den Erfolg jener Geldsammlung deutlich überzeichnet hat. ${ }^{12}$ In der ländlichen Bevölkerung Dänemarks, die mit Thorvaldsens Namen weniger vertraut gewesen sein dürfte, hatte es im Zusammenhang mit der Geldsammlung vereinzelte kritische Stimmen gegeben, was die finanziellen Möglichkeiten der einfachen Leute betraf. ${ }^{113}$ Von der genannten Summe wurden denn auch mehr als zwei Drittel von Einwohnerinnen und Einwohnern der Hauptstadt gespendet. ${ }^{114}$

\section{Gottlieb Bindesbøll}

Als in Dänemark die Geldsammlung für Thorvaldsens Museum lief, hielt sich der oben erwähnte Architekt Bindesbøll in Rom auf. ${ }^{115}$ Die Zeichnungen, die dieser im Rahmen des Wettbewerbs des Kopenhagener Kunstvereins von 1833 schuf, markierten für ihn den Beginn einer sich über mehrere Jahre erstreckenden Reihe von Entwürfen für ein Museum für den Bildhauer. Am 16. Januar 1837 schrieb er an seinen Bruder Severin: „Ich sitze zu Hause und bin fleißig sowohl früh als auch spät. - Es sieht wild aus bei mir; hier liegen so viele Museen, dass ich selbst nicht recht weiß, wie viele es sind. "116 Im selben Jahr porträtierte Constantin Hansen den Architekten in seiner Wohnung an der Via Sistina, wo dieser während seines Romaufenthalts lebte (Taf. IX). Bindesbøll, dessen liegende Haltung und Position im Bild an Diogenes in Raffaels Schule von Athen erinnert, ist das Zentrum der Aufmerksamkeit sowohl der Bildbetrachtenden als auch seiner dänischen Künstler-

112 Komitee zur Errichtung von Thorvaldsens Museum (Comitteen for Oprettelsen af Thorvaldsens Museum), 1837, TMA, Thorvaldsens Museums Oprettelse, 25b; Dansk Folkeblad, 2:51, 27. Januar 1837, 203 - 204; Jonas Collin an Bertel Thorvaldsen, 4. Februar 1827, TMA, Ref. m21 1837, nr. 6; Komitee zur Errichtung von Thorvaldsens Museum (Comitteen for Oprettelsen af Thorvaldsens Museum) an Bertel Thorvaldsen, 18. Juli 1837, TMA, Ref. m21 1837, nr. 41. Siehe auch Thiele 1831-1850, Bd. 3, 149; Thiele 1852 - 1856, Bd. 2, 325; Bruun, C./Fenger 1892, 11; Oppermann 1930, 107 - 109; Ravn 1938a, 49; Miss 1991, 353. Die Errichtung von Thorvaldsens Museum kostete ca. 200.000 dänische Reichstaler; siehe dazu Thule Kristensen 2013, 69.

113 Siehe bspw. „Et Par Ord om det paatænkte Thorvaldsenske Museum“, Fyens Stiftstidende, 32, 17. Februar 1837, 126 - 127; Theodor Olshausen, „Das Correspondenz-Blatt hält Stand!“, Kieler Correspondenzblatt, 30, 5. April 1837, 118 - 119 (bei diesem Artikel handelt es sich um eine Bestärkung einer bereits früher vom Kieler Correnspondenzblatt geäußerten Kritik an der Geldsammlung für Thorvaldsens Museum). Zur Kritik an der Geldsammlung siehe auch Drees 1991, 118-122.

114 Miss 1991, 353. In diesem Zusammenhang ist ferner Jacob Rasmus Damkiers letztlich wenig erfolgreich gebliebener, explizit an die ländliche Bevölkerung gerichteter Spendenaufruf bemerkenswert: Jacob Rasmus Damkier, Et Par Ord om „Thorvaldsens Museum“. Et Sendebrev til Menigmand isor i Jylland, Aalborg: Stiftsbogtrykkeriet, 1837.

115 Bindesbøll hielt sich zwischen 1836 und 1838 in Rom auf; Miss 1991, 348.

116 Gottlieb Bindesbøll an Severin Bindesbøll, 16.01.1837, zit. nach Bruun, C./Fenger 1892, 12: „Jeg sidder hjemme og er flittig baade tidlig og sildig. - Det seer vildt ud hos mig; her ligger saa mange Musæer, saa jeg ikke selv rigtig veed, hvor mange der er." Siehe auch Bramsen 1959, 50; Henschen/Jørnæs 1987, 9; Kat. Nürnberg/Schleswig 1991, 701. 
kollegen Hansen (der Maler des Gemäldes), Rørbye, Marstrand, Küchler, Blunck und Sonne (v.l.n.r.). ${ }^{117}$ Auf dem Tisch rechts im Bild ist einer von Bindesbølls zahlreichen Entwürfen für Thorvaldsens Museum erkennbar. Bei dem hier abgebildeten Grundriss handelt es sich um einen relativ frühen Entwurf für ein klassizistisches Gebäude mit einem kleinen Tempel im Innenhof.

Während der Bezug zur örtlichen Umgebung des Museums in den frühen Zeichnungen Bindesbølls nicht erkennbar ist, sieht dies in späteren Entwürfen anders aus: So zeichnete er 1838 einen Entwurf für Thorvaldsens Museum in Form eines Rundbaus auf dem Standort der Marmorkirche (Abb. 97). Die umliegenden Gebäude verband Bindesbøll im Unterschied zu Hetsch zu Arkaden, die den Rundbau auf drei Seiten umgeben sollten. Dieser Entwurf veranschaulicht exemplarisch, dass man in Kopenhagen die Fundamente jener unvollendeten Kirche noch lange Zeit als den idealen Ort für ein Thorvaldsen-Museum betrachtete. ${ }^{118}$ Dabei dürfte gerade im größeren Zusammenhang des damaligen Geniekults und der Hegel'schen ,Kunstreligion' die Ausstrahlung des ursprünglichen Sakralbaus eine nicht geringe Rolle gespielt haben, wie etwa aus einem Brief von Malling an Collin hervorgeht: „Der Vorschlag war dem großen Künstler würdig; das Gebäude konnte die öffentliche Gottesverehrung mit der Anbringung von Ehrendenkmälern für hochverdiente Männer des Staates vereinen. "119

Thorvaldsen selbst scheint den wohl um die 20.000 Objekte zählenden Umfang seiner Hinterlassenschaft stark unterschätzt zu haben, was von den Zeitgenossen erneut als die oft konstatierte Bescheidenheit des Dänen gewertet wurde. ${ }^{120}$ So soll er gemeint haben, er wolle „[n] ur eine Räumlichkeit, [...] die feuer- und bombenfest ist, und ein gutes Licht hat! Ich habe nicht so viele Sachen! - Man mache nur nicht so viel Wesens daraus!"121 Außerdem wünschte er aus denselben Sicherheitsgründen ein freistehendes Gebäude. ${ }^{122}$ Thorvaldsen hatte bereits seit Bindesbølls längerem Aufenthalt in Rom ab 1836 mit diesem

118 Siehe auch Kat. Nürnberg/Schleswig 1991, 703.

119 Peder Malling an Jonas Collin, 13. Dezember 1838, TMA, Thorvaldsens Museums Oprettelse, 89: „Forslaget var den store Kunstner værdigt; Bygningen kunde forene den offentlige Gudsdyrkelse med Anbringelsen af Hædersminder for Statens høitfortiente Mænd.“

120 Siehe bspw. Thiele 1852-1856, Bd. 3, 60; Jørnæs 2011, 220. Thorvaldsens Erbe umfasste die Originalmodelle sowie vereinzelte Bozzetti und Marmorausführungen von über 900 Statuen, Porträtbüsten und Reliefs sowie rund 1.100 eigenhändige Zeichnungen. Zu seinen umfangreichen Sammlungen zählten rund 360 alte und zeitgenössische Gemälde, eine Fülle von Zeichnungen und Druckgrafiken, fast 10.000 römische, etruskische, griechische und ägyptische Antiken, Gipsabgüsse nach antiken Skulpturen, Medaillen und Schmucksteine, Totenmasken, eine Bibliothek, rund 4.000 Briefe sowie persönliche Gegenstände; siehe bspw. Helsted 1982b, 61; Melander 1991, 296; Miss 1991, 341; Miss 2008, 29; Kofoed 2015a.

121 Zit. nach Thiele 1852-1856, Bd. 3, 60. Siehe auch Trier 1903, 233; Jørnæs 2011, 220.

122 Bertel Thorvaldsen an Jonas Collin, 24.Oktober 1837, TMA, Thorvaldsens Museums Oprettelse, 50; auch Thiele $1852-1856$, Bd. 3, 60 . 


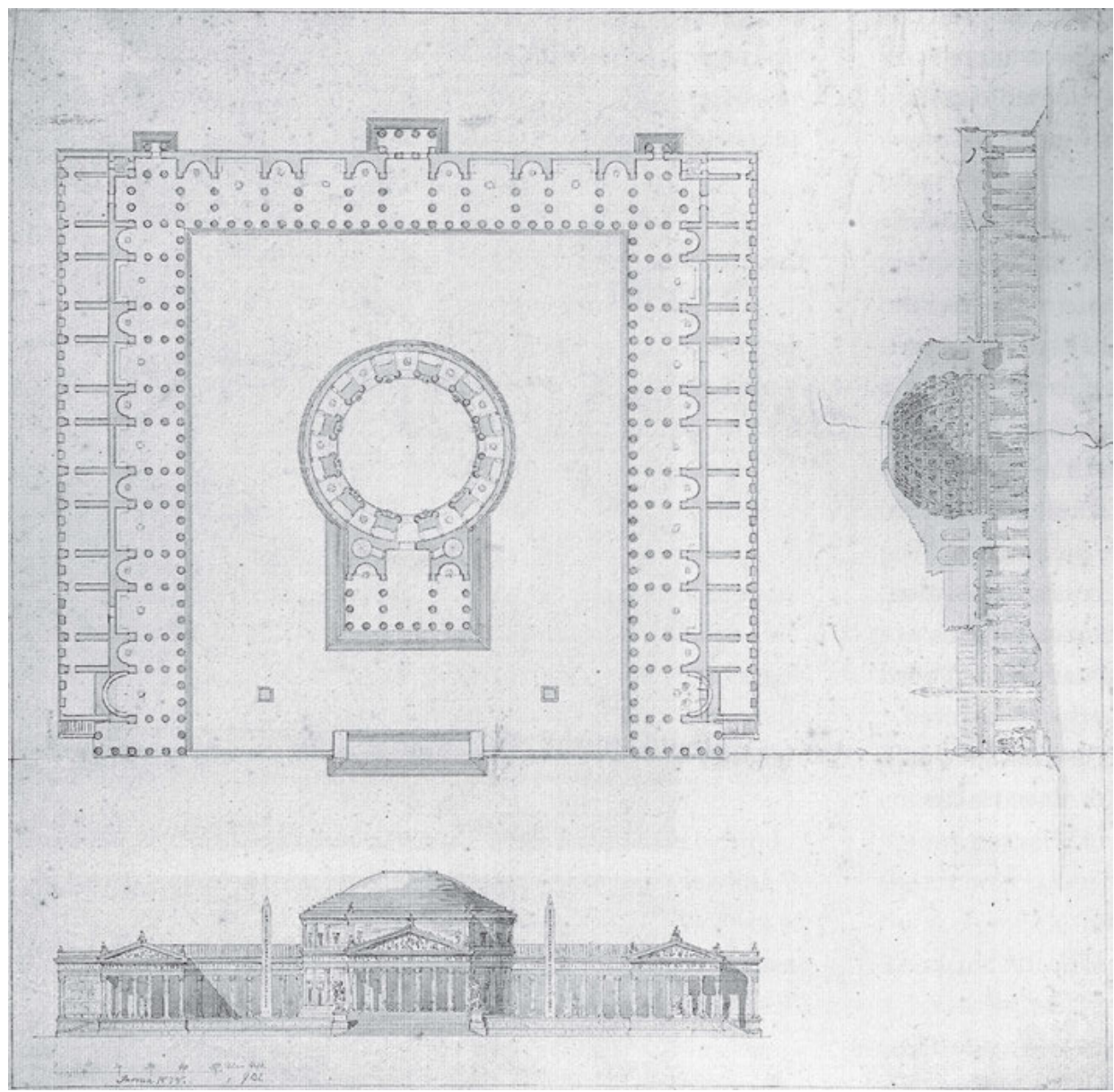

97__Gottlieb Bindesbøll, Entwurf zu einem Museum für Thorvaldsen auf dem Platz der Frederikskirche, 1838, Bleistift, Tusche und Wasserfarbe auf Papier, $494 \times 494$ mm, Kopenhagen, Danmarks Kunstbibliotek

in Kontakt gestanden und sich mit ihm auch über sein geplantes Museum beraten. ${ }^{123}$ In der Tat basiert das von Bindesbøll skizzierte, sogenannte Teleskop-Projekt von 1837 auf Thorvaldsens eigenen pragmatischen Ideen für den Museumsbau und führt diese weiter: Dank der Aneinanderreihung von Räumen könnte das Museum jederzeit vergrößert werden (Abb. 98). ${ }^{124}$ Darüber hinaus würde ein solches Gebäude kein Risiko bergen, dass die

124 Gottlieb Bindesbøll an Jonas Collin, 24. Juni 1837, TMA, Thorvaldsens Museums Oprettelse, 41; auch Bruun, C./Fenger 1892, 11 - 12 und 166; Bramsen 1959, 57; Jørgensen 1984, 237; Kat. Nürnberg/Schleswig 1991, 702; Miss 1991, 349. 


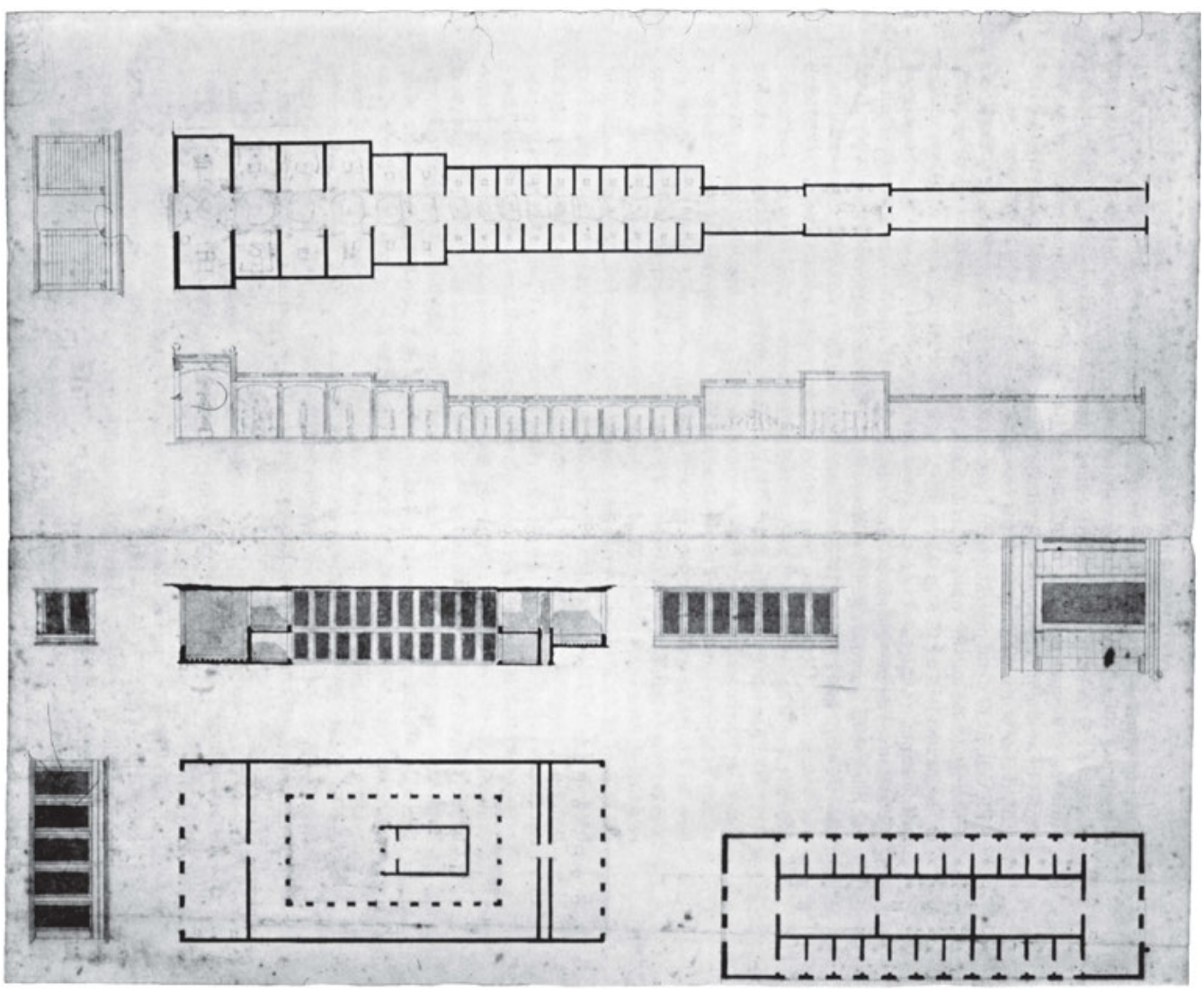

98_Gottlieb Bindesbøll, Zwei Entwürfe zu einem Museum für Thorvaldsen (oben das sog. Teleskop-Projekt), um 1837, Bleistift, Tinte und Wasserfarbe auf Papier, $292 \times 348$ mm, Kopenhagen, Danmarks Kunstbibliotek

Ausstellungsstücke von monumentaler Architektur überstrahlt würden. ${ }^{125}$ Dieses damals neuartige Verständnis des Museumsbaus, das seine Umsetzung im Ausstellungskonzept des White Cube des 20. Jahrhunderts erfahren sollte, kann als ein bewusster Gegenvorschlag Thorvaldsens zu den teils beinahe utopischen Projekten von Bindesbøll betrachtet werden. 


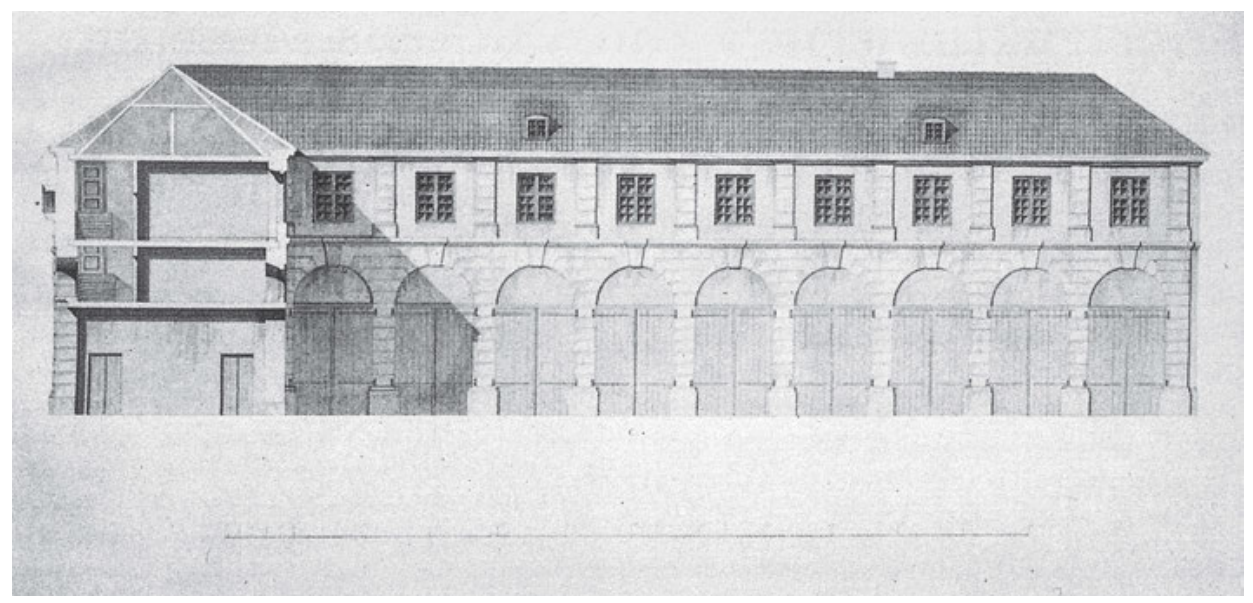

99_Unbekannter Künstler, Das königliche Wagendepot neben Schloss Christiansborg, wohl 1820er Jahre, Kupferstich, Maße unbekannt, Kopenhagen, Nationalmuseet

\section{Der Standort des Museums}

Über den Standort von Thorvaldsens Museum wurde erst Ende 1838 entschieden. ${ }^{26}$ Dies ist der Grund für Bindesbølls äußerst unterschiedliche Entwurfszeichnungen seit 1836, die von klassizistischen, durch antike Tempel sowie Schinkels Altes Museum von 1830 in Berlin beeinflussten Gebäuden bis hin zu Pantheon-ähnlichen Rundbauten reichen. ${ }^{127}$ Wie erwähnt, behielt sich Thorvaldsen in seinem Testament vom 5. Dezember 1838 die Möglichkeit vor, die noch in Rom befindlichen Objekte im Falle von Schwierigkeiten bei der Suche nach einer passenden Lokalität für sein Museum von der Schenkung auszunehmen. Womöglich als direkte Reaktion auf diese Vorbehaltserklärung stellte Frederik VI. Ende Dezember 1838 das Grundstück der ehemaligen königlichen Remise, das neben Schloss Christiansborg auf der Insel Slotsholmen im Zentrum Kopenhagens gelegen ist, für Thorvaldsens Museum zur Verfügung (Abb. 99). ${ }^{128}$ Das Wagendepot war 1741 errichtet und beim großen Brand von Christiansborg 1794 beschädigt worden. Im Jahr 1820 setzte le 1852 -1856, Bd. 3, 60; Bruun, C./Fenger 1892, 14- 15 und 19.

127 Siehe auch Miss 1991, 348 - 349; Thule Kristensen 2013, 66. Zur Entstehungsgeschichte von Thorvaldsens Museum, Bindesbølls Entwürfen und einer Beschreibung des fertigen Gebäudes siehe ausführlich Bruun, C./Fenger 1892; Bramsen 1959, 49 - 97; Millech 1960; Lange, B. 2002.

128 Frederik VI. von Dänemark an das Komitee zur Errichtung von Thorvaldsens Museum (Comitteen for Oprettelsen af Thorvaldsens Museum), Ultimo 1838, TMA, Thorvaldsens Museums Oprettelse, 98a. Siehe auch Thiele 1852 - 1856, Bd. 3, 60; Bruun, C./Fenger 1892, 20 -25; Schultz 1948a, 49; Millech 1960, 7; Kat. Kopenhagen 1974, 32; Kat. Nürnberg/Schleswig 1991, 703; Miss 1991, 349; Jørnæs 2011, 22. 


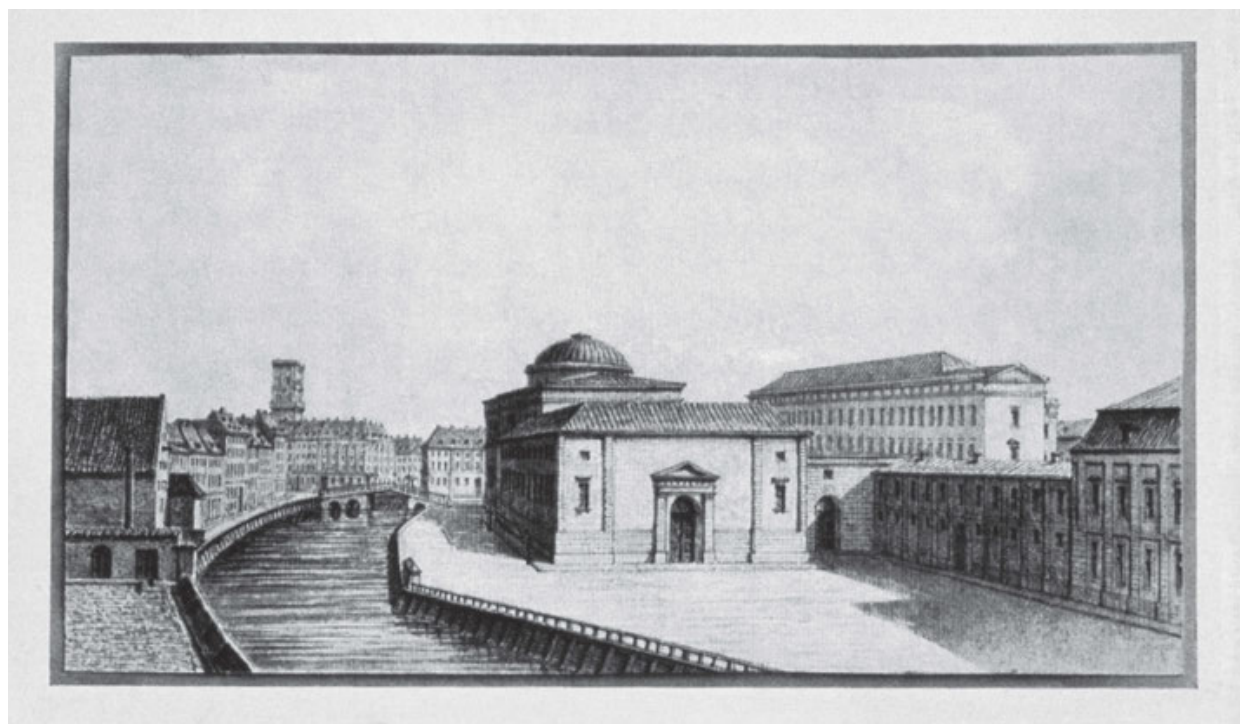

100_Christian Frederik Hansen, Das königliche Wagendepot (Längsschnitt), um 1820, Technik, Maße und Verbleib unbekannt

der Architekt Christian Frederik Hansen die Remise wieder instand. ${ }^{129}$ Er war es auch, der die dahinter liegende Schlosskirche errichtete sowie Christiansborg nach dem Brand wiederaufbaute. Das Erdgeschoss der Remise wurde als Kutschendepot und das obere Stockwerk als Atelier für die Gestaltung von Bühnenbildern genutzt. ${ }^{130}$ Die Remise bestand aus zwei gleich langen Flügeln, die auf der Westseite durch ein Torhaus verbunden waren (Abb. 100). Gegen die Schlosskirche hin war der Innenhof des Wagendepots offen. Zudem war die Remise mit einer schmalen Passage über einem Torbogen mit dem Schloss zusammengebaut. Eine Ansicht dieses Portals hielt Constantin Hansen 1830 in einem Gemälde fest: Vor dem genannten Durchgang spielen drei Kinder mit einem Ball, während der im Torbogen stehende Mann in erster Linie die Monumentalität dieser architektonischen Konstruktion hervorzuheben scheint (Abb. 101). Im Mittel- und Hintergrund sind links die Remise mit zwei wartenden, vor einen Wagen gespannten Pferden sowie schließlich die überkuppelte Schlosskirche zu sehen.

Das Angebot des Königs, den Baugrund des Wagendepots für das Museum zu verwenden, nahm Thorvaldsen am 5. Januar 1839 an. ${ }^{131}$ Daraufhin wurde eine Baukommis-

130 Thule Kristensen 2013, 70; auch Schultz 1948a, 61; Millech 1960, 7.

131 Bertel Thorvaldsen an Jonas Collin, 5. Januar 1839, TMA, Thorvaldsens Museums Oprettelse, 99. Siehe auch Thiele $1852-1856$, Bd. 3, 61-62. 
101_Constantin Hansen, Blick durch den Torbogen zwischen Schloss Christiansborg und dem königlichen Wagendepot, 1830, Öl auf Leinwand, $49 \times 38,7 \mathrm{~cm}$, Kopenhagen, Københavns Museum (Inv.-Nr. 1925:105X0001)

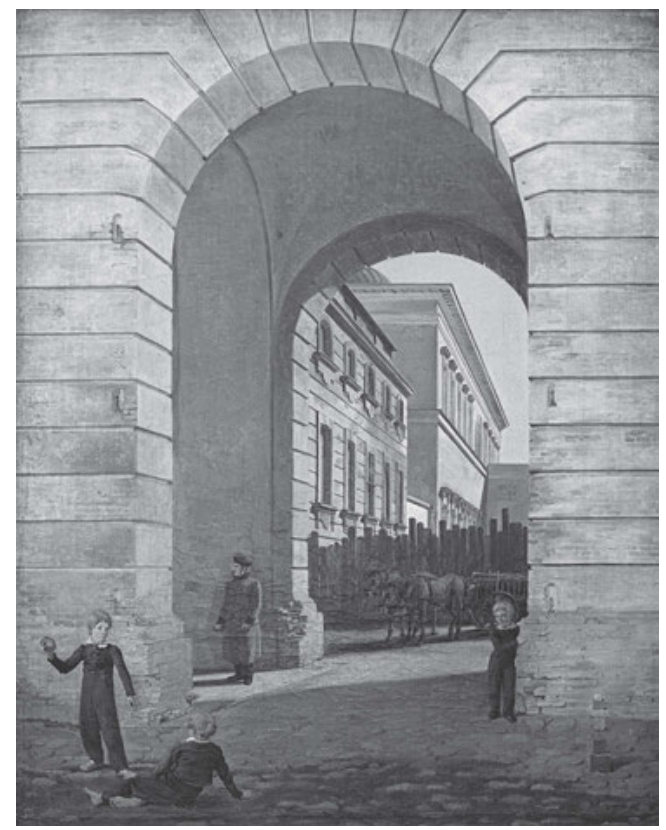

sion einberufen, die neben Bindesbøll und Hetsch die Architekten Jørgen Koch und Frederik Ferdinand Friis umfasste. ${ }^{132}$ Die Mitglieder dieser Kommission zeichneten nun erneut Entwürfe für das Museumsgebäude. Dieses musste angesichts von Thorvaldsens umfangreicher Schenkung geräumiger sein als das noch stehende Wagendepot. Zudem sollten die Fenster so platziert werden, dass natürliches Licht die Köpfe der Statuen beleuchten würde. ${ }^{133}$ Die ursprüngliche Idee eines gemeinsamen Entwurfs der vier Architekten der Baukommission musste indessen wegen Unstimmigkeiten bald aufgegeben werden. ${ }^{134}$ Am Ende vermochte sich Bindesbøll gegen seine etablierten Mitstreiter durchzusetzen, und am 13. November 1839 bewilligte Frederik VI. seinen Vorschlag. ${ }^{135}$ Dieser ist in Thorvaldsens Museum in zwei leicht voneinander abweichenden Sätzen von signierten und datierten Zeichnungen erhalten: Zum einen sind dies die neun vom König approbier2011, 220.

133 Kat. Nürnberg/Schleswig 1991, 703.

134 Ebd., 704-705.

135 Thiele 1852-1856, Bd. 3, 68; Bruun, C./Fenger 1892, 52 - 55; Trier 1903, 238; Bramsen 1959, 68 - 69; Kat. Kopenhagen 1974, 32; Bott, G. 1981, 348; Kat. Nürnberg/Schleswig 1991, 705; Miss 1991, 350; Lange, B. 2002, 37; Thule Kristensen 2013, 70. Bindesbøll bewarb sich 1848 zudem auf den Posten als erster Direktor des Museums, auf den jedoch der Numismatiker Ludvig Müller gewählt wurde; Bruun, C./Fenger $1892,160-161$. 


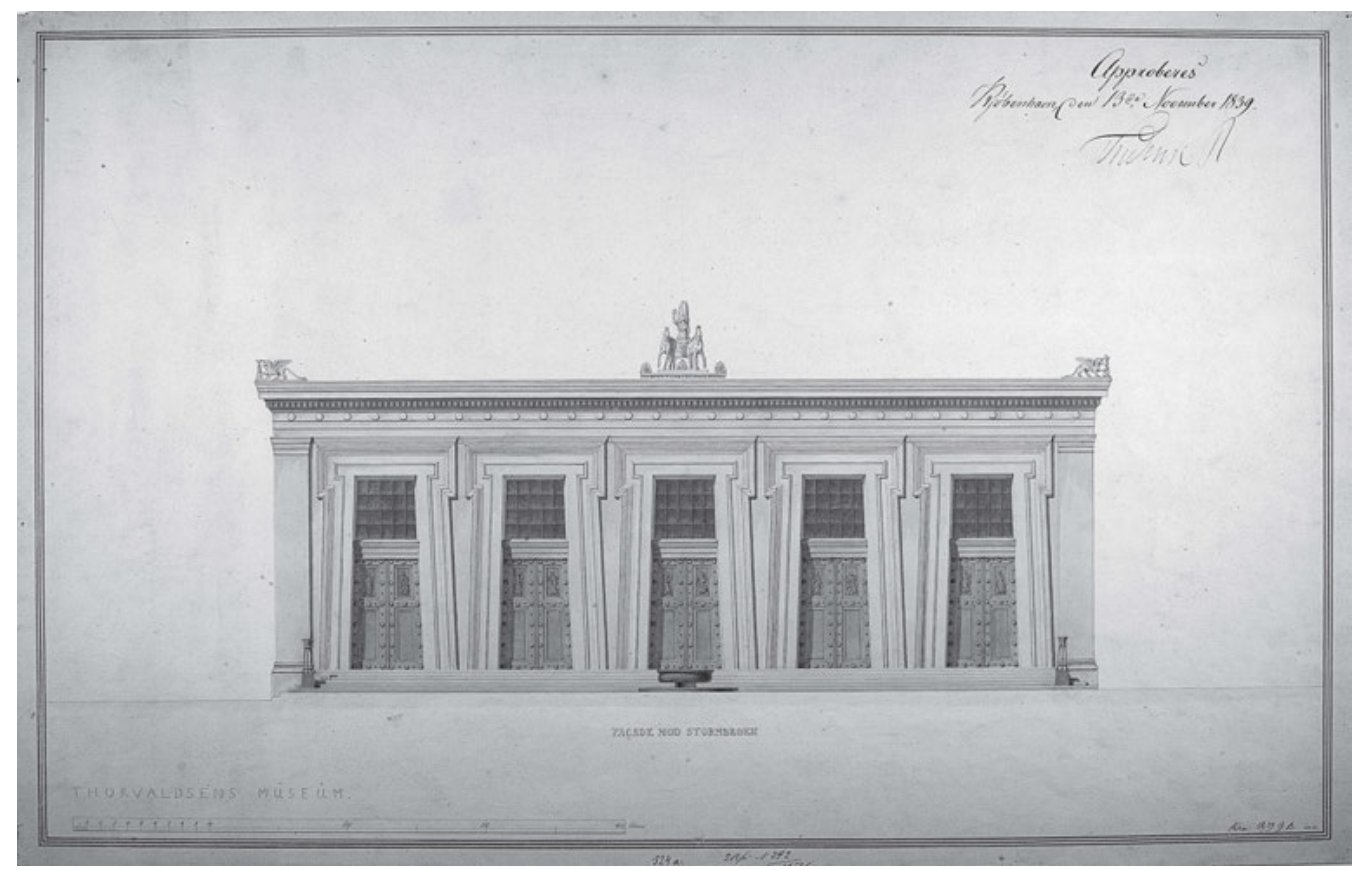

102_Gottlieb Bindesbøll, Ansicht der Hauptfassade von Thorvaldsens Museum, 1839, Bleistift- und Federzeichnung grau laviert sowie Wasserfarbe auf Papier, $400 \times 627$ mm, Kopenhagen, Thorvaldsens Museum (Inv.-Nr. D1592)

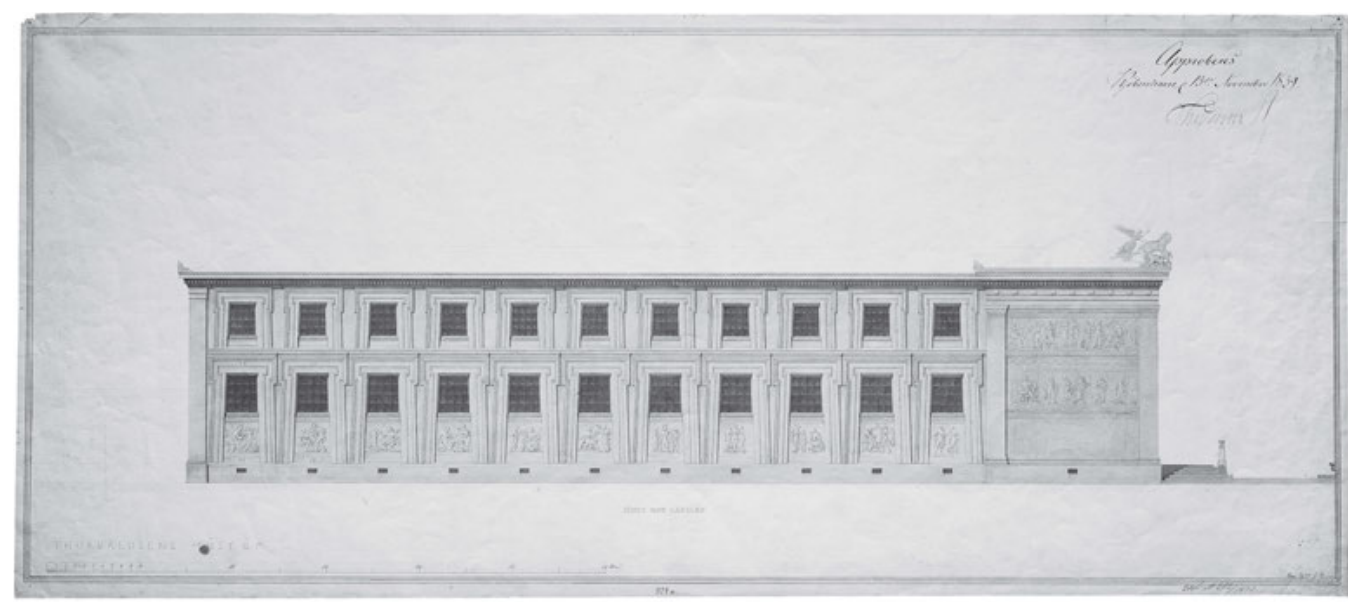

103_Gottlieb Bindesbøll, Ansicht der Nordfassade von Thorvaldsens Museum, 1839, Bleistift- und Federzeichnung grau laviert sowie Wasserfarbe auf Papier, 403/400 ×911/916 mm, Kopenhagen, Thorvaldsens Museum (Inv.-Nr. D1593) 


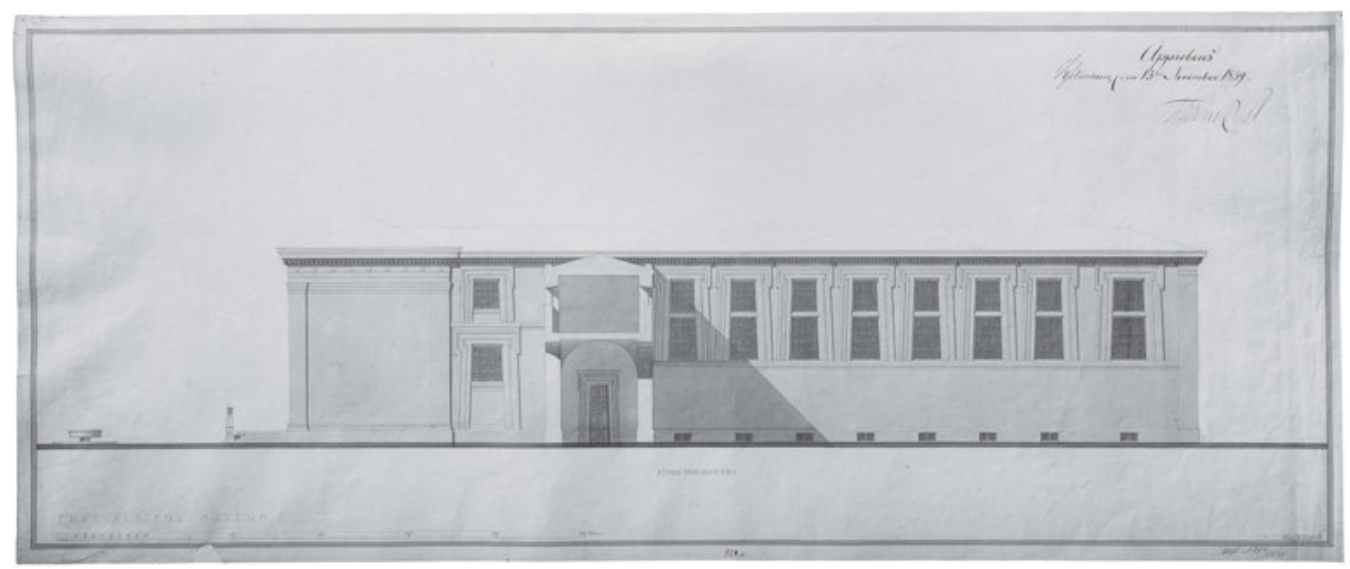

104_Gottlieb Bindesbøll, Ansicht der Südfassade von Thorvaldsens Museum, 1839, Bleistift- und Federzeichnung grau laviert sowie Wasserfarbe auf Papier, 402/401 ×970/972 mm, Kopenhagen, Thorvaldsens Museum (Inv.-Nr. D1595)

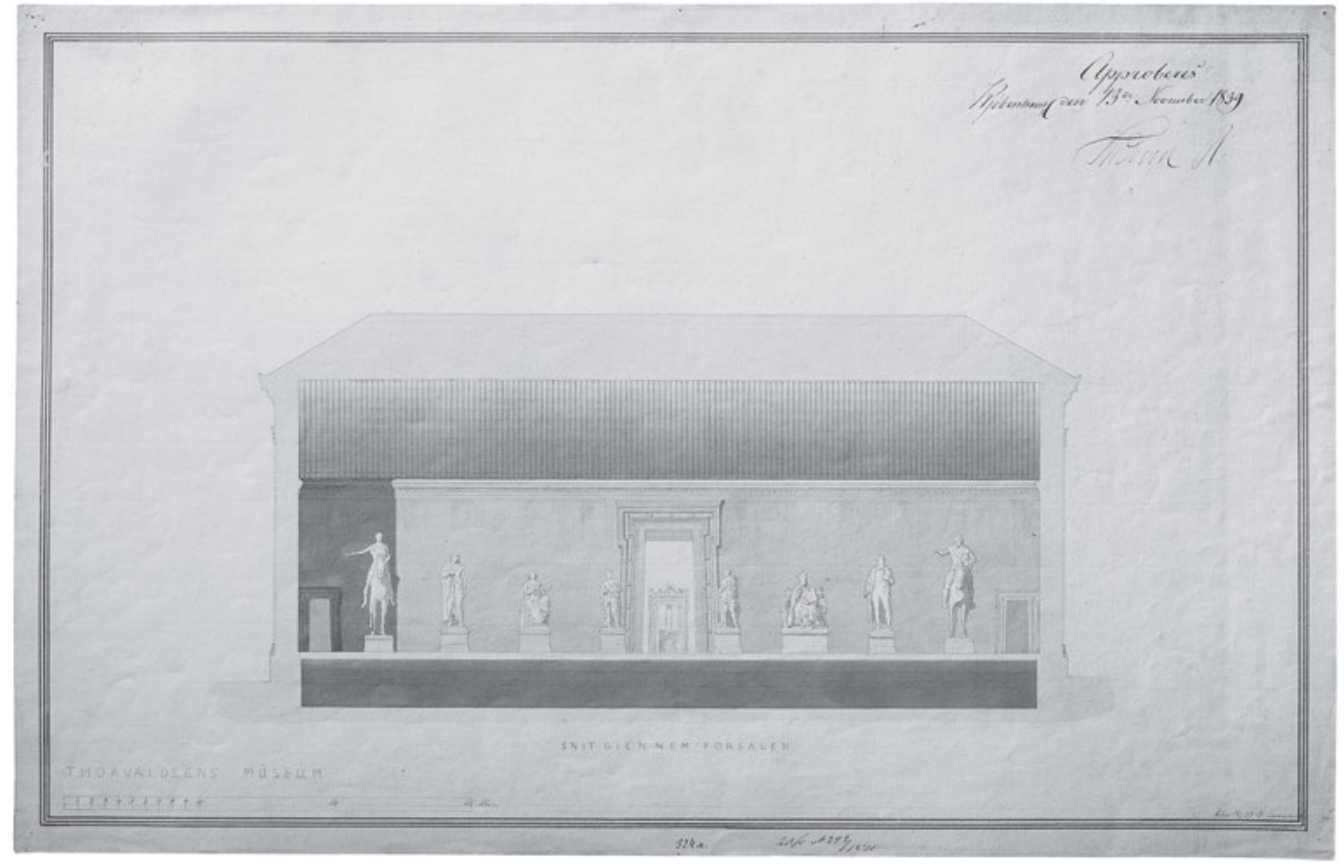

105_Gottlieb Bindesbøll, Vorhalle von Thorvaldsens Museum (Längsschnitt), 1839, Bleistift- und Federzeichnung grau laviert sowie Wasserfarbe auf Papier, $406 \times 628 / 627 \mathrm{~mm}$, Kopenhagen, Thorvaldsens Museum (Inv.-Nr. D1596) 


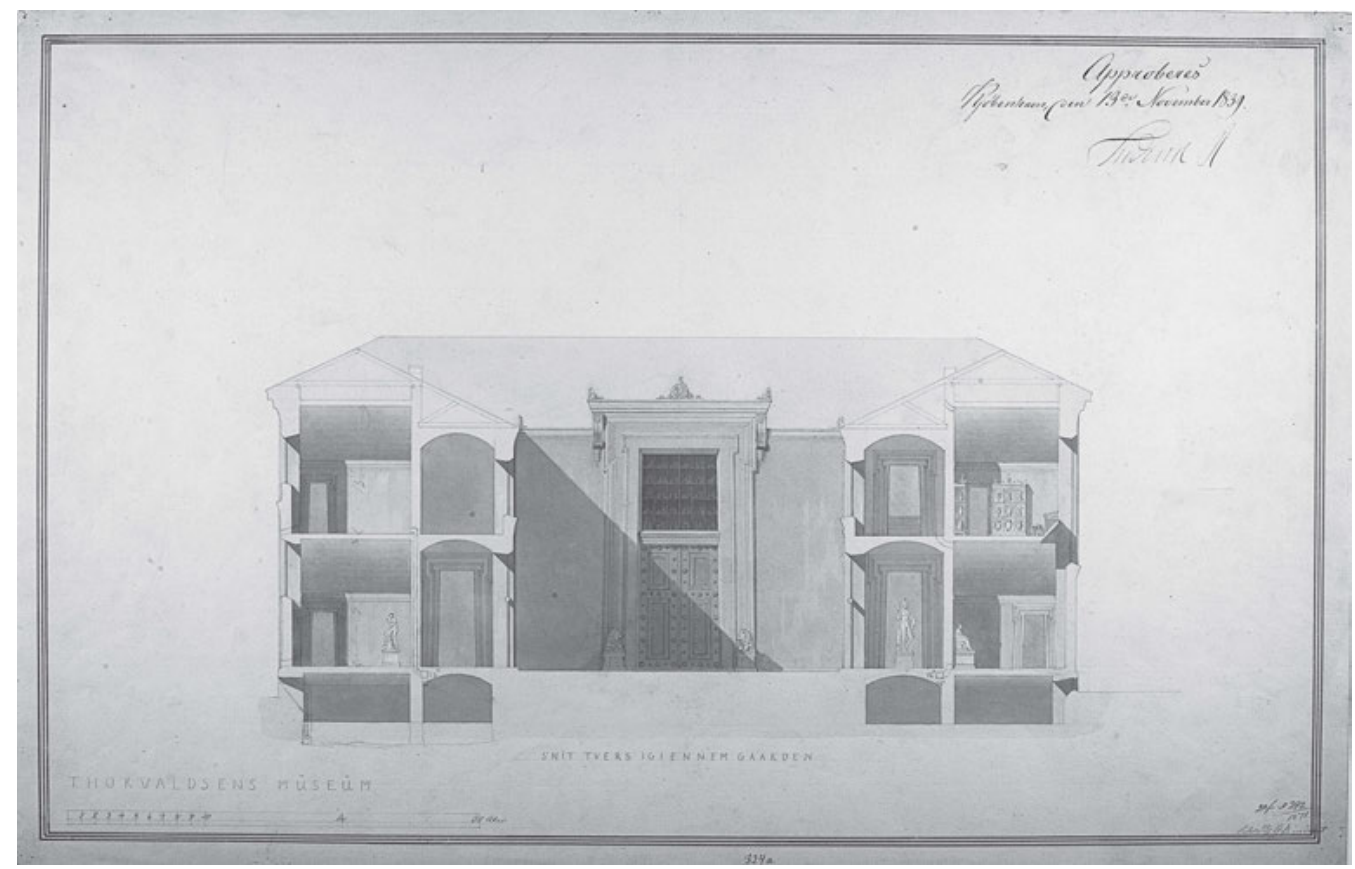

106_Gottlieb Bindesbøll, Innenhof von Thorvaldsens Museum (Querschnitt), 1839, Bleistift- und Federzeichnung grau laviert sowie Wasserfarbe auf Papier, $403 \times 627$ mm, Kopenhagen, Thorvaldsens Museum (Inv.-Nr. D1597)

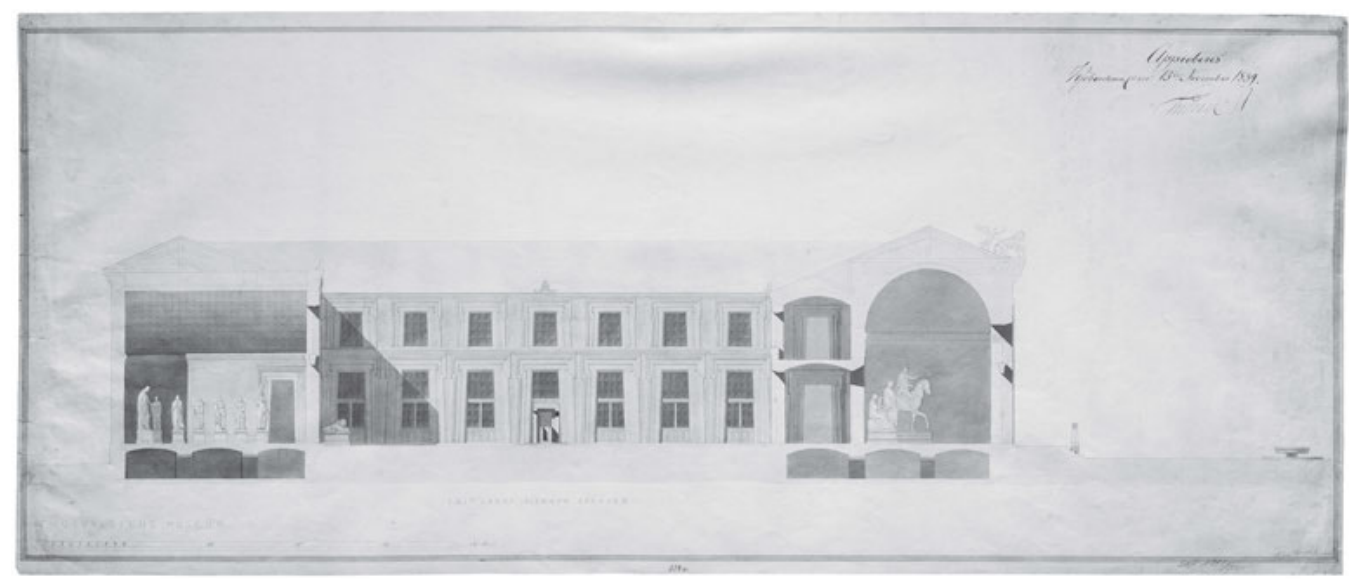

107_Gottlieb Bindesbøll, Innenhof von Thorvaldsens Museum (Längsschnitt), 1839, Bleistift- und Federzeichnung grau laviert sowie Wasserfarbe auf Papier, 418/416 × 983/981 mm, Kopenhagen, Thorvaldsens Museum (Inv.-Nr. D1598) 


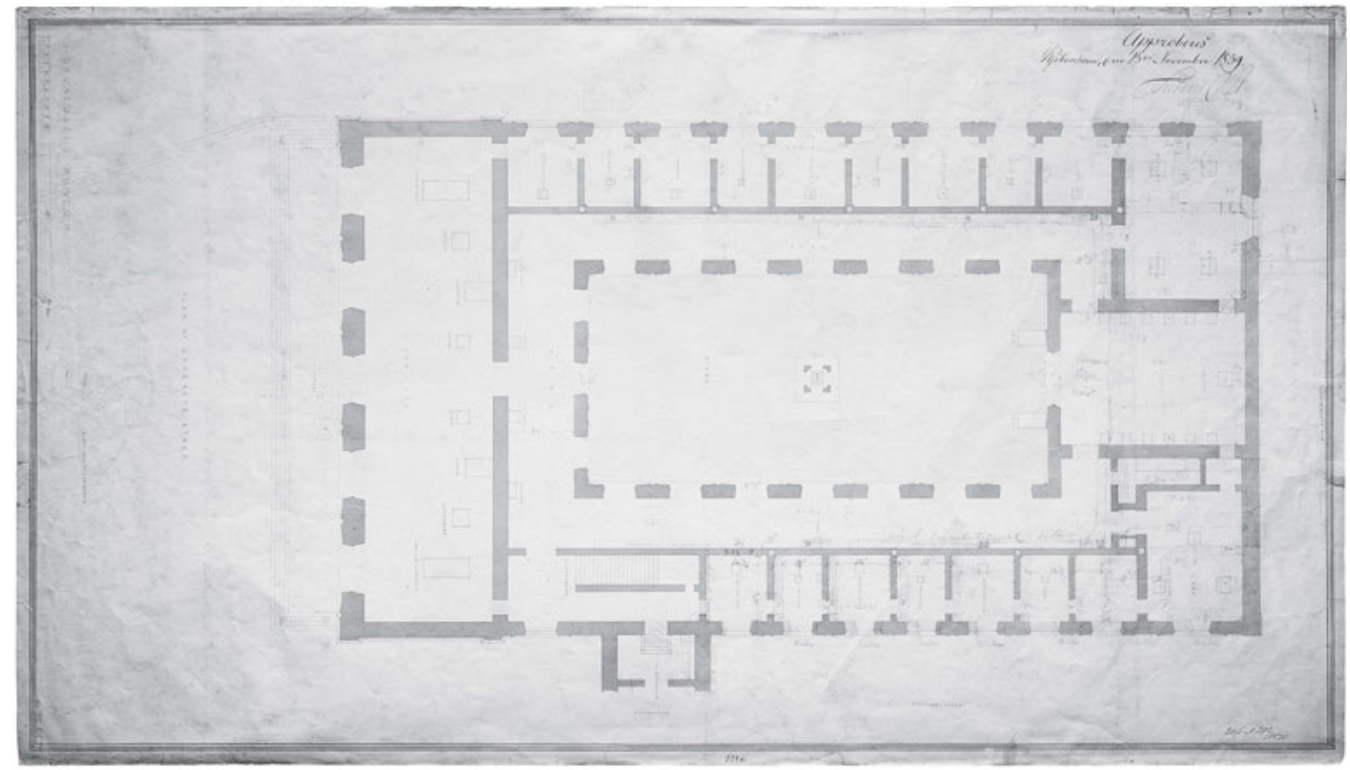

108_Gottlieb Bindesbøll, Plan des Erdgeschosses von Thorvaldsens Museum, 1839, Bleistift- und Federzeichnung grau laviert sowie Wasserfarbe auf Papier, $552 \times 967$ mm, Kopenhagen, Thorvaldsens Museum (Inv.-Nr. D1599)

ten Entwürfe (darunter Abb. 102 - 108), zum anderen acht kleinere Pläne. ${ }^{136}$ Sigurd Schultz vermutet, dass es sich bei den kleineren Plänen um überarbeitete Kopien handelt, die Thorvaldsen von Bindesbøll als Geschenk erhielt. ${ }^{137}$

Die Entscheidung des Königs und der Baukommission für Bindesbølls Entwürfe dürfte auch dadurch begünstigt worden sein, dass es sich dabei um das kostengünstigste Projekt handelte. Der Grund dafür war seine prinzipielle Weiterverwendung der Bausubs$\tan z$ der königlichen Remise. ${ }^{138}$ Wie Peter Thule Kristensen in seiner 2013 erschienenen Monografie über Bindesbøll festgestellt hat, bildet Thorvaldsens Museum „die dritte Schicht in einem architektonischen Palimpsest, wo Überreste aus zwei früheren Epochen Teil des endgültigen Gebäudes wurden“"139 Damit verweist Thule Kristensen darauf, dass bereits Hansens Remise von 1820 auf dem vom Brand verschont gebliebenen Mauerwerk des Kutschendepots von 1741 errichtet worden war und Bindesbøll nun erneut die beste-

138 Miss 1991, 341; Lange, B. 2002, 39 und 50; auch Thiele 1852 - 1856, Bd. 3, 62; Bramsen 1959, 83 und 159.

139 Thule Kristensen 2013, 69: „In this way, the Thorvaldsen Museum was the third layer in an architectural palimpsest, where remains from two earlier epochs became part of the final building." 
hende Bausubstanz verwendete. Auf die Architektur des Museums wird im Kapitel IV.2 genauer eingegangen.

\section{Baubeginn und weitere Bestimmungen Thorvaldsens}

Die Bauarbeiten am Museum begannen im Herbst 1839. ${ }^{140}$ Am Tag nach der Rückkehr von seiner Romreise mit der Familie Stampe, dem 25. Oktober 1842, konnte Thorvaldsen erstmals sein überdachtes und festlich dekoriertes Museum betreten. ${ }^{141}$ Auch hier gab es einen feierlichen Empfang für den Bildhauer mit Ansprachen und Gesang. Wie die Tageszeitung Dagen berichtete, verschob man sich nach der in der Vorhalle stattfindenden Rede des Kopenhagener Oberpräsidenten Andreas Christian Kierulff in die „Kapelle“ des Museums, den heutigen Christussaal, wo der Studentenverein ein Lied von Holst vortrug. ${ }^{142}$ Nach diesem ersten Besuch Thorvaldsens in seinem Museum verfügte dieser, dass die Zinsen von zusätzlichen 25.000 dänischen Reichstalern aus seinem Erbe für die posthume Marmorausführung von bei seinem Tod unvollendeten Arbeiten sowie für Sockel und weitere Hilfsmittel zur Präsentation seiner Werke eingesetzt werden sollten. ${ }^{143}$

In Anbetracht der Fortschritte des Bauprozesses verfasste Thorvaldsen wenige Monate nach jener Besichtigung seines Museums einen ausführlichen Nachtrag zu seinem Testament vom 5. Dezember 1838. Eine wichtige Änderung im Dokument vom 25. Januar 1843 ist die Bestimmung, dass das gesamte Vermögen des Bildhauers in dessen Museumsfonds fließen sollte. ${ }^{144}$ Von dieser Verfügung nahm er einzig 4.000 dänische Reichstaler als Festanlage aus, während er die ursprünglich geplante Rente für seine Tochter Elisa und deren Nachkommen widerrief. Damit stellte Thorvaldsen die Sicherung seines posthumen Ruhms über jegliche familiäre Bande. Die Verwaltung des Museumsgebäudes und seiner Sammlungen übertrug Thorvaldsen den Testamentsvollstreckern Collin, Thiele, Clausen, Schouw, Bissen und einem zu ernennenden Mitglied der Kopenhagener Regierung. ${ }^{145}$ Die genannten Testamentsvollstrecker befugte er darüber hinaus,

140 Miss 1991, 350.

141 „Albert Thorvaldsen“, Dagen, 40:292, 25. Oktober 1842, o. S. [Titelseite]; Thiele 1831-1850, Bd. 4, 183; Thiele 1852-1856, Bd. 3, 149; Wilckens 1875, 88; Bruun, C./Fenger 1892, 103; Baronesse Stampes Erindringer 1912, 211; Kat. Kopenhagen 1974, 32; Miss 1991, 350; Jørnæs 2011, 238.

142 „Albert Thorvaldsen“, Dagen, 40:292, 25. Oktober 1842, o. S. [Titelseite]: „Man begav sig derefter ind i det tilstødende Capel i Musæet, der er bestemt for Thorvaldsens ,Christus', ,Apostlerne' m. m., hvor Studentersangforeningen afsang følgende særdeles smukke Sang af Digteren H. P. Holst: [...].“

143 Thiele 1831-1850, Bd. 4, 183; Thiele 1852 - 1856, Bd. 3, 150.

144 Bertel Thorvaldsen, Testament vom 25. Januar 1843, TMA, Thorvaldsens Museums Oprettelse, 190, $\$ 5$ und $₫ 6$. Siehe zu diesem Dokument auch Thiele 1831-1850, Bd.4, 191-192 und 196-198; Thiele 1852 - 1856, Bd. 3, 156-158; Ravn 1938a, 57 - 58.

145 Ebd., $\$ 10$. 
die zu ihrer Disposition gegebenen Mittel auf Instandhaltung und Vermehrung der Kunstsachen des Museums, sowie auf Verschönerung des Innern desselben zu verwenden, damit es stets ein würdiges Monument dänischer Kunst und Prästationen dänischer Künstler verbleibe. ${ }^{146}$

Ferner brachte Thorvaldsen in dem Nachtrag seine Hoffnung zum Ausdruck, dass sein Museum künftig auf Kosten der Stadt Kopenhagen instandgehalten würde, und bestimmte, dass die bei seinem Tod unvollendeten Werke unter der Aufsicht von Bissen (statt von Freund und Galli) ausgeführt werden sollten. ${ }^{177}$ Der gesamte Bestand des Museums sollte schließlich in einen Katalog aufgenommen und in Buchform gedruckt werden. ${ }^{148}$ Dies geschah durch den ersten Direktor des Hauses, Ludvig Müller, der in den Jahren 1849 bis 1850 einen fünf Bände umfassenden Sammlungskatalog publizierte. ${ }^{149}$ Aus seiner Beschreibung der Exponate wird ersichtlich, dass die Dauerausstellung der Werke seit der Eröffnung des Museums bis heute kaum verändert wurde. ${ }^{150}$ Einzig das Kellergeschoss wurde in den späten 1960er Jahren renoviert und mit einer zeitgemäßen Präsentation der Objekte versehen. ${ }^{151}$

\section{Museumsgeschichtlicher Kontext}

Die über mehrere Jahre hinweg aufgesetzten und laufend präzisierten Testamente von Thorvaldsen veranschaulichen dessen Bemühungen zur Regelung seines umfangreichen Nachlasses. Ein Spezifikum von Künstlertestamenten bilden, wie Kerstin Hegener und Thomas Pöpper gezeigt haben, klare Vorstellungen über die Gestaltung der letzten Ruhestätte. ${ }^{152}$ Obwohl Thorvaldsens Museum am Ende auch als Mausoleum des Bildhauers dienen sollte, hielt er diesen Wunsch nicht testamentarisch fest. Hingegen muss die Errichtung eines eigenen Museums als materialisierte Form von Thorvaldsens eifrigen Memorialbestrebungen und in diesem Sinn als Steigerung des eigenen Grabmals betrachtet werden. ${ }^{153}$

Mary Carruthers hat die Memorialfunktion von Museen mit Mnemosyne, der mythologischen Göttin der Erinnerung und Mutter der neun Musen, verbunden. ${ }^{154}$ Auf den

146 Bertel Thorvaldsen, Testament vom 25. Januar 1843, TMA, Thorvaldsens Museums Oprettelse, 190, $\$ 7$ : „Som Følge af de i de tvende næstforegaaende $\$ \$$ indeholdte Bestemmelser, vil den umiddelbare og udelukkende Bestyrelse af Museet, tilkomme og paaligge meerbemeldte Executorer, som jeg herved ydermere bemyndiger til at anvende de til deres Disposition satte Midler for at vedligeholde og forøge Museets Konstsager og at forskjønne dets Indre, saa at det altsaa kan blive et hæderligt Monument for Dansk Konst og Danske Konstneres Præstationer.“ Deutsche Übersetzung nach Thiele 1852 - 1856, Bd. 3, 157.

147 Ebd., $\$ 1$ und $\$ 9$.

148 Ebd., $\$ 8$.

149 Müller, L. $1849-1850$.

150 Siehe bspw. Jørgensen 1984, 245; Henderson 2005, 26; Miss 2008, 34.

151 Kat. Kopenhagen 1974, 35; Jørnæs 1982c, 64; Jørgensen 1984, 248.

152 Zum Künstlertestament siehe ausführlich Hegener/Pöpper 2012, hier bes. 24 und 43.

153 Zur Deutung von Künstlerhäusern als gesteigerter Form von Grabmälern siehe Schweikhart 2001, 263.

154 Carruthers 2003, 112. 
Tempel der Letzteren, das museion, geht das heutige Museum sowohl etymologisch als auch funktionell zurück. So wie Mnemosyne die Mutter der Musen ist, kann folglich die Erinnerungs- und Gedächtnisfunktion als Mutter der Museen sowie im Endeffekt auch der darin enthaltenen Objekte betrachtet werden. Dies wird in den Anfängen des modernen Kunstmuseums in der ersten Hälfte des 18. Jahrhunderts deutlich: Während die besonders seit dem 16. Jahrhundert entstandenen Raritätenkabinette, Kunst- und Wunderkammern Objekte aus verschiedenen Zeitepochen vor allem nach dem Kriterium ihres Kuriositätswerts versammelten, waren die ersten - durchaus auf jenen frühen Sammlungen aufbauenden - Museen in Europa weitgehend der griechischen und römischen Antike und damit der eigenen Vergangenheit gewidmet. ${ }^{155}$ Das früheste Kunstmuseum im heutigen Sinn war das 1734 eröffnete Museo Capitolino in Rom, dem 1771/1772 das Museo Clementino im Vatikan folgte; dieses wurde in den 1780er Jahren zum Museo Pio-Clementino ausgebaut. ${ }^{156}$ Als erstes modernes Museum nördlich der Alpen gilt das zwischen 1769 und 1779 errichtete Fridericianum in Kassel, während das erste öffentliche Museum in Skandinavien das 1794 eingeweihte Königliche Museum (heute Nationalmuseum) in Stockholm war. ${ }^{157}$

Die dänische Sammlungs- und Museumsgeschichte reicht bis zu Ole Worms ab 1621 aufgebauter naturhistorischer Wunderkammer zurück. ${ }^{158}$ Die Sammlung ging noch im selben Jahr in den Besitz von König Frederik III. über und bildete einen Teil der spätestens 1650 gegründeten königlichen Kunstkammer. Diese wurde zwischen 1811 und 1824 aufgelöst. Die infolgedessen auf verschiedene Sammlungen verteilten Objekte stellten im 19. Jahrhundert den Grundstock der ersten spezialisierten Museen in Dänemark, allen voran des Dänischen Nationalmuseums. Daneben prägten öffentlich zugängliche Privatsammlungen das kulturelle Leben im Kopenhagen des frühen 19. Jahrhunderts, darunter jene von Graf Moltke oder dem Konsul West, die im Übrigen beide bereits während Thorvaldsens frühen Schaffensjahren mit diesem in Verbindung standen. ${ }^{159}$

Thorvaldsens Museum war das erste öffentliche Museum in Dänemark, das nicht aus einer königlichen Sammlung erwuchs. ${ }^{160}$ Es war grundsätzlich allen Interessierten zugänglich, doch wurde erwartet, dass man Sonntagskleidung trug, und Kinder unter 14 Jahren wurden nur in Begleitung einer erwachsenen Person zugelassen. ${ }^{161}$ Aus der öffentlichen Zugänglichkeit, der oben genannten Beschäftigung einer Aufsichtsperson, dem Eintrittsgeld und dem Sammlungskatalog wird ersichtlich, wie modern Thorvaldsens

Siehe auch Gaehtgens 2004, 138 - 139; Muschler 2010, 31 - 32.

Siehe bspw. Miss 1991, 343; Collins 2010, 189; auch Haskell/Penny 1981, 63 und $70-71$. Zu den frühen europäischen Kunstmuseen siehe ausführlich Paul 2012.

Miss 1991, 343; Söderlind 1998, 46 - 47; Gaehtgens 2004, 144 - 147.

Kat. Kopenhagen 1974, 3-7; Gundestrup 1985, 129-133.

Kat. Kopenhagen 1974, $23-25$.

Ebd., 3; Jørnæs 1982c, 63; Miss 1991, 341 und 351; Lange, B. 2002, 80; Miss 2005b, 7.

Ravn 1948, 16; Kat. Kopenhagen 1974, 4 und 31; Jørnæs 1982c, 63; Jørgensen 1984, 245. 
Museumskonzept war. ${ }^{162}$ Außerdem legte er Wert auf die Bildungsfunktion seines Museums, wie bereits aus seinem ersten Testament vom 8. August 1830 hervorgeht: „Zum Nutzen von Kunst und Wissenschaftlichkeit in Dänemark“.163 Schließlich wurde schon im April 1840 in der Gipserei Antonettis Enke an der Kopenhagener Østergade eine Art Museumsshop eingerichtet, wo man für wenig Geld kleinformatige Reproduktionen nach Thorvaldsens Werken kaufen konnte ${ }^{164}$ Bereits in Rom hatte Thorvaldsen für kurze Zeit von November 1836 bis Mai 1837 - mit den Künstlern Karl Brandenburg und Johann Georg Gmelin zusammengearbeitet, denen er die Rechte zur günstigen Reproduktion seiner Reliefs verkauft hatte. ${ }^{165}$ Das erwähnte Geschäft an der Østergade in Kopenhagen diente offiziell ebenfalls der Bildung und der Verbreitung von Thorvaldsens Schöpfungen, sollte jedoch faktisch zur finanziellen Unterstützung des Museums beitragen. ${ }^{166}$ Von 1850 bis 1858 übertrug man jene Herstellung von Thorvaldsen-Figurinen dem Gipser Thomas Christian Thomsen. Ab 1877 wurden neue Gussformen zur Reproduktion von Thorvaldsens Werken hergestellt und im Keller des Museums gelagert, bis dort schließlich im Sommer 1922 eine eigene Gipserei eingerichtet wurde. Hier konnte man offenbar bis in die zweite Hälfte des 20. Jahrhunderts hinein Abgüsse nach Werken des Bildhauers in voller Größe erwerben. Im Jahr 1938 standen nicht weniger als 175 Werke zur Auswahl, deren Preisspanne von nur drei Kronen für kleine Reliefs bis hin zu 6.000 Kronen für den gesamten Alexanderzug reichte (Letzteren konnte man alternativ auch laufmeterweise kaufen). ${ }^{167}$

\section{Thorvaldsens Museum und andere frühe Künstlermuseen}

Thorvaldsens Museum war nicht nur das erste öffentliche Kunstmuseum in Dänemark, sondern auch das erste von einem Künstler für sein eigenes Werk initiierte und tatsächlich errichtete Museum überhaupt. Die Gründung von Personalmuseen generell ist untrennbar verbunden mit dem Genie- und Künstlerkult. ${ }^{168}$ Mit Blick auf Thorvaldsen war sein

Zur Modernität von Thorvaldsens Museumsgedanken siehe auch Kronberg Frederiksen 2014b und 2014c.

Bertel Thorvaldsen, Testament vom 8. August 1830, TMA, Ref. m29 I, nr. 6, §1: „Til Gavn for Konst og Videnskabelighed i Danmark, skienker jeg til Kiøbenhavn alle mine samtlige Konstsager, bestaaende i: [...]." Siehe auch Thiele 1852 - 1856, Bd. 2, 236; Miss 1991, 347. Die Bildungsfunktion von Thorvaldsens Museum wurde nach dessen Errichtung bspw. von Hammerich 1876, 154-155, betont. Zum Bildungsanspruch von Sammlungen und Museen um 1800 siehe ausführlich Gaehtgens 2004.

Schultz 1948b, 84-86.

Karl Brandenburg an Bertel Thorvaldsen, 3. November 1836, TMA, Ref. m27, nr. 21. Siehe auch Tesan 1998, 71. Die Zusammenarbeit scheiterte nach wenigen Monaten, als sich Gmelin wegen finanzieller Schwierigkeiten zurückzog; Johann Georg Gmelin an Bertel Thorvaldsen, 17. Mai 1837, TMA, Ref. m21 1837, nr. 25.

Kronberg Frederiksen 2014b und 2014c.

Schultz 1948b, 84, 89-96 und 102.

Gohr 1977b, 90. 
Museum zweifellos das effektivste Mittel zur Überführung und Umwandlung seiner diesseitigen, vergänglichen celebrity in posthumen, unsterblichen Ruhm.

Für die historische und kulturelle Einordnung von Thorvaldsens Museum ist ein erneuter Vergleich mit Canova unerlässlich. Der gläubige Katholik hatte bereits um 1802 testamentarisch verfügt, dass mit einem Teil seines Vermögens eine Kirche in seinem venezianischen Geburtsort Possagno wiederaufgebaut werden sollte. ${ }^{169}$ Sein letztes, am Tag vor seinem Tod am 13. Oktober 1822 mündlich diktiertes Testament sah schließlich vor, dass sein gesamtes Vermögen in die Vollendung jenes Baus fließen sollte. ${ }^{170}$ Der Tempio Canoviano wurde ab 1819 nach Plänen des Bildhauers errichtet und 1832 - zehn Jahre nach dessen Tod - eingeweiht (Abb. 109a und 109b). ${ }^{171}$ Diese Kirche beherbergt nicht nur verschiedene Werke von Canova, sondern auch die Grabstätten des Bildhauers sowie des Geistlichen Giambattista Sartori, seines Zeichens Canovas Halbbruder und Universalerbe. ${ }^{172} \mathrm{Im}$ Tempio vereinten sich Canovas künstlerische Tätigkeit als Bildhauer und Maler mit seinem tiefen Katholizismus. ${ }^{173}$

Canova bezweckte mit dem imposanten Tempio nicht nur den Wiederaufbau der alten Kirche von Possagno, sondern setzte sich damit ein wirkmächtiges Denkmal. ${ }^{174}$ Dies zeigt sich in der Pantheon-ähnlichen Form des Tempio, seinem Portikus nach dem Vorbild der dorischen Säulenordnung des Parthenons sowie seiner Beherbergung von Canovas Grabstätte. In diesem Zusammenhang ist auch Canovas früheres Bestreben von zentraler Bedeutung, das Pantheon in Rom in eine Ruhmeshalle für Künstler zu verwandeln - ein Plan, den er ab 1804 durch die Aufstellung zahlreicher Porträtbüsten von Künstlern mit der Erlaubnis von Papst Pius VII. während einiger Jahre in die Tat umsetzen durfte. ${ }^{175}$ Im Tempio in seinem Geburtsort konnte er jene lange gehegte Vision schließlich in Form einer für sich selbst errichteten Ruhmeshalle zumindest teilweise verwirklichen. Rund zehn Jahre nach Canovas Tod begann man in Possagno zudem mit dem Bau der Gipsoteca Canoviana als Ausstellungsort für seine Originalmodelle, bei der es sich sowohl um das älteste Künstlermuseum als auch um das erste monografische Skulpturenmuseum

169 Myssok 2011, 19; Myssok 2012a, 244.

170 Bätschmann 1997, 83 - 84; Myssok 2012a, 248.

171 Guderzo 2011, 85; Myssok 2011, 22; Myssok 2012a, 245.

172 Die im Tempio befindlichen Werke Canovas umfassen dessen Selbstbildnisbüste (1812), eine Bronzeversion der Kreuzabnahme Christi (1828; zusammen mit Bartolomeo Ferrari) und das Gemälde der Beweinung Christi (1821); siehe bspw. Rigon 1985; Guderzo 2011, 85-86. Neben diesen Werken von Canova schmücken auch Gemälde und Skulpturen anderer Künstler wie Luca Giordano, Palma il Giovane, Moretto da Brescia oder Cincinnato Baruzzi den Tempio. Zum Verhältnis zwischen Canova und Sartori siehe Myssok 2012a, bes. 234-235.

173 Siehe auch Guderzo 2011, 85.

174 Siehe auch Bätschmann 1997, 84; Myssok 2011, 19; Myssok 2012a, 247.

175 Kat. Nürnberg/Schleswig 1991, 703; Bätschmann 1997, 83 - 84. Zu Canovas am Ende gescheitertem Projekt für das Pantheon siehe bspw. Münch 2011, 20. 

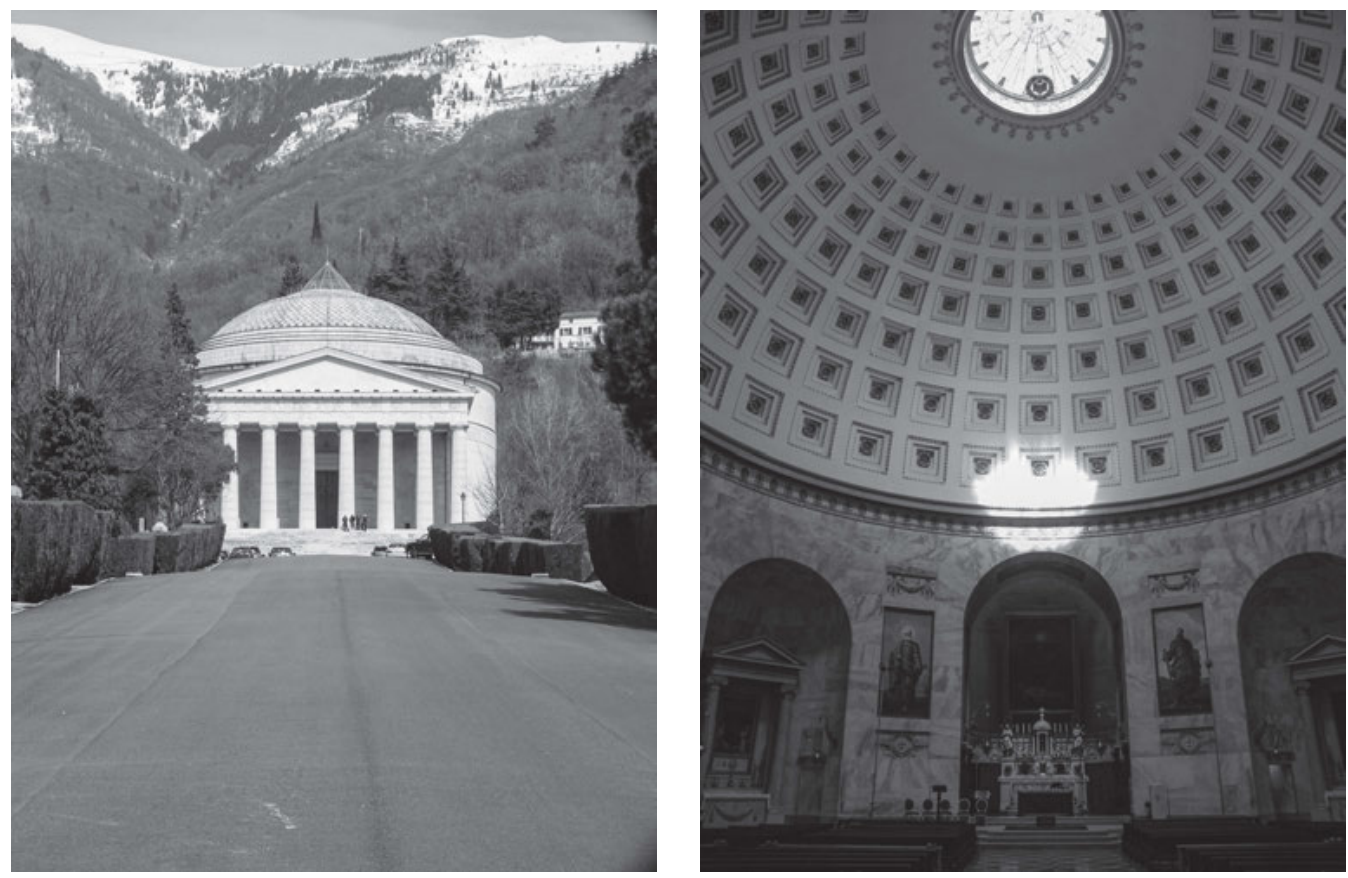

109a und 109b__Tempio Canoviano, Possagno, Außen- und Innenansicht, 2013

handelt. ${ }^{176}$ Die 1836 fertiggestellte Gipsoteca steht auf demselben Grundstück wie Canovas Geburtshaus, wo sich ein Teil der Kunstsammlung des Bildhauers sowie persönliche Gegenstände befinden. ${ }^{177}$

Die Errichtung besonders des Tempio dürfte Thorvaldsens Überlegungen zu seinem Vermächtnis nachhaltig geprägt haben. Dies lässt etwa sein Besitz von Missirinis 1833 publizierter Schrift Del tempio eretto in Possagno da Antonio Canova vermuten. ${ }^{178}$ Auch Høyen thematisierte 1837 in seiner Begleitschrift zum Spendenaufruf für Thorvaldsens Museum die Verbindung zwischen dem Tempio von Canova (die Gipsoteca scheint ihm noch nicht bekannt gewesen zu sein) und dem geplanten Museum in Kopenhagen: „Dieser [Canova] erbaute eine Kirche an seinem Geburtsorte, als prachtvolles Denkmal seiner

Myssok 2011, 22 -23; Myssok 2012a, 253; auch Miss 1991, 351. Gibson, der sowohl mit Canova als auch mit Thorvaldsen in engem Austausch gestanden hatte, folgte seinen beiden großen Vorbildern und vermachte die bei seinem Tod 1866 noch in seinem römischen Atelier befindlichen Werke sowie sein gesamtes Vermögen der Londoner Royal Academy; siehe bspw. Hartmann 1955, 232 - 233.

177 Sartori hatte jedoch nach Canovas Tod einen großen Teil von dessen Sammlung italienischer Gemälde aus der Zeit um 1800 veräußert; Guderzo 2011, 81.

178 Jørnæs 1989c, 33; Miss 1991, 351. 
Frömmigkeit; Jener stiftete ein Heiligthum der Kunst zu Nutzen und Ehren für sein Vaterland [...]. ${ }^{179}$ Damit betonte Høyen erneut die Bedeutung des Museums für das dänische Selbstverständnis. Architektonisch und dekorativ hat Thorvaldsens Museum jedoch kaum etwas mit der stark am Braccio Nuovo des vatikanischen Museo Chiaramonti orientierten Gipsoteca und dem Pantheon-ähnlichen Tempio gemein. ${ }^{180}$

Hingegen dürfte für das Konzept von Thorvaldsens Museum die in Possagno erfolgte Verbindung von Museum und Mausoleum von zentraler Bedeutung gewesen sein, worauf im Kapitel IV.3 zurückgekommen wird. Während dies in Possagno jedoch in zwei separaten, durch eine höchst wirkungsvolle Straßen- oder Prozessionsachse verbundenen Gebäuden geschah, sind Thorvaldsens Museum und Mausoleum in einem einzigen Bau vereint. ${ }^{181}$ In Kopenhagen könnte man allerdings auch die von Thorvaldsen in den 1820er Jahren skulptural ausgestattete Frauenkirche in die Betrachtung einbeziehen, die von der Kirchenbaukommission mehrfach mit einem Museum für Thorvaldsen verglichen wurde (Taf. X). So schrieb die Kommission im Juli 1828, ein knappes Jahr vor der Einweihung der Kirche, diese werde

ein Musæum für Thorvaldsens Kunstwerke und für sie alleine, und diese Kommission würde sich glücklich schätzen, die Verwaltung eines so herrlichen Musæums im Norden gehabt zu haben, das sicher Fremde nach Kopenhagen ziehen würde, um eine solche Seltenheit zu beschauen. ${ }^{182}$

Die Frauenkirche kann gleichsam als Ankündigung von Thorvaldsens ungefähr in jener Zeit erstmals geäußertem Museumsgedanken betrachtet werden. Dafür sprechen seine bereits erwähnten, durchaus skrupellosen Bemühungen, den prestigeträchtigen Auftrag zur skulpturalen Ausstattung der Frauenkirche für sich zu beanspruchen, und die von ihm am Ende deutlich zu groß ausgeführten Apostelfiguren für die dafür vorgesehenen, heute zugemauerten Nischen in den Pfeilern des Kirchenschiffs. ${ }^{183}$

179 Høyen 1837, 8. Siehe auch Miss 1991, 351; Bätschmann 1997, 91.

180 Zur Architektur, dekorativen Gestaltung und Skulpturaufstellung in der Gipsoteca Canoviana siehe bspw. Myssok 2011, $23-25$.

181 Siehe auch Myssok 2011, 23; Myssok 2012a, 253; Trempler 2011, 206 - 207.

182 Kirchenbaukommission (Kommissionen ang. genopførelse af Vor Frue Kirke $i$ København) an Bertel Thorvaldsen, 8. Juli 1828, TMA, Ref. m13 1828, nr. 68: „Vor Frue Kirke blev da et Musæum for Thorvaldsens Kunstværker og for dem alene, og denne Commission vilde agte sig lykkelig ved at have havt Bestyrelsen af et saadant herligt Musæum i Norden, som sikkert vilde drage Fremmede til Kjøbenhavn, for at beskue en saadan Sjeldenhed. “ Siehe auch Kronberg Frederiksen 2014c. Hagen 1844, 35, bezeichnet die Frauenkirche als ein „heilige[s] christliche[s] Museum“.

$183 \mathrm{Zu}$ Thorvaldsens skrupellosem Verhalten im Hinblick auf den Auftrag für die Frauenkirche siehe auch Kap. III.1. Zu den zu groß ausgeführten Apostel-Statuen siehe Thiele 1852-1856, Bd. 2, 194-195; auch Trier 1903, 128-129; Henschen/Jørnæs 1987, 11; Jørnæs 2011, 155. Als Thorvaldsen von der Kirchenbaukommission auf die zu großen Dimensionen seiner Apostelfiguren aufmerksam gemacht wurde, antwortete er, dass er „nicht begreifen“ könne, wie das passieren konnte, und erklärte es sich mit inkorrekten Maßangaben von Seiten der Kirchenbaukommission; Bertel Thorvaldsen an die Kirchenbau- 
Entgegen einer verbreiteten Meinung dürfte Canova nur den Tempio selbst initiiert haben, während die Gründung der Gipsoteca auf Sartori zurückzugehen scheint. ${ }^{184}$ Der erste Künstler, der ein Museum für die eigenen Werke anregte, war gemäß Gunter Schweikhart der Maler Bernardino India. ${ }^{185}$ Dieser hinterließ bei seinem Tod 1590 seinem Neffen sämtliche noch in seinem Besitz befindlichen Gemälde, Zeichnungen und Malutensilien. Dazu verfügte er testamentarisch, dass für sein Werk - vor allem Porträts berühmter Männer - und die von ihm benutzen Arbeitsgeräte ein Museum in seinem Wohnhaus errichtet werden sollte. Diese frühe Idee eines eigenen Personalmuseums spiegelt - auch wenn sie vermutlich nicht umgesetzt wurde - das in der Renaissance erwachte Selbstbewusstsein der Künstler wider.

Seit dem frühen 19. Jahrhundert war indessen die posthume Konservierung der Geburts- oder Wohnhäuser von Künstlern oder anderen illustren Persönlichkeiten durch Zeitgenossen, meist Familienangehörige, besonders aktuell und klarer Ausdruck des damaligen Geniekults. ${ }^{186}$ Mit der Erhaltung ehemaliger Privathäuser von Künstlern, sogenannter Künstlerhäuser, oder auch Ateliers mit persönlichen Gegenständen versuchte man die ,Aura' des jeweiligen Ortes für die Nachwelt zu bewahren. ${ }^{187}$ Durch Künstler selbst initiierte Personalmuseen sind folglich von den zahlreichen Museen zu unterscheiden, die durch Drittpersonen nicht nur posthum, sondern auch bereits zu Lebzeiten der betreffenden Künstler errichtet wurden. ${ }^{188}$ Ein bemerkenswertes Beispiel dafür ist die Gründung des Museums für Thorvaldsens Zeitgenossen und Kontrahenten d'Angers: Der französische Bildhauer hatte seiner Heimatstadt Angers bereits 1811 einen Teil seiner Werke ohne den Wunsch nach einem eigenen Museum geschenkt. Doch obwohl er fand, dass nur verstorbene Künstler mit einem Museum geehrt werden sollten, errichtete ihm die Stadt 1839 - also noch zu seinen Lebzeiten - ein solches, die heutige Galerie David d'Angers. ${ }^{189}$

kommission (Kommissionen ang. genopførelse af Vor Frue Kirke i København), 5. Februar 1829, KB, Ref. NKS 3756, $4^{\circ}$ (Transkript im TMA): „At Apostlerne ikke passer til Nicherne, kan jeg ikke begribe; thi Hovedet staaer i Centrumet af Cirklerne i Nicherne, som De har havd den Godhed at oversende mig, saa at Maalet ikke maae være rigtigt." Siehe auch Thiele $1852-1856$, Bd. 2, 197.

184 Siehe dazu ausführlich Myssok 2011, 20 -21; Myssok 2012a, 249-255; auch Rigon 1985; Bott, G. 1993, 373; Bätschmann 1997, 83. Muschler 2010, 36 - 37, geht hingegen davon aus, dass Canova auch sein eigenes Museum persönlich veranlasst hatte und es sich dabei folglich um das erste selbst initiierte und tatsächlich errichtete Künstlermuseum handelte.

185 Schweikhart 2001, 259-263.

186 Siehe auch Muschler 2010, 37 - 38; Plachta 2014, 9; Giles Waterfield, in: Bätschmann u. a. 2014, 44. Weitere frühe Beispiele sind die in der ersten Hälfte des 19. Jahrhunderts musealisierten Wohn- bzw. Arbeitsstätten von Raffael in Urbino und Dürer in Nürnberg.

187 Siehe auch Schwarz 1990, 3; Schweikhart 2001, 257; Plachta 2014, 9; Giles Waterfield, in: Bätschmann/ De Poli/Gamboni/Herrmann/Waterfield 2014, 44.

188 Siehe auch Muschler 2010, 37.

189 Ebd., 162. 
Als das älteste, von einem Künstler für sich selbst angeregte, tatsächlich verwirklichte Museum nimmt jenes von Thorvaldsen einen wichtigen Stellenwert in der Museumsgeschichte ein. Dass es Thorvaldsen als erstem abendländischem Künstler gelang, mit der tatkräftigen Unterstützung seiner Landsleute ein eigenes Museum umzusetzen, veranschaulicht einmal mehr seinen celebrity-Status. Angesichts des engmaschigen deutsch-dänischen Künstlernetzwerks im Rom des frühen 19. Jahrhunderts liegt ferner die Vermutung nahe, dass die ersten Personalmuseen in Deutschland unter dem unmittelbaren Eindruck von Thorvaldsens Museum in Kopenhagen entstanden: 1844 eröffnete in Schinkels ehemaliger Wohnung in der königlichen Bauakademie in Berlin ein Museum für den drei Jahre zuvor verstorbenen Architekten, das bis in die 1870er Jahre in der ursprünglichen Form bestand. ${ }^{190}$ Auch wenn Schinkel sein Museum nicht selbst angeregt hatte, dürfte er den Fortschritt von Thorvaldsens Museum bis zu seinem Tod mit Interesse verfolgt haben, hatte er doch Bindesbøll bei den Entwurfszeichnungen beraten. Als erster deutscher Künstler initiierte der Bildhauer Schwanthaler in seinem Todesjahr 1848 ein $\mathrm{Mu}$ seum für seine eigenen Werke. ${ }^{191}$ Dieses befand sich in seinem ehemaligen Atelier in München und wurde im Zweiten Weltkrieg zerstört. Auch Schwanthaler war höchstwahrscheinlich mit der Entstehungsgeschichte des Museums für Thorvaldsen vertraut, in dessen römischer Werkstatt er in den Jahren 1826/1827 und 1832-1834 gearbeitet hatte. ${ }^{192}$ Darüber hinaus hatte der Däne ihn 1835 für die Bildhauereiprofessur an der Münchner Kunstakademie vorgeschlagen, die Schwanthaler daraufhin bis zu seinem Tod innehatte. ${ }^{193}$ Nach jenen frühen Personalmuseen begannen sich die von Künstlern selbst veranlassten Museumsgründungen erst in der zweiten Hälfte des 19. und vor allem im Laufe des 20. Jahrhunderts zu häufen. Ein herausragendes Beispiel ist das zwischen 1863 und 1865 errichtete Museo Vela im schweizerischen Ligornetto, welches Wohnhaus, Atelier und Museum des Bildhauers Vincenzo Vela in sich vereinte. ${ }^{194}$ Zweifellos das prominenteste von einem Künstler für sein eigenes Werk veranlasste Museum ist indessen das 1919 eröffnete Musée Rodin in dem von Auguste Rodin seit 1911 bewohnten Hôtel Biron in Paris. ${ }^{195}$ Während im Unterschied zu Thorvaldsen sicherlich nicht alle der genannten Künstler Objekte eines Personenkults waren oder gar als celebrities bezeichnet werden können, ist sämtlichen Personalmuseen gemein, dass sie Namen und Lebenswerke bewahren und zum Nachruhm des mit dem Museum geehrten Individuums beitragen sollten. lungen, namentlich jenen des Bildhauers Rauch und des Politikers Peter Beuth, wurde der Schinkel'sche Nachlass in den 1920er Jahren der Berliner Nationalgalerie unterstellt.

191 Muschler 2010, 37.

192 Tesan 1998, 224; Kofoed 2014c.

193 Ludwig von Schwanthaler an Bertel Thorvaldsen, 15. Februar 1835, TMA, Ref. m20 1835, nr. 14. Siehe dazu auch Kap. III.1. Für weitere Beispiele früher Künstlermuseen siehe Muschler 2010, 37 - 40 und 163 - 170.

194 Siehe dazu bspw. Bätschmann 1997, 93 - 94.

195 Siehe dazu bspw. Le Norman-Romain 2011, 60. 


\section{Die Architektur von Thorvaldsens Museum}

Thorvaldsens Museum wurde am 17. September 1848 - exakt zehn Jahre nach der Ankunft des Bildhauers in Kopenhagen - eingeweiht und einen Tag später für das Publikum geöffnet. ${ }^{196}$ Weitere zehn Jahre später malte Constantin Hansen ein Bild jenes Gebäudes, worauf der radikale Bruch mit der damals in Kopenhagen vorherrschenden, streng klassizistischen Architektur zu erkennen ist: Das Museum hebt sich sowohl farblich als auch in seiner Formensprache klar von dem dahinter liegenden Schloss Christiansborg ab (Taf. XI). ${ }^{197}$ In architektonischer Hinsicht - gerade auch im Kontrast mit den umliegenden klassizistischen Bauten - ist Bindesbølls Einführung neuer Formen auffallend: Thorvaldsens Museum ist nicht mehr von strengen Waag- und Senkrechten, sondern von schräg verlaufenden Linien geprägt. ${ }^{198}$ Dies zeigt sich besonders in den fünf trapezförmigen Portalen in der gegen Südwesten ausgerichteten Hauptfassade sowie in den weiß bemalten Lisenen an allen Seiten des Gebäudes. Mehr noch als durch seine neuartige Formensprache sticht Thorvaldsens Museum durch sein polychromes Äußeres aus der architektonischen Umgebung auf der Insel Slotsholmen hervor. An allen vier Außenfassaden dominiert die Farbe Ocker. Während der Errichtung von Thorvaldsens Museum spalteten sowohl Bindesbølls Entwurf insgesamt als auch die genannte Farbwahl im Spezifischen die Gemüter, weshalb der Bauprozess des Museums mehrfach unterbrochen werden musste. ${ }^{199}$ Erst im Kopenhagen des späteren 19. Jahrhunderts sollte Ocker vermehrt als Fassadenfarbe benutzt werden und bestimmt infolgedessen nach wie vor gewisse Quartiere der dänischen Hauptstadt. ${ }^{200}$

Das vorliegende Kapitel befasst sich mit der eklektizistischen Architektur und dekorativen Gestaltung von Thorvaldsens Museum. ${ }^{201}$ Dabei soll gezeigt werden, dass die Übersetzung von Elementen und Motiven aus fernen Kulturen im Museumsbau, die darin vorgenommene Verschränkung von Vergangenheit und Gegenwart sowie bewusst eingesetzte Anachronismen wesentlich zur Stilisierung des Bildhauers zum Nationalhelden ei-

196 Bruun, C./Fenger 1892, 162 und 165; Müller, S. 1893, 301; Ravn 1948, 11 - 12 und 16; Kat. Kopenhagen 1974, 30; Jørnæs 1982c, 63; Miss 1991, 341; Henderson 2005, 40; Miss 2005b, 7; Jørnæs 2011, 250.

197 Eine Ölskizze zu Hansens Gemälde befindet sich im Metropolitan Museum of Art in New York (Inv.Nr. 2009.400.73).

198 Siehe auch Lange, B. 2002, 55.

199 Siehe bspw. Miss 1991, 350. Zu den Kontroversen im Bauprozess des Museums siehe auch Bruun, C./ Fenger 1892, 56-85. Kritische Stimmen zur Farbwahl am Museum finden sich bspw. in „Museo di Thorvaldsen in Copenaghen“ 1846, 353: „La facciata esterna di questo monumento è del gusto orribile che si vede nel disegno [Abbildung im Bericht], nè vi faremo sopra altro comento.“; Macmillan 1869, 346: „[...] a square yellowish-looking building in the Egyptian style, singularly ugly.“

200 Lange, B. 2002, 50 und 65.

201 Siehe zu diesem Thema auch Schindler 2017. 
nerseits und internationaler Berühmtheit andererseits beitrugen. Thorvaldsens Museum kann gerade aufgrund seiner eigenwilligen Architektur und Bemalung als die Visualisierung des Künstler- und celebrity-Kults um Thorvaldsen par excellence betrachtet werden, die ferner das Selbstverständnis des dänischen Volkes um das europäische Revolutionsjahr 1848 widerspiegeln sollte.

\section{Vom Wagendepot zum Museum}

Bindesbøll behielt die Größe und architektonische Struktur der beiden Längsflügel des ehemaligen Wagendepots bei (Abb. 100 und 107). Jedoch verband er Letztere auf der Seite der Schlosskirche durch die Errichtung des heute als Christussaal bekannten Ausstellungsraumes, in dem die Originalmodelle von Thorvaldsens Christus- und Apostel-Statuen sowie seinem Taufengel für die Kopenhagener Frauenkirche aufgestellt sind. ${ }^{202} \mathrm{Zu}$ dem ergänzte der Architekt das Wagendepot dem Innenhof entlang auf drei Seiten mit einem Korridor. ${ }^{203}$ Durchaus treffend hat Siegfried Gohr die Gesamtstruktur des Gebäudes mit dem Innenhof und dem an dessen nordöstlicher Seite anschließenden Christussaal als „säkularisierte[n] Kreuzgang“ bezeichnet. ${ }^{204}$ Dieser Korridor sollte zum einen selbst als Ausstellungsraum vor allem für Thorvaldsens Gipsmodelle dienen, die dank den Glastüren von natürlichem Licht erhellt würden. Zum anderen verkleinerte der Gang die einzelnen Zimmer gerade so weit, dass die dort aufgestellten Marmorskulpturen in einer für ihre Beleuchtung optimalen Distanz zu den Fenstern in den Außenwänden des Gebäudes platziert werden konnten. ${ }^{205}$

Bindesbøll vergrößerte ferner das ehemalige Torhaus zu einer monumentalen, hinter fünf trapezförmigen Portalen gelegenen Vor- oder Eingangshalle mit Tonnengewölbe. ${ }^{206}$ Jene braun bemalten Türen durchbrechen zusammen mit den weißen, sich über die gesamte Höhe des Baus erstreckenden Lisenen und unterhalb des Dachs entlanglaufenden Stucktondi die ockerfarbene Fläche an der Hauptfassade des Museums (Taf. XI). Die fünf Portale dienten ursprünglich als Haupteingang zum Museum. Sie erwiesen sich jedoch als unpraktisch, weshalb man sie bereits in der zweiten Hälfte des 19. Jahrhunderts nur noch zu besonderen Anlässen benutzte und das Gebäude seither durch einen kleinen Nebeneingang auf der Südseite betritt. ${ }^{207}$

Mit der Vorhalle und dem Christussaal umfasst das Gebäude folglich zwei große, über beide Stockwerke reichende Ausstellungshallen. Die Zweigeschossigkeit im Mittelteil des Museums ist von außen an den Süd- und Nordfassaden in Form von zwei übereinan- 
der liegenden Fensterreihen zu erkennen. Diese Fenster sind wie die Portale an der Hauptfassade von weißen Lisenen umgeben. Die Lisene auf der Rückseite des Museums veranschaulicht wiederum, dass der Christussaal dahinter über beide Geschosse reicht. Im Weiteren entfernte der Architekt die Verbindungspassage zu Schloss Christiansborg, die im vorangegangenen Kapitel erwähnt wurde. ${ }^{208}$ Wie noch zu zeigen sein wird, muss dies angesichts der von Thorvaldsens Museum vermittelten ideologischen Werte gleichsam als symbolischer Akt verstanden werden. Schließlich wurde ein Kellergeschoss gebaut, das ursprünglich nebst dem Magazin die Wohnung von Thorvaldsens früherem Kammerdiener Wilckens enthielt, der zugleich der erste Hauswart des Museums war. ${ }^{209}$

Während am Bau und der dekorativen Gestaltung von Thorvaldsens Museum unzählige Künstler und Handwerker beteiligt waren, geht das Gesamtkonzept auf Bindesbøll zurück. ${ }^{210}$ Dieser umschrieb seine Idee folgendermaßen: „Was die Wahl des Stils betrifft, so haben antike Formen die allermeisten von Thorvaldsens Werken durchdrungen: sodass die Muster der antiken Architektur auch die besten Motive zu diesem Gebäude abgeben müssen. "211 Darin, dass Bindesbøll einen passenden, will heißen ,stilechten' Rahmen für Thorvaldsens klassizistische Werke schaffen wollte, ist seine Orientierung am architektonischen Konzept des Museo Pio-Clementino in Rom erkennbar. ${ }^{212}$ Im Kopenhagener Museumsgebäude dominiert sowohl außen als auch innen die eklektizistische Aneignung von Elementen aus der antiken Kunst und Architektur. Dabei ging es Bindesbøll nicht nur um Anleihen aus der griechischen und römischen Architektur, sondern auch um etruskische und ägyptische Elemente. ${ }^{213}$ Aufgrund der eklektizistischen Architektur bezeichnete die Satirezeitschrift Corsaren Thorvaldsens Museum 1847 als einen „äußerst originellen, in nordisch-arabisch-ägyptischem Stil errichteten Kasten“.214 Dieses

Thule Kristensen 2013, 76.

209 Kat. Kopenhagen 1974, 34 - 35, Anm. 64; Jørnæs 1982c, 64; Miss 1991, 341; Jørnæs 2011, 250; Thule Kristensen 2013, 71.

210 Siehe bspw. Miss 2005b, 7; Thule Kristensen 2013, 114-145.

211 Gottlieb Bindesbøll an das Komitee zur Errichtung von Thorvaldsens Museum (Comitteen for Oprettelsen af Thorvaldsens Museum), 15. Juni 1839, TMA, Ref. gmIX, nr. 1, Absatz 13: „Med Hensyn til Valget af Stilen, da har de antikke Former saaledes gjennemtrængt de allerfleste af Thorwaldsens Arbeider, at Mønstre af antik Architectur ogsaa maa give de bedste Motiver til denne Bygning [...]. " Deutsche Übersetzung nach Miss 1991, 350. Siehe auch Bramsen 1959, 84; Jørgensen 1970, 11; Henschen/Jørnæs 1987, 11 .

212 Miss 1991, 350.

213 Siehe auch Moltesen 1926, 43; Miss 1991, 350. Nach Bramsen 1959, 90 - 92 und 159-160, nimmt Thorvaldsens Museum hingegen ausschließlich etruskische, klassisch-antike und fantastische Elemente auf, die fälschlicherweise als ägyptisch betrachtet worden seien.

214 Corsaren, 5. November 1847, TMA, Thorvaldsens Museums Småtryk-Samling 1847, Corsaren 5.11: „[...] den yderst originale, i Norsk-Arabisk-Ægyptisk Stiil opførte Kasse [...]. Etwas später beschrieb O. Otto Thorvaldsens Museum als „halb in ägyptischem, halb in pompejanischem Stil“ gehaltenes Gebäude; Otto 1869, 671. 
Zitat betont mehr die Verschiedenartigkeit der Elemente als deren tatsächliche Herkunft. Denn nordische und arabische Einflüsse sucht man vergeblich; hingegen werden die griechischen, römischen und etruskischen Elemente in dem zitierten Artikel nicht angesprochen.

Das prominenteste Element aus der antiken Architektur ist zweifellos das durch die fünf Portale gebildete, von einer Quadriga gekrönte Triumphtormotiv der Hauptfassade des Museums. ${ }^{215}$ In der Tat kann Thorvaldsens Museum selbst als ein „Triumphdenkmal“ für den Bildhauer betrachtet werden, wie Bente Lange dies getan hat. ${ }^{216}$ Der Gesamteindruck der Hauptfassade lässt Bindesbølls Orientierung an dem 1788-1791 gebauten Brandenburger Tor in Berlin erkennen. ${ }^{217}$ Die Skulptur der von Viktoria geführten Quadriga auf dem Dach des Museums war kurz nach Thorvaldsens Tod von König Christian VIII. bestellt worden. ${ }^{218}$ Die Siegesgöttin geht, wie im vorangegangenen Kapitel erwähnt wurde, auf einen Entwurf von Thorvaldsen aus dem Jahr 1827 zurück. Ausgeführt wurde sie schließlich zwischen 1845 und 1848 von Bissen und dessen Lehrling Stephan Ussing. ${ }^{219}$ Das Viergespann wiederholt seinerseits die 1840 durch Freund geschaffenen Reliefs von Triumphwagen in den Pilasterkapitellen an den Ecken der Hauptfassade des Museums sowie die wagenlenkenden Genien an den Wänden des Innenhofs; eine getreue Abbildung des Letzteren zeigt Christian Olavius Zeuthens Gemälde von 1847 (Taf. XII). ${ }^{220}$ Die Gestaltung des Bodenbelags im Innenhof aus schwarzen und weißen Granitplatten nimmt ferner die Form eines römischen Circus und damit ein weiteres antikes Motiv auf. ${ }^{221}$

\section{Thorvaldsens Museum und die Ägyptomanie}

Während das Triumphtormotiv und die Quadrigen eindeutig der römischen Architektur und Kunst entlehnt sind, gehen die schrägen Linien, die in Form von Lisenen, Fensterund Türrahmen das gesamte Äußere von Thorvaldsens Museum prägen, auf ägyptische Monumente wie Pylone, Obelisken und Pyramiden zurück. Das alte Ägypten - oder richtiger die Vorstellung davon - war seit der Antike ein wiederkehrendes Thema in der abendländischen Kultur, welches sich insbesondere durch Napoleons Ägyptenfeldzug zwischen 1798 und 1801 zu einer ganz Europa ergreifenden Ägyptomanie steigerte. ${ }^{222} \mathrm{Na}-$ poleons Feldzug resultierte in der Publikation zahlreicher Berichte, allen voran der zwan-

215 Siehe auch Jørgensen 1970, 12; Lange, B. 2002, 60; Henderson 2005, 28.

216 Lange, B. 2002, 60.

217 Bramsen 1959, 92; Miss 1991, 351.

218 Lange, B. 2002, 71.

219 Ebd.; auch Thiele 1852-1856, Bd. 3, 188.

220 Melander 1998, 102; Henderson 2005, 24 - 25; Thule Kristensen 2013, 105.

221 Siehe auch Henderson 2005, 25; Thule Kristensen 2013, 114.

222 Curl 1994, XIV und 119 - 120. Für die architektonische Ägyptenrezeption waren zudem die Kupferstiche von Giovanni Battista Piranesi von Bedeutung; Curl 1994, XVII, 108 und 130. 
zig Bände umfassenden Description de l'Égypte von 1809 bis 1828, und hatte in Form der Ägyptologie eine wissenschaftlichere Erforschung des alten Ägypten zur Folge. ${ }^{223}$

Die postnapoleonische Ägyptenfaszination stieß im Europa des aufkommenden romantischen Klassizismus auf fruchtbaren Boden: Nachdem die griechische Kunst und Architektur den wichtigsten Referenzpunkt des Klassizismus des 18. Jahrhunderts gebildet hatte, griff dessen ,romantische' Periode in ihrer Formensprache auf die visuelle Kultur des alten Ägypten zurück. ${ }^{224}$ Um 1800 war die ägyptische Kultur noch wenig erforscht, doch entsprach ihre Vorliebe für Monumentalität und Erhabenheit den zeitgenössischen Idealen.225 Infolgedessen war die Ägyptomanie des frühen 19. Jahrhunderts sowohl durch eine verstärkte Erforschung des alten Ägypten als auch durch lebendige Imaginationen jener noch fremden Kultur charakterisiert.

Thorvaldsen, selbst ein Sammler ägyptischer Funde, und Bindesbøll waren sich des wachsenden Interesses ihrer Zeitgenossen an der ägyptischen Kultur bewusst: In Rom waren sie sowohl mit ägyptischen Motiven wie Obelisken und der Cestius-Pyramide als auch mit ägyptisierender Architektur wie jener von Luigi Canina konfrontiert. ${ }^{226} \mathrm{Da}$ Thorvaldsen zu den Freimaurern zählte, ist ferner die Tatsache nennenswert, dass die Wurzeln der freimaurerischen Ideologie und Formensprache ebenfalls in der ägyptischen Kultur lagen. ${ }^{227}$ Außerdem pflegten Thorvaldsen und Bindesbøll enge Kontakte zu Personen, die für ihr Wissen über das alte Ägypten bekannt waren. Beispielsweise hatte Thorvaldsens frühester Förderer und Kritiker Zoëga mit Numi Ægyptii imperatorii (1787) und De origine et usu obeliscorum ad Pium sextum pontificem maximum (1797) bereits zwei Bücher zu ägyptischen Themen veröffentlicht. ${ }^{228}$ Ein besonders lebhaftes Interesse an der visuellen Kultur Ägyptens zeigte auch Hope, dem Thorvaldsen 1803 seinen künstlerischen Durchbruch verdankte. In derselben Zeit, zwischen 1799 und 1804, renovierte Hope sein

Zum Aufkommen der Ägyptomanie um 1800 siehe ausführlich Curl 1994, XVII und 98 - 186; Kat. Paris/ Ottawa/Wien 1994, 29-263. Die im Zusammenhang mit Napoleons Ägyptenfeldzug erschienenen Publikationen umfassten auch Dominique-Vivant Denons Voyage dans la Basse et la Haute Égypte von 1802, die als eigentlicher Grundstein der Ägyptologie gelten kann; siehe dazu Curl 1994, 119. Eine Schlüsselfigur für die Ägyptologie war außerdem Jean-François Champollion, der in den 1820er Jahren den während des napoleonischen Ägyptenfeldzuges gefundenen Stein von Rosetta entziffern konnte. Champollion besuchte Thorvaldsen 1825 in seinem römischen Atelier; http://arkivet.thorvaldsensmuseum.dk/people/champollion-jean-francois (zuletzt aufgerufen am 15. April 2020). Curl 1994, XVII. Ebd., 110; Lange, B. 2002, 57. Siehe auch Miss 1991, 351; Lange, B. 2002, 57; Thule Kristensen 2013, 98. Curl 1994, XVIII und 134-135; zu Thorvaldsens Sympathien für die Freimaurer siehe bspw. Jørnæs 2011, 131. Ein Gesang, der am 27. Oktober 1819 zu seinen Ehren durch die Kopenhagener Freimaurerloge „Friedrich zur gekrönten Hoffnung“ vorgetragen wurde, scheint der einzige eindeutige Beleg für die Zugehörigkeit des Bildhauers zu den Freimaurern zu sein; TMA, Ref. M18,7 (Thorvaldsens Museums Småtryk-Samling 1819). 
Haus an der Duchess Street in London, wobei vor allem dessen sogenanntes ägyptisches Zimmer die Bewunderung der Zeitgenossen erntete. ${ }^{229}$ Ebenfalls 1803 veröffentlichte der sich mehrfach in Rom aufhaltende Antoine Chrysostôme Quatremère de Quincy seine bereits 1785 verfasste Untersuchung De l'Architecture égyptienne, eine vergleichende Studie über ägyptische und griechische Architektur. ${ }^{230} 1807$ folgte die Publikation von Hopes Buch Household Furniture and Interior Decoration, das ausgehend von der Renovierung seines eigenen Hauses auch Entwürfe für ägyptisierende Möbel und andere Interieurdekorationen enthält. ${ }^{231}$ Diese Zeichnungen basieren auf archäologischen Funden und veranschaulichen Hopes aktive Auseinandersetzung mit der Formensprache des alten Ägypten. Mit Kestner, der sich ab 1825 in Rom aufhielt und ebenfalls im deutsch-dänischen Künstlerkreis verkehrte, teilte Thorvaldsen schließlich die Leidenschaft für das Sammeln ägyptischer Objekte. Gemäß Kestner war der Bildhauer „hierin mein einziger Rival in Rom “.232

Einen prägenden Eindruck bei Bindesbøll dürfte indessen der Architekt Franz Christian Gau hinterlassen haben. ${ }^{233}$ Gau, den Bindesbøll 1823 in Paris kennen lernte, hatte bereits Reisen nach Pompeji und Ägypten unternommen; Letztere schlug sich besonders in seinem 1822 veröffentlichten Stichwerk Antiquités de la Nubie nieder. ${ }^{234}$ Die Tafel 19 in dieser Publikation zeigt den Innenhof des Tempels von Kalabscha, der eine äußerst ähnliche Erscheinung darbietet wie die Hauptfassade von Thorvaldsens Museum und Bindesbøll daher höchstwahrscheinlich als Inspirationsquelle diente (Abb. 110). ${ }^{235}$ Bindesbølls Bekanntschaft mit dem ebenfalls von der ägyptischen Kunst faszinierten Schinkel wird ihrerseits besonders in den 1837 entstandenen, sogenannten römischen oder polychromen Entwürfen für Thorvaldsens Museum ersichtlich, die eine deutliche Orientierung am Alten Museum in Berlin offenbaren. ${ }^{236}$ Diese Ausführungen zu Thorvaldsens und Bindesbølls direkter und indirekter Auseinandersetzung mit der visuellen Kultur des alten Ägypten sind keineswegs vollständig und bleiben ein Thema für die weitere Forschung.

In der kunsthistorischen Literatur werden als mögliche Inspirationsquellen für Thorvaldsens Museum ägyptische Tempel wie jener auf der Nil-Insel Elephantine vorgeschla-

229 Curl 1994, 120 -126; auch Kat. Paris/Ottawa/Wien 1994, 128; Floryan 2003, 49-50. Zu Thorvaldsens künstlerischem Durchbruch siehe Kap. sI.1.

230 Curl 1994, 107.

231 Siehe auch Floryan 2003, 50.

232 Kestner 1850, 75. Siehe auch Lange, J. 1894, 121.

233 Moltesen 1926, 43; Sass 1969, 92 - 93; Jørgensen 1984, 239.

234 Gau 1822. Zu Bindesbølls Bekanntschaft mit Gau siehe auch Bøyesen 1946-1947, 176; Bramsen 1959, 17 -18; Sass 1969, 93.

235 Das diesem Stich zugrunde liegende Aquarell befindet sich im Kupferstichkabinett der Akademie der bildenden Künste Wien.

236 Bramsen 1959, 52; Jørgensen 1984, 239; Miss 1991, 351; Curl 1994, XVIII, 107 und 141; Floryan 1998, 28 - 30; Lange, B. 2002, 28; Trempler 2011, 209. 
110__Franz/François Christian Gau, Kalabscha (Ansicht der Fassade im Inneren des Hofes), 1819, Aquarell, Maße unbekannt, Kupferstich von Alexandre-Charles Dormier, in: Gau 1822, Tafel 19

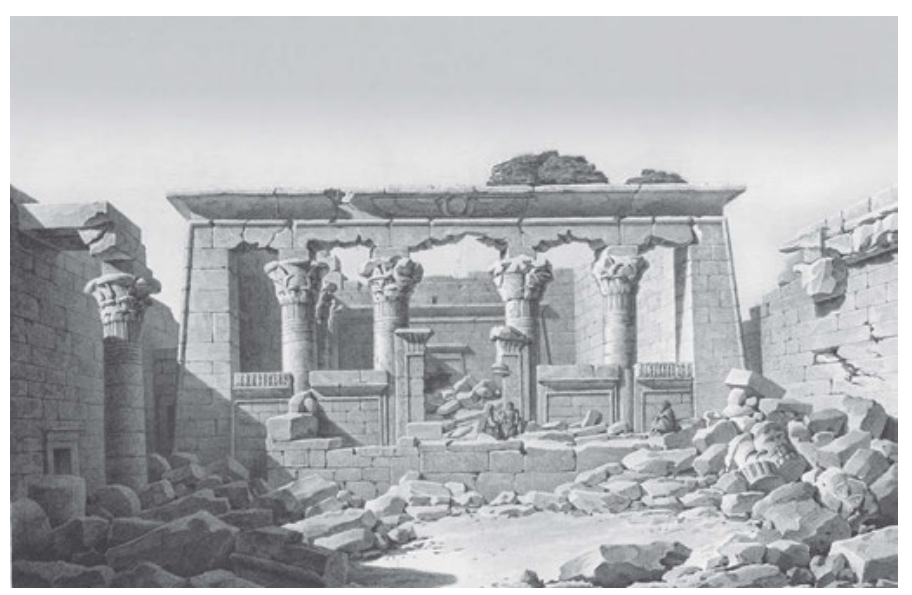

gen. ${ }^{237}$ Ein bemerkenswertes, in der Thorvaldsen-Forschung bislang unbeachtetes Beispiel für den visuellen Gesamteindruck der Museumsarchitektur stammt indessen ebenfalls aus Skandinavien: In den 1780er Jahren schuf der schwedische Künstler und Architekt Carl August Ehrensvärd die Aquarellzeichnung Tempel (Ägyptische Architektur in einer nordischen Landschaft), die eine auffallend ähnliche Fassadengliederung wie jene von Thorvaldsens Museum zeigt (Abb. 111). ${ }^{238}$ Die Fassade von Ehrensvärds gezeichnetem Tempel besteht aus fünf massiven, sich nach oben stark verjüngenden dorischen Säulen, die damals als ägyptisch betrachtet wurden. ${ }^{239}$ Bindesbølls Fassade wird hingegen nicht von Säulen, sondern von fünf trapezförmigen Portalen gegliedert. Dennoch ist es durchaus möglich, dass der Gesamteindruck von Ehrensvärds Zeichnung dem Architekten von Thorvaldsens Museum als Inspirationsquelle diente. Immerhin war Ehrensvärd einer der bekanntesten Skandinavier, die im späten 18. Jahrhundert nach Italien gereist waren, weshalb Bindesbøll mit dessen Schaffen vertraut gewesen sein dürfte.

\section{Kulturelle Übersetzung}

Die von Bindesbøll rezipierte neuere Architektur - besonders Klenzes Glyptothek und Alte Pinakothek in München (Eröffnung 1830 bzw. 1836) sowie Gottfried Sempers Museumspavillon für den Freiherrn Conrad Hinrich von Donner in Altona (1834) - geht ebenfalls auf die antike Baukunst zurück. ${ }^{240}$ Außerdem befasste sich Bindesbøll intensiv mit

240 Zu Bindesbølls Vorbildern siehe bspw. Bramsen 1959, bes. 39, 52 - 53, 60, 97 und 159; Jørgensen 1970, 12 -14; Jørgensen 1972b, 29 - 30; Gohr 1977b, 92; Jørgensen 1984, 239-240; Kat. Nürnberg/Schleswig 1991, 707; Miss 1991, 351; Trempler 2011, 209. 


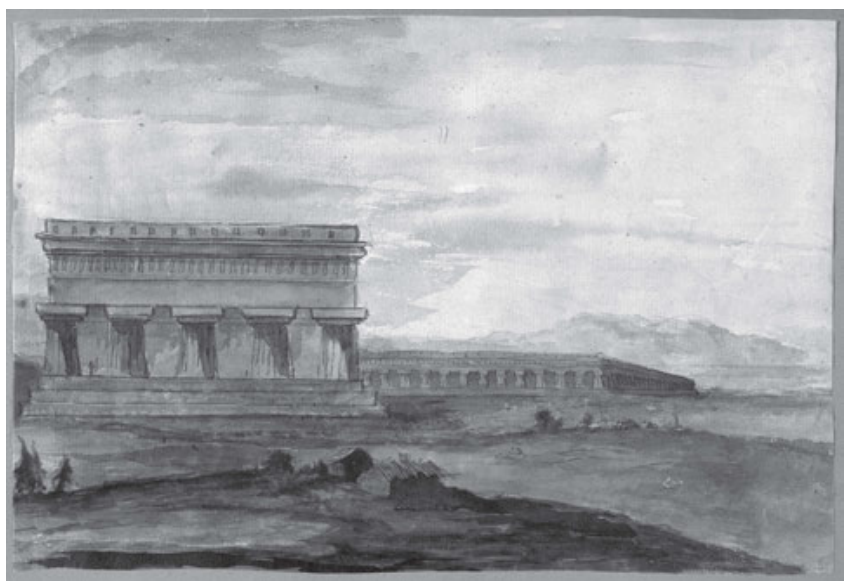

111_Carl August Ehrensvärd, Tempel (Ägyptische Architektur in einer nordischen Landschaft), 1780er Jahre, Bleistift und Wasserfarbe auf Papier, $163 \times 239 \mathrm{~mm}$, Stockholm, Nationalmuseum (Inv.-Nr. H0179-1866)

Sempers Architekturtheorie. ${ }^{241}$ In den 1834 publizierten Vorläufigen Bemerkungen über bemalte Architectur und Plastik bei den Alten empfiehlt Semper beispielsweise für nordische Länder polychrome Gebäude mit der etwas vagen Begründung, dass Blumen ebenfalls nicht weiß oder grau seien. ${ }^{242}$ Dabei handelt es sich nicht nur um einen frühen Kommentar zur kulturellen Übersetzung von antiker Polychromie in der nordischen Baukunst, sondern es wird hier auch der diskursive Kontext von Thorvaldsens eigenem Vergleich seines Museums mit einer Blume veranschaulicht. ${ }^{243}$

Peter Burke beschreibt kulturelle Übersetzung (cultural translation) als einen „doppelten Prozess aus Dekontextualisierung und Rekontextualisierung “.244 Diese Definition ist gerade auch für das Verständnis der Architektur und dekorativen Gestaltung von Thorvaldsens Museum hilfreich: In Prozessen des Kulturaustauschs werden Elemente fremder Kulturen - das heißt visuelle Motive aus anderen geografischen Regionen oder auch Zeit-

241 Jørgensen 1984, 239-240; Floryan 1998, 29 - 30; Thygesen 1998, 42 - 43; Lange, B. 2002, 66 - 67.

242 Semper 1834, 42. Siehe auch Lange, B. 2002, 66.

243 Thorvaldsen soll während eines Spaziergangs am 23. März 1844, einen Tag vor seinem Tod, beim Anblick seines im Bau befindlichen Museums neben dem von Hansen erbauten Schloss Christiansborg gemeint haben: „Schauen Sie einmal, [...] wie hässlich die schmutzigen Mauern grinsen; (sie grinsen über Hansen), nein, das Museum, es lächelt, schauen Sie einmal, es ist wie eine Blume“; zit. nach Baronesse Stampes Erindringer 1912, 252: „See engang, [...] hvor de skidne Mure griner stygt; (de griner af Hansen), nei, Museet det smiler, see engang, det er ligesom en Blomst“. Siehe auch Repholtz 1911, 138; Sass 1969, 96; Jørgensen 1972b, 30; Lange, B. 2002, 66.

244 Burke 2007, 10: „[...] double process of decontextualization and recontextualization [...].“ Dieses Verständnis von kultureller Übersetzung geht auf anthropologische Untersuchungen aus der Mitte des 20. Jahrhunderts, u. a. von Edward Evans-Pritchard, zurück; für einen Überblick siehe Burke 2007, 8 -10; Burke 2009, $70-71$. 
epochen - nicht nur in einen neuen Kontext transferiert und darin imitiert. Vielmehr werden sie während dieses Aneignungsprozesses in einem anderen kulturellen Umfeld reflektiert und verändert. ${ }^{245}$ Dementsprechend ist das Zusammentreffen verschiedener Kulturen keineswegs ein einseitiger Prozess, in dem Wissen von einer Kultur in einer anderen, passiv rezipierenden übernommen wird. Folglich sollte nach Burke bei diesem Vorgang weniger von Transfer oder Austausch als von Übersetzung gesprochen werden.

Für die vorliegende Monografie ist signifikant, dass ab dem frühen 19. Jahrhundert ein neuer Zugang zur Aneignung von Elementen aus anderen Kulturen zu beobachten ist: Man versuchte das Fremde nicht mehr nur in das eigene Umfeld einzupassen, sondern vermehrt ebenjene Fremdheit zu betonen. ${ }^{246}$ Burke bezeichnet diese Zeit, die ihrerseits Teil des romantischen Klassizismus und des aufkommenden Historismus war, als die Periode der foreignization. ${ }^{247}$ Darin spiegelt sich zugleich das stark lokal verwurzelte Verständnis von Kultur wider - oder anders formuliert: die Tatsache, dass Übersetzung stets das lokale Verständnis einer Kultur benötigt, um sich Elemente aus ,fremden' Kulturen anzueignen. ${ }^{248}$ Das von Burke als foreignization bezeichnete Phänomen prägt auch Thorvaldsens Museum, das sich durch seine eklektizistische Architektur und dekorative Gestaltung radikal von den klassizistischen Bauten der Kopenhagener Innenstadt abhebt.

Neben den erwähnten Motiven aus der griechischen, römischen, etruskischen und ägyptischen Kultur an den Außenfassaden und im Innenhof von Thorvaldsens Museum ist die dekorative Gestaltung der Innenräume ein weiteres Beispiel für die von Bindesbøll betriebene kulturelle Übersetzung. Basierend auf der visuellen Kultur der römischen Antike, sind die Räume in unterschiedlichen Wandfarben gehalten und weisen individuelle Deckenmalereien und Mosaikböden auf (Taf. XIII). Ihre Farbtöne und Formensprache orientieren sich an den kurz zuvor entdeckten Bauten in Pompeji und Herculaneum sowie an Neros Domus Aurea in Rom. ${ }^{249}$ Die Deckenmalereien, in denen die Übersetzung antiker Grotesken und Ornamente perfektioniert wurde, führten Købke und Georg Hilker mit der Hilfe von über dreißig Künstlern zwischen 1843 und 1847 aus. ${ }^{250}$ Wie eine Reihe von Zeichnungen vermuten lässt, hatte Bindesbøll um 1835 selbst Pompeji und die dortigen Fresken besichtigt. ${ }^{251}$ Die Wirkung, die diese Wandmalereien ebenso wie die polychromen Fragmente auf der Akropolis auf ihn ausübten, vermitteln die Farbstudien in

Eine solche lokale Verwurzelung von Kultur bildet zudem die Grundlage der von Stephen Greenblatt geprägten mobility studies; Greenblatt 2010a, 252-253.

249 Siehe bspw. Miss 1991, 342; Lange, B. 2002, 107; Henderson 2005, 25.

250 Bruun, C./Fenger 1892, 105, 109 - 110 und 114-117; Houkjær 1998; Ramsing 1998; Lange, B. 2002, 113; Thule Kristensen 2013, 126.

251 Bramsen 1959, 34; Millech 1960, 46; Lange, B. 1997, 81; Thygesen 1998, 39; Lange, B. 2002, 64. 
seinem Notizbuch aus jener Zeit, das in Thorvaldsens Museum aufbewahrt wird. ${ }^{252}$ Bindesbølls Reisen unter anderem nach Athen, Pompeji und Rom führten folglich zu einer Übersetzung fremder Elemente in sein Gesamtkonzept für Thorvaldsens Museum. Die Idee einer pompejianischen Dekoration könnte zudem auf Thorvaldsen selbst zurückgehen: Der Bildhauer hatte die Fresken in Pompeji und Herculaneum als junger Künstler ebenfalls besucht und 1830 offenbar geplant, ein Zimmer in seiner Wohnung durch Martens in jenem Stil ausmalen zu lassen. ${ }^{253}$ Bezeichnenderweise sollte es sich um den Raum handeln, der seine Bücher- und Antikensammlungen beherbergte. Damit hatte schon der Bildhauer den Gedanken gehegt, seinen Sammlungen einen passenden Rahmen zu geben, wie dies schließlich durch Bindesbøll formuliert und umgesetzt wurde.

Das starke Interesse des frühen 19. Jahrhunderts an nicht-westlicher Kunst schlug sich auch in der Kunstgeschichtsschreibung nieder und kulminierte 1842 in Franz Kuglers Handbuch der Kunstgeschichte, das die Fachrichtung der Weltkunstgeschichte begründete. Bereits 1826 hatte Goethe aufgrund seiner Überzeugung, dass Kunst und Wissenschaft nicht patriotisch sein könnten, sondern der ganzen Welt gehörten, den Begriff der Weltliteratur eingeführt. ${ }^{254}$ In diesem Zusammenhang können auch die Äußerungen von Thorvaldsens Zeitgenossen verstanden werden, dass ein großer Künstler wie er der ganzen Welt angehöre. ${ }^{25}$ Darüber hinaus vereint die Architektur und dekorative Gestaltung von Thorvaldsens Museum mit der kulturellen Übersetzung einerseits und dem im Folgenden besprochenen Fries von Sonne andererseits den Anspruch auf Internationalität mit dänischem Nationalstolz, was den gesamten Künstler- und celebrity-Kult um Thorvaldsen prägte.

\section{Jørgen Sonnes Fries}

Das auffallendste und für den vorliegenden Kontext eines der wichtigsten Elemente am Museumsbau ist der unterhalb der Fenster an den drei Nebenfassaden angebrachte Monumentalfries (Taf. XIV und XV). Der konzeptionell auf Bindesbøll zurückgehende Fries wurde vom Maler Sonne entworfen und zwischen 1846 und 1849/1850 mit der Hilfe von drei weiteren Künstlern in einer Mosaiktechnik aus gefärbtem Zement aufgetragen. ${ }^{256}$ Bei einer Renovierung in den 1950er Jahren durch den Künstler Axel Salto wurden diese Ze1984, 240; Jørgensen 1989, 179; Miss 1991, 350; Henderson 2005, 23.

253 Glarbo 1944, 58 - 62; Helsted 1982b, 61; Lange, B. 2002, 87.

254 Greenblatt 2010b, 4.

255 Siehe dazu Kap. I.2.

256 Schultz 1938, 46; Bøyesen 1946-1947, 159; Sass 1969, 107; Kat. Nürnberg/Schleswig 1991, 707; Mildenberger 1991, 196; Lange, B. 2002, 125; Miss 2005b, 7-9. Bei den drei Künstlern, die den Fries unter Sonnes Aufsicht ausführten, handelte es sich um I. A. G. Barlach, F. C. Lund und J. Hallager. 
mentintarsien entfernt und durch Fresken ersetzt; Fragmente des ursprünglichen Frieses sind im Kunstmuseum von Aarhus erhalten. ${ }^{257}$

Ausgehend von der Fregatte Rota in der nordöstlichen Ecke des Museumsgebäudes, stellt der Fries in insgesamt fünfzig Feldern zwei zeitgenössische, für die dänische Kulturgeschichte sehr bedeutsame Ereignisse dar: Die Nordseite zeigt Thorvaldsens triumphale Ankunft in Kopenhagen und den pompösen Empfang durch seine Landsleute am 17. September 1838, während die Ost- und Südseite dem Transport seiner Originalmodelle und Sammlungen zum Museum gewidmet sind. Durch die Wiedergabe jener Ereignisse an den Außenwänden von Thorvaldsens Museum werden sie zugleich zur Metapher für den Eingang des Bildhauers in die „Ewigkeit des Nationalruhms“, wie Jörg Traeger es treffend formuliert hat. ${ }^{258}$ Die Ikonografie und Struktur von Sonnes Fries sind in der Forschungsliteratur verschiedentlich detailliert beschrieben worden, weshalb der Fokus im Folgenden auf den für unsere Fragestellung zentralen Bildfeldern liegen soll. ${ }^{259}$

An beiden Seitenfassaden des Museums kulminiert die Erzählung in je einer langrechteckigen Darstellung, deren Größe die übrigen Bildfelder deutlich übersteigt. Auf der Nordseite ist dieses Bildfeld Thorvaldsens Empfang durch seine Landsleute an der Zollstelle Toldboden gewidmet (Taf. XVI). Die Darstellung bildet zweifellos den Höhepunkt des gesamten Frieses und ebenso des dargestellten Geschehens. Sie zeigt, wie Thorvaldsen, gestützt durch Kapitän Dahlerup, an Land geht und hier von Freund, Thiele, Collin, Schouw, Koch, Hetsch, Clausen, Lund, Bissen, Eckersberg, Høyen sowie von Frauen und Kindern begrüßt wird (v.l.n.r.). ${ }^{260}$ Diesbezüglich ist eine Bemerkung in der Satirezeitschrift Corsaren vom 5. November 1847 sprechend, wonach Sonnes Darstellung die Akademiemitglieder „vor der Vergessenheit gerettet“ habe. ${ }^{261}$ Thiele steche indessen aus der Menge heraus, da er seine Arme übermäßig weit ausstrecke - in der Tat erscheinen sie unverhältnismäßig lang. Mit dieser Präsentation von Thiele wollte Sonne gemäß Corsaren

symbolisch [...] darstellen, dass der genannte Justitsraad [d.h. Thiele] am erfolgreichsten darin gewesen ist, etwas von Thorvaldsens Berühmtheit für sich in Anspruch zu nehmen, und hat sich dadurch selbst Unsterblichkeit gesichert. ${ }^{262}$

257 Siehe bspw. Ragn Jensen 1998, 162.

258 Traeger 1981, 43.

259 Für Beschreibungen von Sonnes Fries siehe bspw. Schultz 1938, 50 - 56; Bøyesen 1946 - 1947, 160 - 175; Ragn Jensen 1998, 157 - 164; Henderson 2005, 45-77.

260 Die Identifizierung der dargestellten Personen wird durch eine 1889 von Frederik Christian Lund hergestellte Serie von Lithografien nach Sonnes Fries ermöglicht. Siehe außerdem Henderson 2005, $44-77$.

261 Corsaren, 5. November 1847, TMA, Thorvaldsens Museums Småtryk-Samling 1847, Corsaren 5.11: „Den store Kunstner bliver modtaget af hele Academiet for de skjønne Kunster, der ved denne sindrige Idee er reddet fra Forglemmelse; [...]."

262 Ebd.: „[...] men Ingen af Alle strækker dog Armene ud i en saa - vi kunne meget godt sige upassende Længde, som Justitsraad Thiele, hvorved Kunstneren udentvivl symbolisk har villet fremstille, at den nævnte Justitsraad har været heldigst $i$ at tage Noget af Thorvaldsens Berømmelse til Indtægt for sig og derved sikkret sig selv Udødelighed.“ 


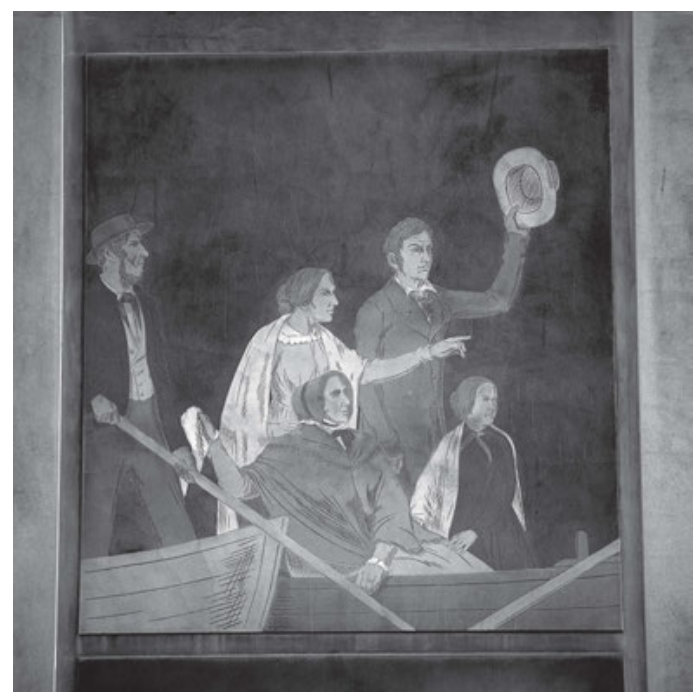

112_Jørgen Sonne, Monumentalfries an Thorvaldsens Museum (Nordfassade), 1846 - 1850, restauriert in den 1950er Jahren durch Axel Salto, Detail, Kopenhagen, Thorvaldsens Museum

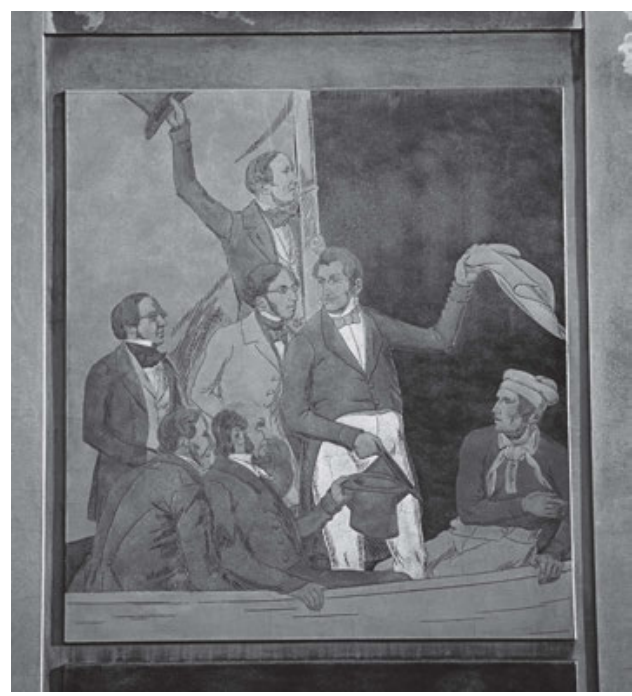

113_Jørgen Sonne, Monumentalfries an Thorvaldsens Museum (Nordfassade), 1846 - 1850, restauriert in den 1950er Jahren durch Axel Salto, Detail, Kopenhagen, Thorvaldsens Museum

Damit spricht die Satirezeitschrift Thieles mannigfaltige Bemühungen um Thorvaldsen an, die ihm zugleich selbst einige öffentliche Aufmerksamkeit sicherten. Das herausragendste Beispiel dafür ist seine jahrzehntelange Arbeit an der Biografie des Bildhauers, die zuweilen stark autobiografische Züge aufweist, worauf in der Einleitung hingewiesen wurde.

Die anderen Bildfelder an der Nordfassade des Museums präsentieren Menschen, die als Zeugen jenes historischen Ereignisses den gefeierten Heimkehrer in Booten begrüßen. Bei den dargestellten Personen handelt es sich teils um identifizierbare Porträts, teils um anonyme Bürgerinnen und Bürger. Auch hierin verdeutlicht sich der Anspruch von Thorvaldsens Museum als der ganzen Nation beziehungsweise allen Gesellschaftsschichten gehörend. Prominente Positionen nehmen jedoch die Boote der Familie Stampe und der Dichter um Andersen und Oehlenschläger ein (Abb. 112 und 113). Bei den identifizierbaren Porträts an der Nordfassade, einschließlich des Bildfeldes von Thorvaldsens Ankunft bei der Zollstelle, handelt es sich folglich um Personen, die bei der Förderung und Verehrung des zurückkehrenden Bildhauers eine zentrale Rolle spielten. ${ }^{263}$

Die Narration der Ost- und Südfassade kulminiert in einem Bildfeld, das den Transport von Thorvaldsens 1819 geschaffenem Modell für das Luzerner Löwendenkmal zeigt 


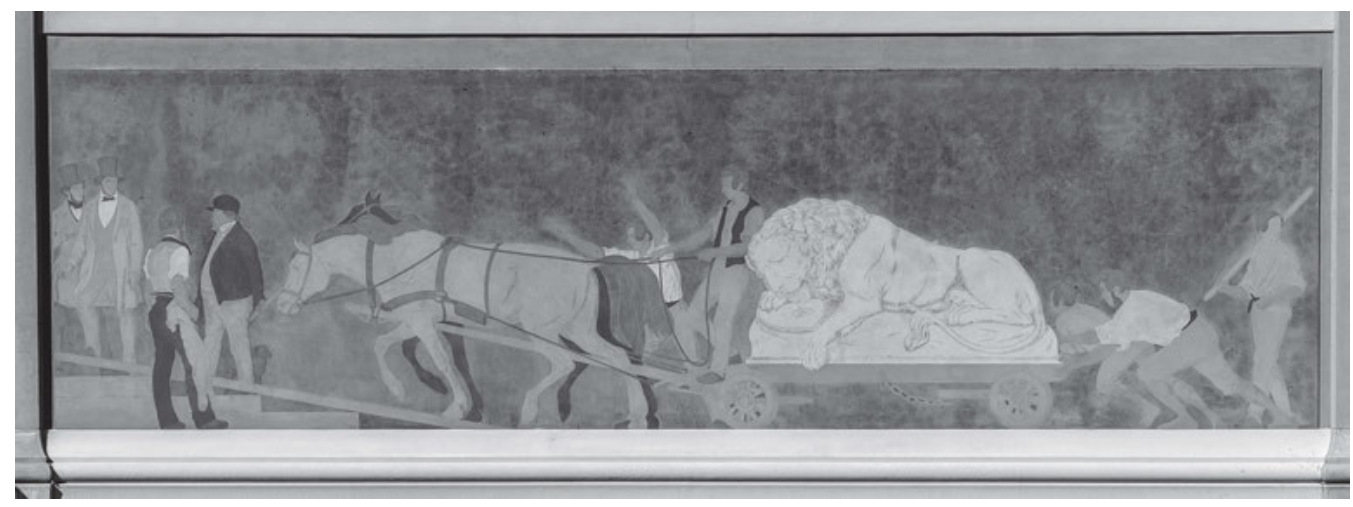

114_Jørgen Sonne, Monumentalfries an Thorvaldsens Museum (Südfassade), 1846 - 1850, restauriert in den 1950er Jahren durch Axel Salto, Detail, Kopenhagen, Thorvaldsens Museum

(Abb. 114). ${ }^{264}$ In Empfang genommen wird der Sterbende Löwe - ebenso wie die im Fries nachfolgenden Kunstwerke - von Bindesbøll, der stellvertretend für das Museum steht (2.v.1.). ${ }^{265}$ Angesichts der zeitgenössischen Vergleiche von Thorvaldsen mit einem Löwen und der Funktion des Museums als Mausoleum des Künstlers könnte dieses Bildfeld ferner als Allegorie auf Thorvaldsens letzte Reise gedeutet werden. ${ }^{266}$ Auf der Ostseite des Museums beginnt der Fries mit der Fregatte Rota und den verpackten Werken und Sammlungsstücken aus Thorvaldsens Besitz, die mit Booten an Land gebracht werden. Im ersten Feld an der Südfassade befinden sich die Objekte noch in Kisten, von denen eine mit Thorvaldsens romanisierten Initialen A. T. bezeichnet ist (Abb. 115). Eine weitere beschriftete Kiste ist im Bildfeld mit dem Gipsmodell des Reiterstandbildes von Józef Poniatowski zu sehen. Wie dieses werden auch mehrere andere Felder auf der Südseite des Gebäudes von Modellen zu prestigeträchtigen Auftragswerken bestimmt, wobei in der Mitte der Fassade das Grabmal für Papst Pius VII. prangt (Abb. 116). Daneben sind vereinzelte Reliefs, griechische Vasen und verschiedene Bildnisplastiken dargestellt. Außer der Porträtstatue der russischen Fürstin Maria Fjodorovna Barjatinskaja und dem Denkmal für Lord Byron sind Büsten von Thorvaldsens Zeitgenossen zu sehen. Darunter entdeckt man jene der Improvisatorin Taddei, die Thorvaldsen 1826 bei einem Auftritt als „un figlio di Dio“ bezeichnet hatte. ${ }^{267}$ Zudem sind die Büsten von Christine Stampe und Oehlenschläger sche Bildhauer Lucas Ahorn das Denkmal für die beim Tuileriensturm 1792 in Paris gefallenen Schweizergardisten in den Fels meißelte; siehe bspw. Henderson 2005, 91; Jørnæs 2011, 127 - 129. 


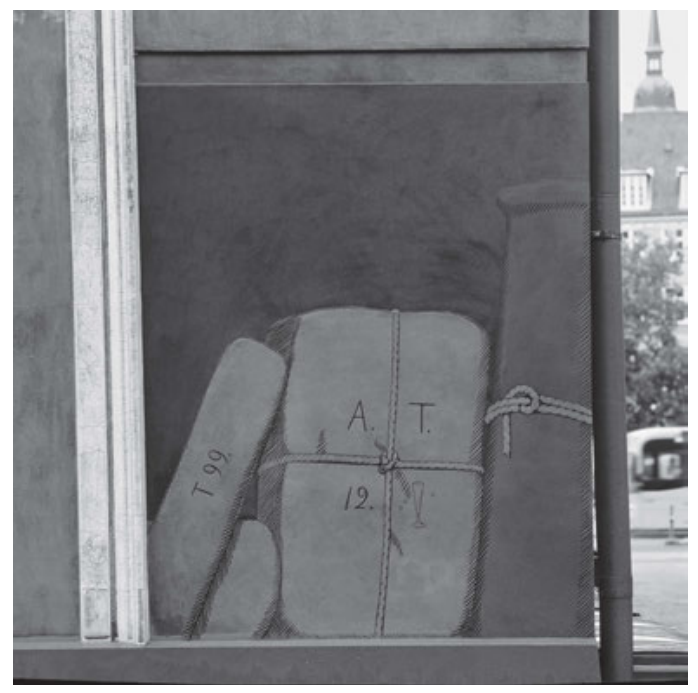

115 _Jørgen Sonne, Monumentalfries an Thorvaldsens Museum (Südfassade), 1846-1850, restauriert in den 1950er Jahren durch Axel Salto, Detail, Kopenhagen, Thorvaldsens Museum

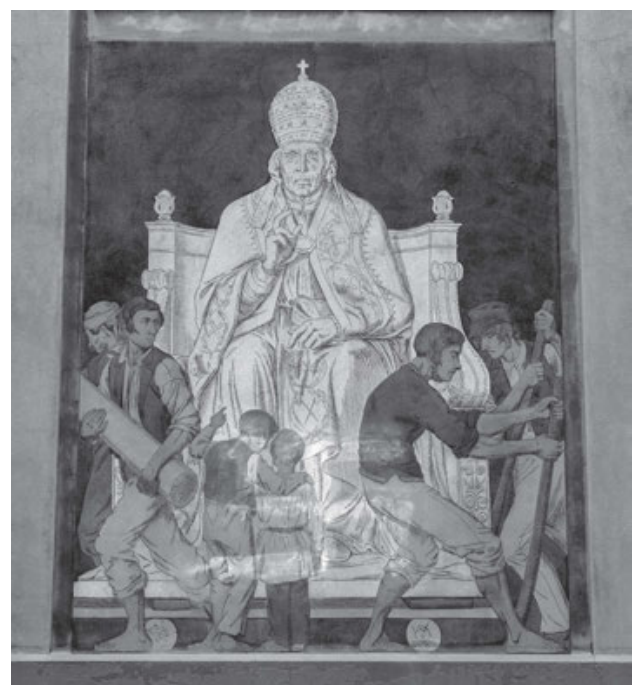

116_Jørgen Sonne, Monumentalfries an Thorvaldsens Museum (Südfassade), 1846-1850, restauriert in den 1950er Jahren durch Axel Salto, Detail, Kopenhagen, Thorvaldsens Museum

wiedergegeben (Abb. 117). Diese zweifache Darstellung der Baronin und des Dichters einmal als Zuschauende bei Thorvaldsens Ankunft und einmal in Form von Porträtbüsten - verknüpft die Nord- mit der Südfassade des Museums. Darüber hinaus betont sie die zentrale Rolle, die vor allem Stampe während Thorvaldsens späten Jahren spielte. Zusätzlich zu Thorvaldsens Werken sind in den kleineren Bildfeldern Zuschauerinnen und Zuschauer wiedergegeben, die die Bedeutung des dargestellten Geschehens für das dänische Volk untermalen und zugleich bis heute als Referenzfiguren für die Betrachterinnen und Betrachter des Frieses dienen.

Während Sonnes Fries auf der Nordseite des Museums ein bestimmtes, genau datierbares Ereignis wiedergibt, erstreckte sich das auf der Ost- und Südseite dargestellte Geschehen in Wirklichkeit über mehr als zwei Jahrzehnte: Thorvaldsens Werke wurden nicht in einem Mal von Italien nach Kopenhagen gebracht, sondern erreichten Dänemark in verschiedenen Sendungen zwischen 1825 und 1845. ${ }^{268}$ Außerdem standen bei Thorvaldsens Rückkehr im Herbst 1838 weder der Standort noch der Architekt seines Museums fest, weshalb die Werke des Bildhauers nicht wie im Fries dargestellt von der Rota direkt 
117 Jørgen Sonne, Monumentalfries an Thorvaldsens Museum (Südfassade), 1846-1850, restauriert in den 1950er Jahren durch Axel Salto, Detail, Kopenhagen, Thorvaldsens Museum

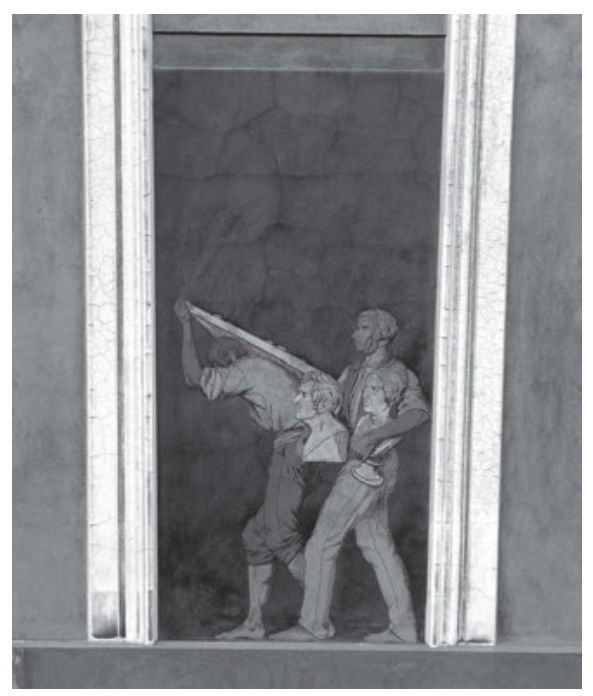

ins Museum gebracht werden konnten. Da dieses zudem erst 1848 vollendet werden sollte, wurden Thorvaldsens Schöpfungen nach ihrer Ankunft in Kopenhagen auf den Antikensaal der Kunstakademie im Schloss Charlottenborg (ab 1828), das dortige Atelier des Bildhauers (ab 1833) sowie auf zwölf zusammenhängende Räume im Schloss Christiansborg (ab 1836) verteilt und so der Öffentlichkeit zugänglich gemacht. ${ }^{269}$ Nanna Kronberg Frederiksen hat diese drei Stätten zusammen mit der von Thorvaldsen skulptural ausgestatteten Frauenkirche die „Vor-Museen“ (før-museer) für den Bildhauer genannt. ${ }^{270}$ In diesem Zusammenhang ist auch das bereits erwähnte, Richardt zugeschriebene Gemälde des Äußeren der Kunstakademie um 1840 zu sehen (Abb. 71). Es zeigt Thorvaldsen in männlicher Begleitung durch den damals an Charlottenborg angrenzenden botanischen Garten spazieren, während im Vordergrund ein junger Mann eine Holzkiste auspackt. Die darauf erkennbaren Initialen T. A. sowie das Gipsmodell von Thorvaldsens Cupido mit der Lyra von 1819 in den Händen des Gehilfen verdeutlichen, dass es sich dabei um neu angekommene Werke des Bildhauers handelt, die nun in der Kunstakademie aufgestellt werden. Im selben Kontext sei noch einmal darauf hingewiesen, dass sowohl die Frauenkirche als auch Thorvaldsens Ateliers bereits von Zeitgenossen mit einem Museum verglichen wurden. Letztere Assoziation ist nicht nur für die römischen Werkstätten belegt, sondern auch für die Arbeitsräume des Bildhauers auf Charlottenborg, wie aus einem vom 1. Sep- 
tember 1841 datierenden Brief von Wilckens an den Bildhauer hervorgeht: „Alles ist in gutem Stand in Ihrem [ $i$ Conferensraadens] Museum Atelier und wird viel besucht. ${ }^{\text {271 }}$

\section{Sonnes Inspirationsquellen}

John Henderson sieht in den zwischen 1796 und 1798 erfolgten Plünderungen durch Napoleon in Rom, deren Auswirkungen Thorvaldsen nach seiner Ankunft in der Ewigen Stadt im März 1797 selbst miterlebt hatte, das ikonografische Vorbild für Sonnes Darstellung des Transports von Werken und Sammlungsstücken des Bildhauers. ${ }^{272}$ Betrachtet man jedoch die Entstehung von Sonnes Fries im größeren Kontext, lässt sich dieser weniger mit dem napoleonischen Kunstraub als mit der 1815 erfolgten Rückführung jener gestohlenen Objekte nach Rom in Verbindung bringen. Diesem Ereignis ist ein 1817 von Francesco Hayez geschaffenes Fresko im vatikanischen Museo Chiaramonti gewidmet. ${ }^{273}$ Während die Ikonografie des Kunstraubs und jene der Rückführung aufs Engste miteinander verwandt sind, unterscheiden sich die beiden Ereignisse inhaltlich grundlegend. Gerade vor dem Hintergrund von Thorvaldsens Stilisierung zum nordischen Künstler und dänischen Nationalhelden sowie der Betrachtung seines Museums als Nationaldenkmal stellt der Transfer seiner Werke von Rom nach Kopenhagen ebenfalls eine - von Zeitgenossen wie Hjort ausdrücklich gewünschte - Rückführung dar. ${ }^{274}$

Trotz der Wiedergabe eines zeitgenössischen Ereignisses verweist Sonnes Fries zudem in verschiedener Weise auf die - auch für Thorvaldsens eigenes Schaffen zentrale griechische Kunst der Antike. Diese Referenzen beginnen bei der auf sie zurückgehenden Bildform des Frieses an sich. Dabei ist die zweiteilige Erzählstruktur, die das Publikum zum ehemaligen Haupteingang des Museums führt, deutlich an jene des Parthenonfrieses angelehnt. Auch inhaltlich lassen sich die beiden Friese miteinander verknüpfen, zeigt doch jener des Parthenons eine Prozession, die Geschenke zum Tempel bringt. ${ }^{275}$ Die Ankunft von Thorvaldsens Werken und Sammlungsobjekten steht ihrerseits für die Schen-

271 Carl Frederik Wilckens an Bertel Thorvaldsen, 1. September 1841, TMA, Ref. m24 1841, nr. 42: „Alt er i godt stand i Conferensraaden[s] Ataleet og Bliver Besøgt meget[.]“ Siehe auch Kronberg Frederiksen 2014b. Thorvaldsen war am 10. September 1838 zum konferensråd, einem königlichen Berater, ernannt worden; Frederik VI. von Dänemark an Bertel Thorvaldsen, 10. September 1838, TMA, Ref. m29 II, nr. 66.

272 Henderson 2005, 31 und 79.

273 Bei Hayez’ Werk handelt es sich um eines von insgesamt 15 lünettenförmigen, von jungen Künstlern ausgeführten Fresken im Museo Chiaramonti, die der Kunstpatronage von Papst Pius VII. gewidmet sind; siehe dazu Hiesinger 1978a, bes. 655 - 656; auch Pinelli 1991, 23. Sowohl für die Rückführung der aus Rom entwendeten Werke als auch für die künstlerische Ausschmückung und die Werkpräsentation im Museo Chiaramonti war Canova verantwortlich. Zu der von Canova eingeleiteten Rückführung der gestohlenen Kunstwerke von Paris nach Rom siehe bspw. Pietrangeli 1993, 145 -154; zu Dohna 2006, $77-90$.

274 Zu Hjort siehe Kap. IV.1.

275 Melander 1998, 99; Lange, B. 2002, 135; Henderson 2005, 23. 
118 _ Jørgen Sonne, Monumentalfries an Thorvaldsens Museum (Südfassade), 1846-1850, restauriert in den 1950er Jahren durch Axel Salto, Detail, Kopenhagen, Thorvaldsens Museum

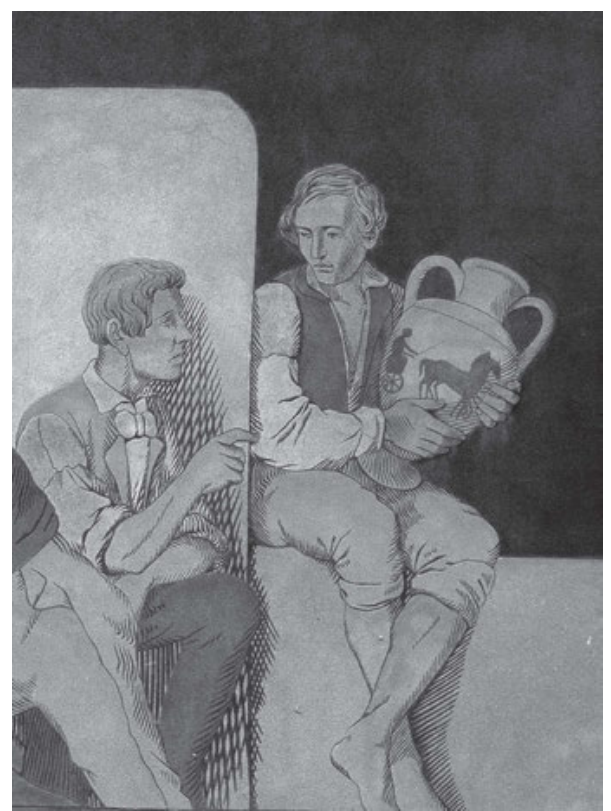

kung des Bildhauers an seine Heimatstadt, während seine Ateliers und sein Museum verschiedentlich mit einem Tempel verglichen wurden.

Einen weiteren Verweis auf die antike Kunst bildet das Kolorit von Sonnes Fries: Auf schwarzem Grund dominieren in allen Szenen die Farben Weiß, Ocker, Beige und Rot. Die Darstellungen weisen keinerlei Bildtiefe auf, sondern sind durchweg flächig gestaltet. Damit erinnert der Fries an die griechische Vasenmalerei, die zweifellos als visuelles Vorbild diente. ${ }^{276}$ Thorvaldsens umfangreiche Sammlungen beinhalteten selbst auch griechische Vasen, von denen zwei leicht abgeändert im Fries wiedergegeben sind (Abb. 118). ${ }^{277}$ Diese Darstellungen sind folglich nicht nur als Objekte aus Thorvaldsens Antikensammlung, sondern auf künstlerischer Ebene zudem als selbstreferenzielle Motive innerhalb von Sonnes Fries zu verstehen.

Insgesamt war die Polychromie von Thorvaldsens Museum der damals noch jungen Erkenntnis verpflichtet, dass die antiken Skulpturen und Bauten in der Regel bemalt waren und damit nicht dem Winckelmann'schen Ideal einer weißen Antike entsprachen. ${ }^{278}$

276 Siehe auch Moltesen 1926, 42; Bramsen 1959, 81 und 159; Sass 1969, 107; Lange, B. 2002, 134-136; Henderson 2005, 28; Thule Kristensen 2013, 111 und 147.

277 Es handelt sich dabei um die Vasen in Thorvaldsens Museum mit den Inv.-Nr. H573 und H552; siehe dazu Melander 1982, 67.

278 Siehe auch Bøyesen 1946-1947, 176 - 177; Bramsen 1959, 91 und 157; Jørgensen 1989, 184; Kat. Nürnberg/Schleswig 1991, 707; Miss 1991, 350; Lange, B. 2002, 66. 
Mit dieser Tatsache war Thorvaldsen beispielsweise konfrontiert, als an den von ihm 1816/1817 restaurierten Ägineten für die Münchner Glyptothek Spuren einer Bemalung zu sehen waren. ${ }^{279}$ Bezeichnenderweise bemalt auch der circumlitor (Statuenmaler), der zusammen mit acht anderen Figuren im Fassadengiebel der Glyptothek die Bildhauerei repräsentiert, eine der äginetischen Koren, die wiederum als Vorbild für Thorvaldsens Göttin der Hoffnung gedient hatten. ${ }^{280}$ Ein breiteres Publikum erreichte die Erkenntnis der polychromen Antike jedoch erst ab den späten 1830er Jahren durch die neu erfundene Farblithografie. $^{281}$

\section{Anachronismen und politische Implikationen in Sonnes Fries}

Aus der Beschreibung von Sonnes Darstellung auf der Nordseite des Museums wurde ersichtlich, dass hier der Fokus auf Personen liegt, die eine wichtige Rolle bei der Förderung von Thorvaldsen und dessen Museum spielten. Durch genrehafte Szenen zwischen den zumeist ungezwungenen Porträts sollte Sonnes Fries, ähnlich den im vorangegangenen Kapitel vorgestellten Gemälden von Eckersberg und Westphal, wie eine Momentaufnahme von Thorvaldsens Ankunft in Kopenhagen am 17. September 1838 wirken. Doch so realistisch der Fries auf den ersten Blick erscheinen mag, so bezeichnend sind seine Anachronismen und Abweichungen von dem historischen Ereignis an jenem Septembertag. Bereits erwähnt wurde, dass die Werke und Sammlungsstücke des Bildhauers in Wirklichkeit nicht mit einer einzigen Schiffsladung, sondern in verschiedenen Frachten über zwei Jahrzehnte hinweg in Kopenhagen eintrafen. Auch konnten die Objekte bei Thorvaldsens eigener Ankunft 1838 nicht direkt in sein Museum gebracht werden, da zu diesem Zeitpunkt noch nicht einmal der künftige Standort des Gebäudes bekannt war.

Die Dissonanzen in Sonnes Fries beziehen sich außerdem auf dargestellte ebenso wie auf weggelassene Personen. Die Familie Stampe etwa nimmt einen prominenten Platz im Fries ein, obwohl sie bei Thorvaldsens Ankunft in Kopenhagen nicht anwesend war (Abb. 112). ${ }^{282}$ Mehr noch: Sie kannte den Bildhauer zu jenem Zeitpunkt möglicherweise noch nicht einmal persönlich. ${ }^{283}$ Dementsprechend existierte auch die ebenfalls im Fries wiedergegebene Porträtbüste der Baronin 1838 noch nicht, sondern entstand erst vier Jahre später (Abb. 117). Dasselbe gilt übrigens für die zusammen mit Stampes Porträt abgebildete Büste von Oehlenschläger, der zwar Thorvaldsens Empfang miterlebt hatte, dessen Büste der Bildhauer aber erst 1839 modellierte.

280 Zum circumlitor siehe Wünsche 2011, 226. Die genannte Kore kommt in diesem Giebelfeld außerdem zusammen mit dem Metall- und dem Tonbildner vor.

281 Siehe bspw. Wünsche 2011, 230.

282 Repholtz 1911, 22; Baronesse Stampes Erindringer 1912, 4; Sass 1969, 108 - 109; Gelius/Henschen/Miss 2001, 7; Helsted 2001a, 7; Helsted 2001b, 8.

283 Siehe dazu Kap. III.3. 
Umgekehrt erhielt die dänische Königsfamilie keinen Platz in Sonnes Fries, obschon ihre Mitglieder zu Thorvaldsens langjährigen Gönnern gezählt und eine entscheidende Rolle für die Errichtung des Museums gespielt hatten. Schließlich fehlt auch der Architekt Hansen, der Thorvaldsen am 17. September 1838 persönlich bei der Zollstelle in Empfang genommen hatte, wie aus dem im vorangegangenen Kapitel zitierten Bericht in der Zeitung Kjøbenhavnsposten sowie aus Westphals Gemälde deutlich wird. ${ }^{284}$ Diese selektive Wiedergabe verleiht dem (vor-)revolutionären Zeitgeist in den Jahren um 1848 Ausdruck, als Sonnes Fries entstand. Bezeichnenderweise war die ursprünglich geplante Außengestaltung in Form von Sgraffitobildern nach Thorvaldsens Reliefs, welche auf den approbierten Entwürfen des Museums angedeutet ist (darunter Abb. 103), erst in den 1840er Jahren durch einen genrehaften Fries mit einem zeitgenössischen Ereignis ersetzt worden. ${ }^{285}$ Gerade das Fehlen der Königsfamilie und des Architekten Hansen in dieser Darstellung ist für die auf Thorvaldsens Museum projizierten Ideale von großer Signifikanz und Brisanz. Denn das Ziel von Bindesbøll, der auch den Fries konzipierte, bestand in einer bewussten Abkehr seines Gebäudes von Hansens Architektur, und darin steckte sowohl eine ästhetische als auch eine politisch-ideologische Aussage. ${ }^{286}$

Auf ästhetischer Ebene rebellierte Bindesbøll mit seinem eigenwilligen, polychromen Gebäude gegen Hansens jahrzehntelange Dominanz des Kopenhagener Stadtbildes. Wie stark dieses durch Hansens streng klassizistische Bauweise geprägt worden war, veranschaulicht auch dessen Einführung einer Steuer auf farbenfroh bemalte Gebäude. ${ }^{287}$ Nach Hansens Tod 1845 distanzierten sich junge Architekten wie Bindesbøll von seinem traditionellen Baustil, was mit Thorvaldsens Museum direkt neben dem von Hansen erbauten Schloss Christiansborg geradezu zelebriert wurde. Bindesbøll hatte sich in einem Brief an seinen Bruder Severin schon 1838 abschätzig über Hansens Architektur, speziell die Frauenkirche, geäußert und diese unter anderem als „roh“ und „elend“ kritisiert. ${ }^{288}$ In ähnlicher Weise soll 1844 auch Thorvaldsen selbst Hansens Architektur als hässlich und die grau bemalten Fassaden als schmutzig bezeichnet haben. ${ }^{289}$ Dieses harte Urteil fällt besonders ins Auge, da der Bildhauer 1827 Hansens Bauwerke noch in den höchsten Tönen gelobt hatte: „Es wäre mir besonders schmeichelhaft, wenn meine Arbeiten auf irgendeine

284 Zu Hansens Begrüßung von Thorvaldsen bei der Zollstelle siehe bspw. Kjøbenhavnsposten, 12:256, 17. September 1838 [erschienen am 18. September 1838], 1032; auch Bøyesen 1946-1947, 160; Lange, B. 2002, 65 .

285 Kat. Nürnberg/Schleswig 1991, 705-707; auch Schultz 1948a, 66; Bøyesen 1946-1947, 182; Bramsen $1959,94$.

286 Lange, B. 2002, 65.

287 Ebd., 64.

288 Gottlieb Bindesbøll an Severin Bindesbøll, 1838, zit. nach Bramsen 1959, 25: „raae og elendig“ und „noget forbandet Møi“. Siehe auch Lange, B. 2002, 65.

289 Baronesse Stampes Erindringer 1912, 252; auch Repholtz 1911, 138; Sass 1969, 96; Jørgensen 1972b, 30; Lange, B. 2002, 66. 
Weise dazu beitragen könnten, Ihre schönen und geschmackvollen Gebäude zu zieren.“290 Da das Ziel dieses Schreibens im Zuschlag von Aufträgen aus der Heimat bestand, kann Thorvaldsens enthusiastische Formulierung als ein weiteres Beispiel für seine strategische, nicht selten opportunistische Selbstvermarktung betrachtet werden.

Bindesbølls und Thorvaldsens kritische Haltung gegenüber Hansen lassen vermuten, dass dessen Fehlen in Sonnes Fries durchaus gewollt war. ${ }^{291}$ Dasselbe gilt für die Abwesenheit der königlichen Familie im Fries, worin sich die politische Aussage von Bindesbølls Gebäude generell und dem Fries im Speziellen widerspiegelt. Denn die Rückgriffe auf Elemente aus der griechischen Kunst können nicht nur auf künstlerischer Ebene, sondern auch im politisch-ideologischen Kontext um 1848 betrachtet werden: Thorvaldsens Museum wurde im europäischen Revolutionsjahr eröffnet und verwies mit seinen Anleihen aus der griechischen Kunst auf das antike Griechenland mit Athen als der ersten Demokratie der Geschichte. Durch seine Formensprache und Polychromie hob es sich zugleich von Hansens Schloss Christiansborg ab, das als monumentales Symbol für die Monarchie stand. ${ }^{292}$ Folglich versinnbildlichte Thorvaldsens Museum den Wechsel von der monarchischen zur demokratischen Staatsform.

Als besonders kühne Tat kann in diesem Zusammenhang auf Bolette Puggaards Befestigung einer Trikolore am Kranz, der im Dezember 1841 das Dach des Museums schmücken sollte, verwiesen werden. Die Malerin Puggaard begründete ihre revolutionär gesinnte Handlung damit, dass Thorvaldsen der Kunst die Freiheit gebracht habe und sein Museum sich deshalb klar von Schloss Christiansborg abheben sollte. ${ }^{293}$ Es darf jedoch stark bezweifelt werden, dass die Flagge tatsächlich auf das Dach gehisst wurde: Erstens wurde Puggaards Tat von den Anwesenden als dreist empfunden, wie aus einem Brief ihrer Tochter Maria Lehmann an Thorvaldsen hervorgeht. ${ }^{294}$ Und zweitens erwähnte Bolettes Ehemann Hans Puggaard, der das Richtfest organisiert hatte, zwar den „ungeheuer

290 Bertel Thorvaldsen an Christian Frederik Hansen, 7. Februar 1827 (Entwurf), TMA, Ref. m28, nr. 102: „Det vilde være mig særdeles smigrende, dersom mine arbeider kunde paa nogen Maade bidrage til at pryde Deres skiønne og smagfulde Bygninger." Siehe auch Thiele 1852 -1856, Bd. 2, 169.

291 Siehe auch Miss 1991, 353; Lange, B. 2002, 65. Schultz 1938, 49, erklärt sich Hansens Fehlen hingegen mit dessen Ableben, bevor Sonne mit dem Fries begann. Da der Fries jedoch ein Ereignis von 1838 darstellt, bei dem Hansen persönlich anwesend war, erscheint Schultz’ Überlegung unlogisch.

292 Siehe auch Bramsen 1959, 81 und 95; Jørgensen 1989, 179; Miss 1991, 343; Lange, B. 2002, 65 - 67 und 130; Miss 2005b, 9.

293 Maria Lehmann an Bertel Thorvaldsen, wohl Sommer 1842, TMA, Ref. m24 1842, nr. 63: „[...] hun lovede nok at skulle forsvare sin Fane, om det saa var for Kongen selv; Frihed i Konsten, mente hun, har Thorvaldsen indført, at den maae bestaae, maae være vor fornemste Atraae, og hans Museum skal staae frit fra enhver Forbindelse med Slottet eller andet deslige." Auf Puggaards Tat verweisen auch Thule Kristensen 2013, 145, und Kofoed 2015a. Thorvaldsens Museum war am 18. Dezember 1841 überdacht worden; Hans Puggaard an Bertel Thorvaldsen, 18. Dezember 1841, TMA, Ref. m24 1841, nr. 53.

294 Maria Lehmann an Bertel Thorvaldsen, wohl Sommer 1842, TMA, Ref. m24 1842, nr. 63: „[...] bandt Moder en stor Krands dertil, og havde den Dristighed (i vore oprørte Tider) at hænge en tricolore Fane 
großen Kranz“, den seine Frau zur Zier des Daches habe binden lassen, nicht aber die Fahne. ${ }^{295}$

Der Zeitgeist um 1848 und der explizite Kontrast zwischen Thorvaldsens Museum und Hansens Christiansborg zeigen sich schließlich auch in der Wiedergabe der einfachen Arbeiter in Sonnes Fries auf der Seite zum Schloss hin. ${ }^{296}$ Generell war die Schenkung des ehemaligen Wagendepots durch den König von verschiedenen Mitgliedern der Baukommission skeptisch betrachtet worden, da man in Thorvaldsen die Symbolfigur einer neuen Ära in Dänemark sah, die mit dem traditionellen, durch die Monarchie geprägten Verständnis von Kunst und Gesellschaft brach. ${ }^{297}$ Umgekehrt spielte aber das dänische Königshaus eine wichtige Rolle bei der Stilisierung Thorvaldsens zum dänischen Nationalhelden, was gerade die Schenkung des zum Christiansborg-Komplex gehörenden Baugrundes veranschaulicht. Wie es für den sich politisch bedeckt haltenden Thorvaldsen üblich war, scheint er sich an solchen Widersprüchen wenig gestört zu haben. Möglicherweise hatte er in jenem Angebot des Königs bereits das Potenzial für sein geplantes Museum und den Nutzen der privilegierten Lage in unmittelbarer Nähe zum dänischen Machtzentrum für die Sicherung seines Nachruhms erkannt.

Die Südseite des Museums mit dem Transport von Werken aus Thorvaldsens CEuvre und Sammlungen bietet einen ersten Eindruck davon, was sich hinter den farbenfrohen und gleichsam sprechenden Mauern verbirgt. Diesen Zweck hatte bereits Bindesbøll intendiert: „Er [der Fries] soll wie das Schild für eine Menagerie dem Volk erzählen, was sie [die Leute] zu sehen bekommen, wenn sie hinein gehen. "298 Nach dem Betreten des Museums durch den Haupteingang fand sich das damalige Publikum in der großen Vorhalle, in der nicht nur Originalmodelle von Thorvaldsens monumentalen Arbeiten, sondern auch jenes des Alexanderzuges ausgestellt waren (und sind). Die zeitgenössischen Besucherinnen und Besucher sahen demnach einen Monumentalfries am Äußeren des Museums, der Thorvaldsens triumphale Rückkehr nach Kopenhagen zeigt, gefolgt von einem monumentalen Relieffries des Triumphzuges Alexanders des Großen in der Vorhalle des

øverst op paa den; vi andre søgte at afskrække med Hovedvagten og Tiltale, som jo hører til Dagens Orden; [...].“

295 Hans Puggaard an Bertel Thorvaldsen, 18. Dezember 1841, TMA, Ref. m24 1841, nr. 53: „Min Kone havde ladet binde en uhyre stor Krands som var Tagets fornemste Prydelse [...].“

296 Siehe auch Miss 2005b, 9.

297 Thule Kristensen 2013, 70 und 142; auch Hammerich 1876, 125; Kat. Nürnberg/Schleswig 1991, 703; Miss 2016, 5 .

298 Zit. nach Lange, B. 1998, 68: „Det skal ligesom Skiltet for et Menageri fortælle Folk, hvad de faar at se, naar de gaar derind." Siehe auch Bøyesen 1946-1947, 187; Millech 1960, 20; Sass 1969, 98; Lange, B. 2002, 130; Miss 2005b, 8; Thule Kristensen 2013, 147; Miss 2016, 6. Eine ähnliche Formulierung findet sich auch in einem Artikel in der dänischen Satirezeitung Corsaren vom 5. November 1847: „Disse Tegninger gjøre accurat samme Nytte, som de udhængte malede Skildte foran Fjæleboderne i Dyrehaven: de give Folk en Idee om, hvad de skulle faae at see indenfor." 
Museums. ${ }^{299}$ Dadurch wurde der Bildhauer erneut mit dem antiken Herrscher assoziiert. Darüber hinaus hatte Babylon seit Jahrhunderten als Referenzpunkt für das Selbstverständnis wachsender Städte und für - teils utopische - städtebauliche Projekte gegolten. Dies ist gerade auch für das frühneuzeitliche Kopenhagen belegt, dessen zwischen 1637 und 1642 errichteter Runder Turm (Rundetårn) mit dem Turm zu Babel verglichen wurde. $^{300}$ Vor diesem Hintergrund ließe sich die Gegenüberstellung der beiden Monumentalfriese auch als Bindesbølls Vision für einen Wendepunkt von der Monarchie zur Demokratie in seiner Heimatstadt lesen. Diese Vision sollte schon bald Realität werden: Unter dem Druck der europäischen Aufstände im März 1848 unterzeichnete der dänische König Frederik VII. am 5. Juni 1849 die dänische Verfassung, mit der die absolutistische Regierungsform durch eine konstitutionelle Monarchie abgelöst wurde.

\section{Die Werkpräsentation in Thorvaldsens Museum}

Es wurde erwähnt, dass das Gesamtkonzept des Museums für Thorvaldsen auf Bindesbøll zurückgeht. Dies gilt auch für die Präsentationsweise von Thorvaldsens Skulpturen sowie seinen Antiken- und Kunstsammlungen. Bereits auf Bindesbølls frühestem Entwurf für das Museum sind in den einzelnen Räumen Skulpturen des Bildhauers zu erkennen (Abb. 96). Außerdem erstellte der Architekt zwischen 1838 und 1848 in seinem Skizzenbuch eine Übersicht von Thorvaldsens Werken, die ihm vermutlich deren Verteilung auf die unterschiedlichen Räume erleichterte. ${ }^{301}$ Bezüglich der Anordnung der Werke und Sammlungsobjekte arbeitete Bindesbøll mit verschiedenen Künstlern zusammen: So half ihm Bissen bei der Präsentation von Thorvaldsens Marmorskulpturen im Erdgeschoss des Museums, Thiele bei der Ausstellung von Thorvaldsens Zeichnungen und der Genremaler Troels Lund bei der Hängung der Gemälde im Obergeschoss. ${ }^{302}$

Insgesamt entsprach die Präsentationsweise in Thorvaldsens Museum den neusten Ausstellungsprinzipien, indem wenige Marmorstatuen aus dem Euvre des Bildhauers in relativ kleinen Räumen so platziert wurden, dass Tageslicht ihre Köpfe und Oberkörper erhellte. ${ }^{303}$ Zwecks einer optimalen Beleuchtung berechnete Bindesbøll die Höhe der Sockel für die Skulpturen; zudem entwarf er mehrere Regale und Schaukästen für Thorvaldsens Sammlungen. ${ }^{304}$ Die Beleuchtung in Thorvaldsens Museum erinnert an jene in einem

299 Siehe auch Melander 1998, 100; Lange, B. 2002, 135.

300 Siehe bspw. Klamt 1975, 159-162.

301 Bindesbølls Skizzenbuch wird in Thorvaldsens Museum in Kopenhagen aufbewahrt (Inv.-Nr. D1778).

302 Zur Aufstellung von Thorvaldsens Skulpturen und der Hängung der Gemälde siehe ausführlich Bruun, C./Fenger 1892, 119 - 158; auch Krohn 1917a, 10; Kat. Kopenhagen 1974, 34, Anm. 64.

303 Kat. Kopenhagen 1974, 4; auch Henschen/Jørnæs 1987, 11.

304 Bruun, C./Fenger 1892, 117; Krohn 1917a, 10; Koch 1948; Kat. Kopenhagen 1974, 34, Anm. 64; Lange, B. $2002,121$. 
Künstleratelier - eine Lösung, die auf den Bildhauer selbst zurückzugehen scheint. ${ }^{305}$ Demnach sollten die rundplastischen Statuen und Büsten durch frontal, die Reliefs hingegen durch seitlich einfallendes Licht beschienen werden, wodurch die Formen der Werke am besten zur Geltung kommen sollten, wie bereits Hammerich beobachtete. ${ }^{306}$ Während Thorvaldsens Zeitgenossen dessen Ateliers mit ihrer Fülle an Originalmodellen als ein Museum bezeichnet hatten, kann sein Museum umgekehrt als ein verewigtes Atelier betrachtet werden. Allerdings erfuhren Thorvaldsens Arbeiten durch ihre Verschiebung von den Werkstätten in ein eigenes Museum eine ideelle Wertsteigerung: Nicht nur wurde ihnen Dänemarks erstes öffentliches Museum gewidmet, das eigens zu diesem Zweck gebaut wurde; überdies erhob die antikisierende Architektur des Gebäudes das Euvre eines zeitgenössischen Künstlers von Beginn an in den klassischen Kanon.

Vom Prinzip her ist die Aufstellung der Skulpturen in kleinen, abgetrennten Räumen durch den vatikanischen Cortile del Belvedere inspiriert, wo die Statuen in Nischen platziert sind. ${ }^{307}$ Die dortige Werkpräsentation wurde bereits von Høyen in seiner Begleitschrift zur Geldsammlung für die Errichtung von Thorvaldsens Museum gelobt. ${ }^{308}$ Ebenfalls Høyen empfahl farbige Wände, um die ausgestellten Werke aus Marmor und Gips möglichst stark zur Geltung zu bringen. ${ }^{309}$ Mit der oben beschriebenen Aufstellung einzelner Statuen in kleinen Räumen ging ferner eine Bedeutungshierarchie der Werke einher: Die durch ihre prominente Präsentation gleichsam als Hauptwerke ausgezeichneten Skulpturen waren in jedem Raum von wenigen ,Nebenwerken' wie Reliefs und Büsten umgeben. Dabei wurden die Reliefs meist in die Wände direkt neben der Marmorskulptur eingelassen und die Büsten auf runden Sockeln bei den Türdurchgängen platziert. Überspitzt gesagt, klassifizierte diese Präsentationsweise die Reliefs und Büsten des einstigen patriarca del bassorilievo als untergeordnete Werke und verlieh ihnen dekorativen Charakter.

Gleichzeitig wurde versucht, die einzelnen Räume thematisch zu gestalten. Dies entpuppte sich jedoch als ein zu ambitioniertes Unterfangen und konnte nur bedingt verwirklicht werden. ${ }^{310}$ Die thematische Geschlossenheit des Christussaals erwuchs gleichsam organisch aus Thorvaldsens umfassendem Auftrag für die Kopenhagener Frauenkirche. Ebenso waren Räume zu Amor, Venus, den Grazien und Musen leicht umsetzbar angesichts von Thorvaldsens zahlreichen Werken zu diesen Themen (Räume 2, 3, 16 und C./Fenger 1892, 166; Gohr 1977b, 91; Jørgensen 1984, 240; Henschen/Jørnæs 1987, 11; Henderson 2005, 25.

306 Hammerich 1876, 149 - 151; auch Jørgensen 1984, 240.

307 Henschen/Jørnæs 1987, 7. Ähnliche Aufstellungen waren auch im Museo Pio-Clementino und dem Museo Chiaramonti in Rom zu finden.

308 Høyen 1837, 22. Hierauf folgen Überlegungen zur konkreten Aufstellung von Thorvaldsens Werken, ohne jedoch den Standort des Museums zu kennen.

309 Ebd., 32. Diesen Effekt beobachteten später auch Macmillan 1869, 346, und Hammerich 1876, 151.

310 Siehe auch Floryan 1998, 33. 
18). Für den vorliegenden Kontext sind jedoch andere Räume von vorrangigem Interesse: Beispielsweise sind in die Wände des Raumes 5, wo heute die Jason-Statue aufgestellt ist, Reliefs mit Szenen der Achilles-Legende eingelassen und verleihen ihm somit das Überthema der Heroendarstellung. Nicht zufällig sind in diesem Raum die Porträtbüsten von Thomas Hope, dem Besteller der Jason-Statue und frühesten Förderer Thorvaldsens, sowie seiner Frau Louisa Hope aufgestellt. Das Selbstbildnis mit der Statue der Hoffnung im Raum 20 ist indessen von Reliefs der Grazien, der Musen Melpomene und Thalia, der Genien der Kunst, Dichtkunst und Harmonie sowie von den Porträtbüsten von Mitgliedern des dänischen Königshauses, Ludwig I. von Bayern und Vincenzo Camuccini umgeben. Durchaus passend zu Thorvaldsens Selbstdarstellung stehen hier die Reliefs für die künstlerische Inspiration und die Büsten für Gönner und Bewunderer von Thorvaldsens Schaffen.

Dank den seit der Eröffnung des Museums regelmäßig publizierten Katalogen lässt sich die Aufstellung der einzelnen Werke relativ genau nachvollziehen. ${ }^{311}$ Die heutige Präsentation entspricht im Wesentlichen der ursprünglichen Aufstellung, indem sich Thorvaldsens Marmorskulpturen vor allem in den kleinen Zimmern im Erdgeschoss und vereinzelt im Obergeschoss befinden, während die Gipsmodelle je nach Größe auf Vorhalle, Christussaal und Korridore verteilt sind. ${ }^{312}$ Einzelne Werke wurden posthum von Thorvaldsens Schülern in Marmor ausgeführt und ersetzten die jeweiligen Gipsmodelle. ${ }^{313}$ Teile der Gemäldesammlung, der Antikensammlungen und der Bibliothek des Bildhauers werden im Obergeschoss gezeigt. Seit 1970 sind zudem im Kellergeschoss eine Auswahl an Zeichnungen und Bozzetti, persönliche Gegenstände des Bildhauers, Gipsabgüsse nach antiken Fragmenten sowie Wechselausstellungen $\mathrm{zu}$ sehen. ${ }^{314}$

\section{Thorvaldsens Museum als Gesamtkunstwerk}

Thorvaldsens Museum war Bindesbølls erstes Werk und sollte sein wichtigstes bleiben. ${ }^{315}$ Mit seinem sämtliche Aspekte des Museumsbaus umfassenden Konzept schuf er ein Gesamtkunstwerk. ${ }^{316}$ Dieser zeitweise fast inflationär verwendete Begriff stammt aus derselben Zeit wie die Idee, Planung und Errichtung von Thorvaldsens Museum: Erstmals in Eusebius Trahndorffs Schrift Ästhetik oder Lehre von der Weltanschauung und Kunst von

Siehe auch Miss 2008, 34. Eine genaue Beschreibung der Ausstellung in Thorvaldsens Museum findet sich auch bei Hammerich 1876, $147-153$.

312 Siehe auch Miss 1991, $342-343$.

313 Miss 2008, 35.

314 Siehe auch Kat. Kopenhagen 1974, 35, Anm. 64.

315 Nach Thorvaldsens Museum baute Bindesbøll mehrheitlich öffentliche Gebäude in dänischen Kleinstädten und Dörfern. Interessant ist jedoch, dass er um 1839/1840 einen Entwurf für ein Atelier für Thorvaldsen auf Nysø zeichnete. Eine Liste von Bindesbølls Bauten und Projekten findet sich bei Bramsen 1959, $165-172$.

316 Siehe auch Thule Kristensen 2013, 144-145. 
1827 erschienen, wurde der Terminus vor allem durch Richard Wagners um die Jahrhundertmitte veröffentlichte Zürcher Schriften geprägt. ${ }^{317}$ Dabei lohnt es sich in Erinnerung zu rufen, dass sich der Begriff des Gesamtkunstwerks nicht auf den Bereich der Artefakte der verschiedenen Künste beschränkt, sondern die Idee oder Utopie eines Wandels der Gesellschaft durch das jeweilige Gesamtkunstwerk miteinbezieht. ${ }^{318}$ Im Umfeld der Revolutionen von 1848 entstanden, spiegelt das Wagner'sche Gesamtkunstwerk als gemeinsames Unterfangen der verschiedenen Kunstgattungen ein neues gemeinschaftliches Verständnis der Gesellschaft wider. ${ }^{319}$ Demnach sollte die künstlerische Schöpfung nicht mehr nur einer Elite zugänglich sein, sondern der ganzen Gesellschaft gehören.

Obwohl bezweifelt werden muss, dass Bindesbøll mit dem Begriff des Gesamtkunstwerks vertraut war, durchdrang die darin enthaltene Idee kulturelle und gesellschaftliche Vorstellungen der Zeit um das Revolutionsjahr 1848 generell und dürfte daher auch die Arbeit des dänischen Architekten geprägt haben. Wie gezeigt wurde, war Bindesbøll sowohl für die Architektur und das Gestaltungskonzept der Außen- und Innendekorationen als auch für die Präsentation von Thorvaldsens Werken und Sammlungen verantwortlich. Darin äußert sich seine Intention einer künstlerischen Vereinigung von Architektur, Malerei, Skulptur und angewandter Kunst. ${ }^{320}$ Die vorangegangenen Ausführungen verdeutlichen zudem, dass Bindesbølls Baukonzept über die Synthese von verschiedenen Kunstgattungen und kulturellen Einflüssen hinaus ein Verlangen nach demokratischer Gesellschaftsveränderung visualisiert; damit entspricht es dem Konzept des Gesamtkunstwerks um die Jahrhundertmitte, das einen Gesellschaftswandel anstoßen wollte. ${ }^{321}$

Das ästhetische Programm des Museums widerspricht der von Zeitgenossen geäußerten und klar unter dem Eindruck des Thorvaldsen-Kults stehenden Ansicht, Bin-

317 Junod 2007, 72 - 73; Finger/Follett 2011, 10 -11; Brandlhuber 2013, 10; Thule Kristensen 2013, 145; spezifisch zu Wagners Verwendung des Begriffs des Gesamtkunstwerks siehe ausführlich Feldmann 2000, 52 - 97. Wagners Zürcher Schriften umfassen Die Kunst und die Revolution (1849), Das Kunstwerk der Zukunft (1850) und Oper und Drama (1851). Für Wagner war das (aufgeführte) Drama die höchste Kunstform, da es in sich alle anderen Kunstgattungen vereine. Die Idee einer Zusammenführung verschiedener Künste, die dem Konzept des Gesamtkunstwerks zugrunde liegt, geht jedoch auf Philosophen des späten 18. Jahrhunderts zurück, besonders auf Friedrich Schlegel, Friedrich Wilhelm Joseph Schelling und Georg Wilhelm Friedrich Hegel; siehe dazu Feldmann 2000, bes. 20 -50; Schefer 2011, bes. $30-31,40$ und $46-48$.

318 Feldmann 2000, bspw. 85 und 92; Finger/Follett 2011, 4; Thule Kristensen 2013, 145.

319 Siehe auch Feldmann 2000, 72 - 73; Finger/Follett 2011, 11; Schefer 2011, 37.

320 Siehe auch Bramsen 1959, 159.

321 Siehe auch Thule Kristensen 2013, 146. In diesem Zusammenhang ist ferner interessant, dass Wagner bei seiner Formulierung des Begriffs ,Gesamtkunstwerk' zwischen 1849 und 1851 noch sozialistisch und internationalistisch gesinnt war. Mit seinen nationalistischen Ansichten in den späteren Jahren begann er auch immer mehr am Wert des Gesamtkunstwerks und den darin vermittelten Ideen zu zweifeln; siehe dazu Feldmann 2000, 8; Finger/Follett 2011, 11. 
desbøll habe sich vollkommen in den Dienst der Werke des dänischen Bildhauers gestellt. So lobte Thiele die Zurückhaltung des Architekten:

Bindesböll hatte sich als Architekt auf den Standpunkt des Bildhauers gestellt; sein Ziel war nicht ein prachtvolles architektonisches, mit Thorvaldsens Arbeiten ausgeschmücktes Gebäude auszuführen: überall an anderen Orten sei die Sculptur die dienende Magd, - hier sollte sie die Frau im Hause sein. [...] Hier galt es den großen Künstlernamen Thorvaldsens, hier handelte es sich darum, seine Ehre als Künstler hervorzuheben. ${ }^{322}$

Auch Hammerich betrachtete Bindesbølls Bau im Gegensatz zu anderen existierenden Museumsgebäuden als eine „Selbstverleugnung“ des Architekten, der nur „dazu helfen [wollte], daß man Thorvaldsen's Werke sehen könne, und daß sie den rechten Eindruck hervorbringen mögen“.323 Atkinson bezeichnete das Gebäude gar als „gewöhnlich“, und noch Curt Michaelis sah darin eine „ernste Einfachheit“. ${ }^{324}$ All diese bis ins frühe 20. Jahrhundert hinein geäußerten Einschätzungen sind bei der Betrachtung von Bindesbølls eigenwilligem Museumsbau kaum nachvollziehbar. Denn in Wirklichkeit schuf der Architekt mit Thorvaldsens Museum das erste Gebäude in Kopenhagen, das grundlegend mit dem damals vorherrschenden Klassizismus brach. ${ }^{325}$

Gleichzeitig scheint sich Bindesbøll intensiv mit der architektonischen und örtlichen Umgebung des Museums auseinandergesetzt und diese in seine Idee des Gesamtkunstwerks miteinbezogen zu haben. Dies geschah jedoch nicht nur durch die Integration der Umgebung, worauf im nächsten Kapitel eingegangen wird, sondern ebensosehr durch Kontraste. So enthalten die Entwürfe, die Bindesbøll Thorvaldsen schenkte, einen Lageplan des Museums auf der Insel Slotsholmen; darauf wird ersichtlich, dass der Architekt mittels Baumreihen, Bänken und einer Statue des Bildhauers dessen Museum deutlich von Hansens Christiansborg abheben und dadurch einen Kontrast schaffen wollte (Abb. 119). ${ }^{326}$ Die in diesem Situationsplan vorgesehene Gestaltung des Außenraumes wurde nicht realisiert. Hingegen setzt sich sein Museum durch die Übersetzung von Elementen aus verschiedenen Kulturen und Zeitepochen sowie die ihnen impliziten ästhetischen und politischen Werte bewusst von Christiansborg ab.

Für die Überlegungen zum Gesamtkunstwerk ist schließlich auch die historische Bedeutung der Lage von Thorvaldsens Museum auf Slotsholmen von Interesse: Hier stand bereits die sogenannte Absalonburg - die von Bischof Absalon 1167 erbaute Burg, die zu-

323 Hammerich 1876, 145-146.

324 Atkinson 1873, 64: „The design both inside and outside is, like the majority of the public buildings in Copenhagen, heavy, uninviting, and common-place."; Michaelis 1912, 9.

325 Siehe auch Bøyesen 1946 - 1947, 181; Lange, B. 2002, 33.

326 Siehe auch Schultz 1948a, 68; Kat. Nürnberg/Schleswig 1991, 705. 
119_Gottlieb Bindesbøll, Lageplan von Thorvaldsens Museum, 1839, Feder- und Pinselzeichnung auf Papier, $420 \times 270 \mathrm{~mm}$, Kopenhagen, Thorvaldsens Museum (Inv.-Nr. D807)

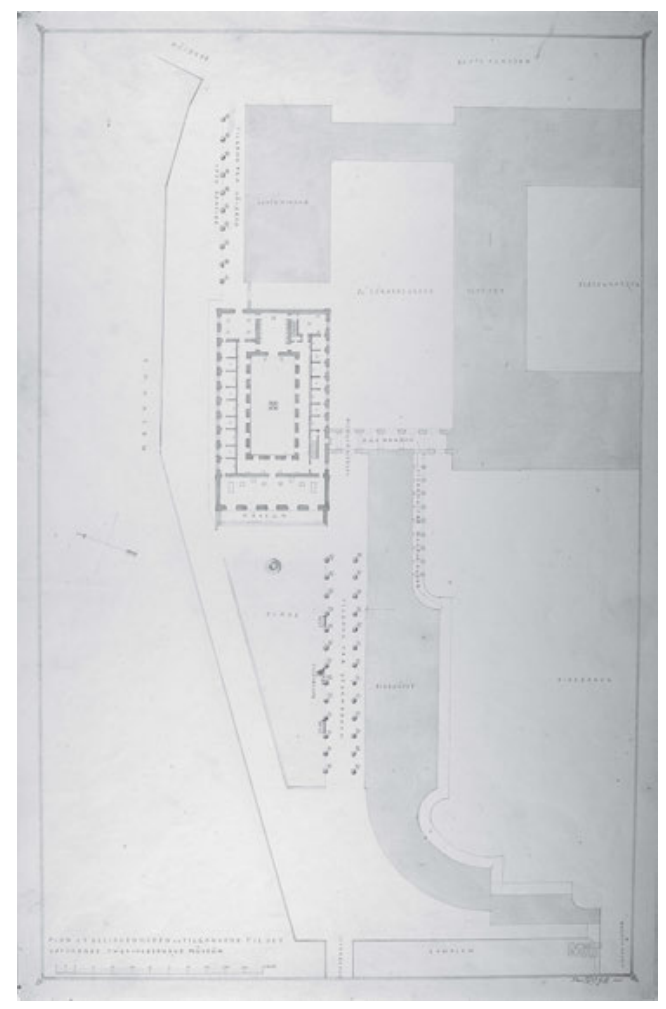

gleich die Gründung der Handelsstadt Kopenhagen markierte. ${ }^{327}$ Folglich war Slotsholmen der Ausgangspunkt der städtebaulichen Ausdehnung Kopenhagens. Nachdem die Absalonburg im Zuge kriegerischer Angriffe zerstört worden war, errichtete man auf ihren Ruinen im ausgehenden 14. Jahrhundert das Kopenhagener Schloss. ${ }^{328}$ Spätestens seit der Errichtung des ersten Schlosses Christiansborg unter König Christian VI. ab 1736 handelt es sich bei dieser Insel um den Sitz der dänischen Regierung mit der ganzen damit verbundenen Ausstrahlung. Große Teile von Christiansborg brannten 1794 und 1884 nieder, wurden jedoch beide Male wiederaufgebaut. Die Bedeutung von Slotsholmen als demjenigen Ort, an dem Kopenhagens Geschichte überhaupt erst begann und von dem aus die Stadt bis in die Gegenwart regiert wird, verleiht der Insel einen Genius loci, der sich auch auf Thorvaldsens Museum überträgt und den Kult um den hiermit geehrten Bildhauer nährt. ${ }^{329}$ Thorvaldsen war sich des Potenzials dieser Örtlichkeit für seinen Nach-

$329 \mathrm{Zu}$ den einen Genius loci konstituierenden Faktoren siehe Norberg-Schulz 1982, 18 - 77; Valena $1994,13$. 
ruhm zweifellos bewusst. Umgekehrt stärkten sein Status als internationale celebrity, seine Stilisierung zum dänischen Nationalhelden, die politische Aussage von Bindesbølls Museumsarchitektur sowie die Eröffnung des Museums im europäischen Revolutionsjahr 1848 wiederum die historische Bedeutung und den Genius loci von Slotsholmen. ${ }^{330}$

Dieser Bedeutungskomplex kommt auch in der Bezeichnung von Thorvaldsens $\mathrm{Mu}$ seum als Bautastein zum Ausdruck: Clausen beschrieb das Gebäude in einem anlässlich der Einweihung publizierten Artikel in der Tageszeitung Fodrelandet als „Bautastein [...], demjenigen würdig, dessen Erinnerung er gewidmet ist“ . ${ }^{331}$ Als unverrückbare Relikte des skandinavischen Mittelalters können Bautasteine (auch Menhire genannt) als manifeste Symbole des nordischen Erbes verstanden werden. Folglich bringt Clausens Aussage den Sinngehalt von Thorvaldsens Museum auf den Punkt, da dieses von Beginn an als dänisches Nationaldenkmal konzipiert war und die nordische Herkunft und triumphale Heimkehr eines der bedeutendsten Künstler des frühen 19. Jahrhunderts untermalen sollte. Dazu trug auch die Errichtung des Museums auf einem vom König zu diesem Zweck geschenkten Baugrund in unmittelbarer Nähe zum Schloss Christiansborg bei, obschon sich der Museumsbau am Ende explizit, ja fast demonstrativ von der monarchischen Dominanz auf Slotsholmen distanzieren sollte. In Bindesbølls weit ausgreifendes Gesamtkunstwerk kann schließlich auch die im nächsten Kapitel besprochene Funktion des Museums als Mausoleum miteinbezogen werden: Nicht nur vereint Thorvaldsens Museum verschiedene Künste und kulturelle Einflüsse, sondern auch verschiedene Zeiten und Zeitlichkeiten, bis hin zur Ewigkeit. ${ }^{332}$

\section{Das Museum als Mausoleum}

Gemäß Wilckens war es Thorvaldsens größter Wunsch, „selbst zu bestimmen, wo meine Arbeiten [im Museum] aufgestellt werden sollen; möchte ich das erleben, dann bin ich zu sterben bereit“. ${ }^{333}$ Diese Hoffnung sollte sich nicht mehr erfüllen: Thorvaldsen starb am 24. März 1844 beim Besuch der Uraufführung von Friedrich Halms Griseldis im Königlichen Theater in Kopenhagen an Herzversagen - sein Sterbesessel befindet sich heute in

Valena 1994, 49, nennt auch das Wirken berühmter Persönlichkeiten als Faktor für den Genius loci eines Ortes.

331 Fodrelandet, 9:258, 17. September 1848, Sp. 1885: „Bautastenen er reist: en Bygning, værdig ham, til hvis Minde den er viet [...]. “ Siehe auch Bruun, C./Fenger 1892, 165; Trier 1903, 238 - 239; Kat. Kopenhagen 1974, 30; Bott, G. 1981, 346; Jørnæs 1982c, 63. Die Bezeichnung von Thorvaldsens Museum als Bautastein findet sich auch in weiteren, vor allem lyrischen Quellen; siehe bspw. Thorvaldsen og den danske Digtere 1844, 9.

332 Siehe in ähnlichem Zusammenhang Finger/Follett 2011, 4.

333 Wilckens $1875,89$. 
seinem Museum. ${ }^{34}$ War schon Thorvaldsens Rückkehr nach Dänemark am 17. September 1838 ein Ereignis von nationaler Auswirkung gewesen, so galt dies umso mehr für den Tod des Bildhauers. Auch dieses Phänomen ist im Kontext des Künstlerkults zu verstehen, denn, wie Martin Warnke es formuliert hat: „Je unsterblicher der Künstler, umso unbegreiflicher sein Tod.“" ${ }^{335}$ Ganz deutlich kommt dieses Phänomen in Steffens’ Brief an die Baronin Stampe vom 6. April 1844 zum Ausdruck:

Und also - Thorvaldsen ist tot - man war geneigt zu glauben, dass der, dessen Werke unsterblich sind, unsterblich sein müsse, wie der Marmor, dem er göttliche Bedeutung gab. Wandelte er doch - die schöne Statue, fest und gesund und unveränderlich - unter uns, erhaben über allen. ${ }^{36}$

Diese beiden Sätze aus Steffens' Schreiben fassen einige zentrale Aspekte des Kults um Thorvaldsen und seines öffentlichen Bildes zusammen. Der Bildhauer wird auf zwei Ebenen mit dem Marmor, dem Material seines Schaffens, verglichen: Zum einen erhoffte man sich angesichts der Dauerhaftigkeit der steinernen Figuren jene ihres Schöpfers, und dies offenbar buchstäblich, nicht nur symbolisch in Form eines Fortlebens des Bildhauers in seinen Werken. Zum anderen wird Thorvaldsens Äußeres mit einer Statue verglichen, die durch ihre Unveränderlichkeit und Größe - wohl weniger die Größe des Körpers als jene seines Genius - über die Mitmenschen hinausrage. Durch Thorvaldsens Tod wurden die Zeitgenossen auf einen Schlag mit der Vergänglichkeit des vergötterten Künstlers konfrontiert. Damit ist erneut die Problematik von diesseitiger celebrity und den Tod überwindendem Ruhm angesprochen, die im Folgenden abschließend anhand der Doppelfunktion von Thorvaldsens Museum als Mausoleum beleuchtet werden soll.

\section{Ein Staatsbegräbnis für den Künstler}

„Ein reiches Blatt in der Geschichte der Kunst ist vor uns aufgerollt und entziffert; Thorwaldsen ist gewesen; sein Leben war ein Triumphzug, das Glück und der Sieg folgten ihm, die Menschen haben in ihm die Kunst erkannt und geehrt. “337 Mit diesen Zeilen, die sich an der Metapher von einem Blatt im Buch der Geschichte inspirieren, beginnt Andersens erstmals in Thorvaldsens Todesjahr erschienene „biographische Skizze“ über den Bildhauer und veranschaulicht die damalige Betrachtung von Thorvaldsens Leben als einem einzigen Siegeszug. Diese Sichtweise wird auch in der Art deutlich, wie die Zeitgenossen dem Bildhauer und berühmten Landsmann die letzte Ehre erwiesen.

336 Heinrich Steffens an Christine Stampe, 6. April 1844, KB, Ref. NKS 1732, $2^{\circ}$ (Transkript im TMA): „Og altsaa - Thorvaldsen er død - man var tilbøyelig til at troe, at den, hvis Værker ere udødelige, maatte være udødelig, som det Marmor, han gav gudommelig Betydning. Vandrede han dog - den skiønne Statue, fast og sund og uforanderlig - mellem os, hævet over alle.“ 
Die Begräbnisfeierlichkeiten zogen sich über zwei Tage hin, die mit einer Totenwache am 29. März 1844 auf Schloss Charlottenborg begannen. Diese fand in dem mit schwarzen Behängen ausgekleideten Antikensaal der Kopenhagener Kunstakademie statt und wurde von Wilckens und jungen Künstlern abgehalten. ${ }^{338}$ Entsprechend der vor allem in der Romantik aufgekommenen Darstellungstradition des sterbenden Künstlergenies entstanden mehrere Bilder von Thorvaldsen auf dem Sterbebett sowie des aufgebahrten, mit einem Lorbeerkranz bekrönten Bildhauers. ${ }^{339}$ Dessen Totenbahre ist in den Zeichnungen von Georg Emil Libert und Anton Melbye umgeben von seinen mit Trauerflor geschmückten Statuen der Himmlischen Weisheit, der Göttlichen Stärke und eines Engels, die passenderweise zum Grabmal für Papst Pius VII. gehörten (Abb. 120 und 121). ${ }^{340}$ Weiter erkennt man bei Libert Abgüsse von Canovas Perseus sowie vermutlich des Alexanderzuges. Die Zusammenstellung dieser beiden Werke verweist auf einen doppelten Triumph von Thorvaldsen, der mit seiner epochalen Jason-Statue explizit Canovas Perseus ,korrigiert' und sich mit dem Alexanderzug zumindest im Bereich des Reliefs gemäß den damaligen Kritikern weit über seinen italienischen Zeitgenossen erhoben hatte. Die Thematik des Triumphs könnte man bei Libert und Melbye auch im Papstgrabmal für den Petersdom sehen, dessen Auftrag ausgerechnet Thorvaldsen als Nicht-Katholik erhalten hatte. Bei der aus einem anderen Blickwinkel skizzierten Zeichnung von Melbye erkennt man im linken Vordergrund zusätzlich Thorvaldsens Sarg mit dem kleinen Gipsmodell seines Selbstbildnisses mit der Statue der Hoffnung, das zusammen mit dem Bildhauer in die Erde gelassen werden sollte. Der Sarg selbst bestand aus Eichenholz und war mit Reliefs von Constantin Hansen verziert. Diese zeigten am Kopfende die Siegesgöttin und am Fußende die Parzen, wodurch erneut auf Thorvaldsens Triumphzug sowie seine irdische Vergänglichkeit hin-

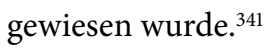

Thiele 1831-1850, Bd. 4, 220; Thiele 1852 - 1856, Bd. 3, 180; Ravn 1944, 13; Kat. Nürnberg/Schleswig 1991, 707 -708; Jørnæs 2011, 246 -248; auch de Loménie 1845, 25-26. Zu Thorvaldsens Aufbahrung siehe bspw. Baronesse Stampes Erindringer 1912, 257 - 258. Detaillierte Ausführungen zu den Begräbnisfeierlichkeiten finden sich bspw. bei Andersen 1845, 69-78; Ravn 1944, 12-19. Zu den ebenfalls sehr ausgedehnten und einem Heiligenkult gleichkommenden Begräbnisfeierlichkeiten für Canova 1822 siehe bspw. Bätschmann 1997, 85-88; Myssok 2012a, 246.

339 Die Bildtradition des sterbenden Künstlers war zunächst eine retrospektive und betraf vor allem Darstellungen von in der Romantik als Genies verehrten Künstlern der Renaissance und des Barock; siehe bspw. Warnke 2008, 80 - 85. Darstellungen von Thorvaldsen auf dem Sterbebett stammen von Anton Melbye (Thorvaldsen am Tag seines Todes, 24. März 1844, Bleistift auf Papier, 180/178 x 232/231 mm, Kopenhagen, Thorvaldsens Museum, Inv.-Nr. D1661) und Johan Vilhelm Gertner (Der tote Thorvaldsen, 25. März 1844, Bleistift auf Papier, Hillerød, Det Nationalhistoriske Museum på Frederiksborg Slot, Inv.-Nr. A 980).

340 Siehe auch Kat. Nürnberg/Schleswig 1991, 708; Bätschmann 1997, 92.

341 Zur Beschreibung von Thorvaldsens Sarg siehe Ravn 1944, 14. 
120_Georg Emil Libert, Thorvaldsen auf der Totenbahre, 29. März 1844, Bleistift- und Federzeichnung laviert auf Papier, $125 \times 155 \mathrm{~mm}$, Kopenhagen, Thorvaldsens Museum (Inv.-Nr. D1748)

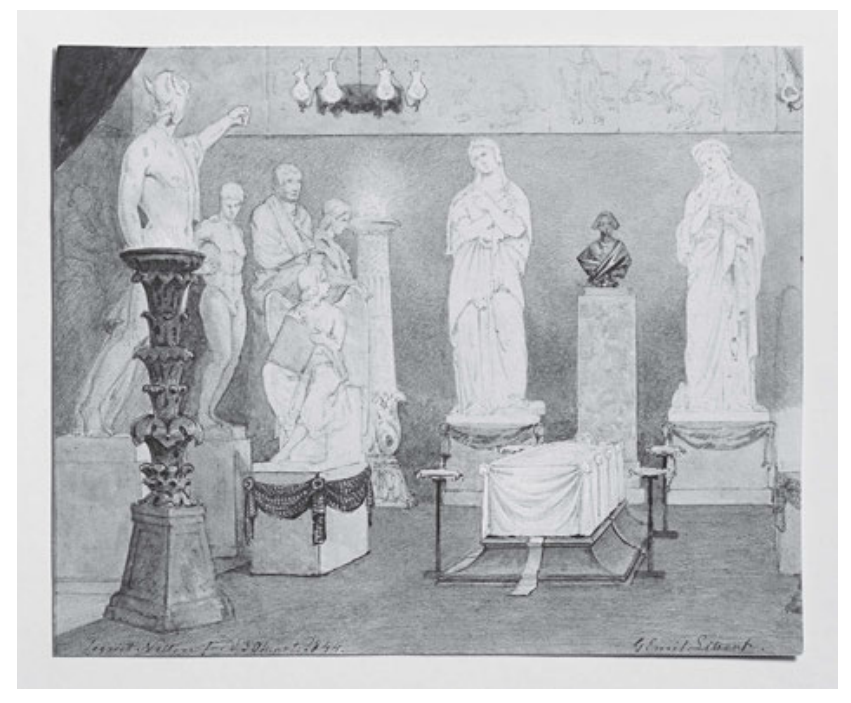

121_Anton Melbye, Thorvaldsen feierlich aufgebahrt, 30. März 1844, Farbstiftzeichnung auf Papier, $195 \times 117 / 119$ mm, Kopenhagen, Thorvaldsens Museum (Inv.-Nr. D1751)

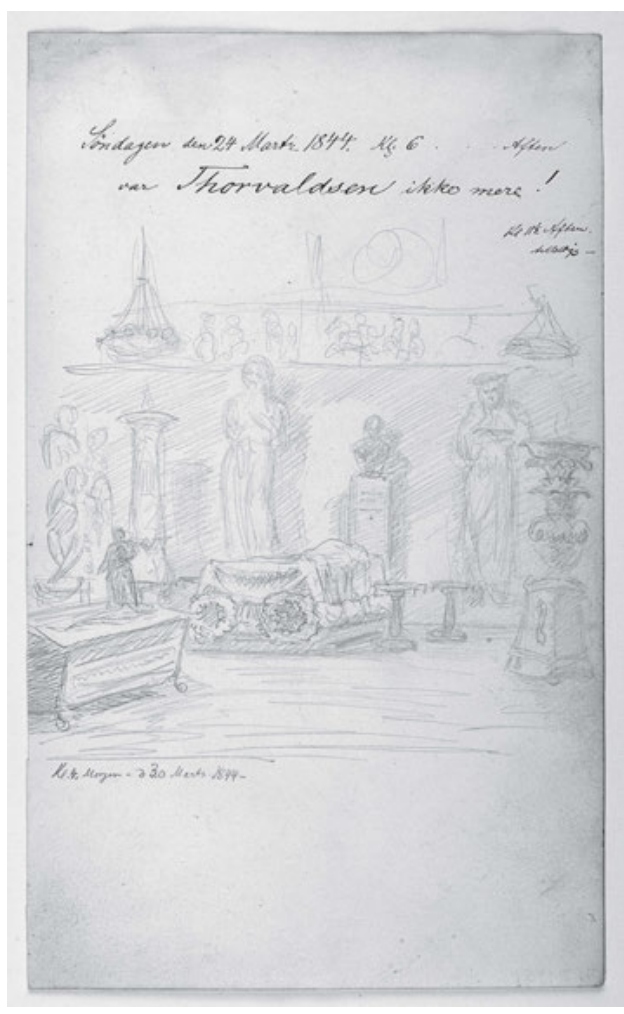


Am Tag nach der Aufbahrung, am 30. März 1844, folgte der Trauerzug von Schloss Charlottenborg zur Frauenkirche. ${ }^{342}$ Auffallend ist in Andersens Beschreibung die Erwähnung des Wetters: „Es ist ein grauer Tag, nicht ein Sonnenstrahl. “343 Der Zeitgenosse Rudolph Schleiden schrieb gar von „Schneegestöber und Kälte“. ${ }^{344}$ Folglich wurde das Zutun höherer Kräfte - diesmal in bedrückender Form - während Thorvaldsens Begräbnisfeierlichkeiten ebenso betont, wie es schon sechs Jahre zuvor durch die Nennung der Nordlichter und des Regenbogens bei der Ankunft des Bildhauers in Kopenhagen geschehen war. ${ }^{345}$ Außerdem habe während des Trauerzuges absolute Stille geherrscht. ${ }^{346}$ Auch diese Anmerkung - wie die Erwähnung des Wetters - untermauert den Gegensatz zwischen dem Leichenzug und dem tosenden Empfang bei der Rückkehr des Bildhauers 1838. Unter bedecktem Himmel und vollkommenem Schweigen also trugen junge Künstler, gefolgt vom Kronprinzen Frederik Carl Christian (später Frederik VII.), dem Maler Eckersberg sowie weiteren Mitgliedern der Königsfamilie und der Kunstakademie, Thorvaldsens Sarg durch die Kopenhagener Innenstadt. ${ }^{347}$ Gemäß Andersens Erzählung bestand der Trauerzug aus

einer Anzahl Seeleute [...], demnächst nahe an 800 Studenten; hinter diesen kamen die Isländer, dann Künstler aller Klassen, welche einander ablösten und darauf die Leiche; hierauf der Kronprinz mit den Mitgliedern der Akademie, beide Militair-Etaten, Beamte und Bürger. ${ }^{348}$

Auch die Straßen waren von Mitgliedern aller Gesellschaftsschichten gesäumt, die für eine gute Sicht auf das bewegende Ereignis sogar auf Bäume und Dächer geklettert seien. ${ }^{349}$ Die Anwesenheit von Menschen der niedrigsten bis höchsten sozialen Ränge, die sich allesamt mit dem aus ärmlichen Verhältnissen stammenden und nun als Berühmtheit gefeierten Bildhauer zu identifizieren wussten, wurde von verschiedenen Zeitzeugen hervorgehoben. ${ }^{350}$ Der Einbezug aller Gesellschaftsschichten war essenziell für die Inszenierung von Thorvaldsen als dänischem Nationalhelden. Wie in den beiden vorangegangenen Kapiteln ausgeführt wurde, hatte diese Stilisierung bereits der 1837 lancierten Geldsamm-

342 De Loménie 1845, 26-27; Thiele 1831-1850, Bd. 4, 221-225; Thiele 1852-1856, Bd. 3, 180-183; Wilckens 1875, 128-129; Jørnæs 1989c, 33.

343 Andersen 1845, 71.

344 Schleiden 1890, 90.

345 Siehe dazu Kap. IV.1.

346 Andersen 1845, 71-72.

347 Jørnæs 1989c, 33.

348 Andersen 1845, 71. Detaillierte Beschreibungen des Trauerzuges finden sich außerdem in: Aftenbladet, 77, 30. März 1844, o.S. [Titelseite]; Allgemeine Zeitung, 99, 8. April 1844, 791; Brandt 1844, 24-26; Møller 1844, 4-5.

349 Andersen 1845, 71; Jørnæs 1989c, 33.

350 Aftenbladet, 77, 30. März 1844, o.S. [Titelseite]; Andersen 1845, 75-76; de Loménie 1845, 25; Thiele 1831-1850, Bd. 4, 224; Thiele 1852-1856, Bd. 3, 182. 
lung zur Errichtung des Museums für Thorvaldsen zugrunde gelegen und fand ihre Visualisierung in Sonnes Fries an den Außenfassaden des Museumsgebäudes. Unter den Kränzen, die Thorvaldsens Sarg schmückten, hoben Andersen und Thiele in ihren Beschreibungen bezeichnenderweise jenen der dänischen Königin und jenen von Schulkindern speziell hervor. ${ }^{351}$ Dabei dürfte es weniger um die Kränze selbst als um eine gesellschaftliche Botschaft gegangen sein: Die Betonung der eigenhändigen Windung des Kranzes durch die Königin einerseits und des für den Silberkranz hergegebenen Ersparten der Kinder andererseits verdeutlicht erneut die Stilisierung von Thorvaldsen zum Nationalhelden sowie die Bedeutung von Thorvaldsens Museum als Nationaldenkmal, an dem sämtliche Mitglieder der dänischen Gesellschaft teilhaben konnten (und sollten).

Wie der Antikensaal auf Charlottenborg war auch die Frauenkirche mit schwarzen Tüchern ausgekleidet - und wie im Saal der Kunstakademie war Thorvaldsens Sarg auch hier von Werken des Bildhauers umgeben: Die Frauenkirche beherbergt bis heute seine ab 1821 modellierten und anschließend in Marmor ausgeführten Statuen des Christus, des Knienden Taufengels und der zwölf Apostel (Taf. X) ${ }^{352}$ Nach der Begräbniszeremonie wurde Thorvaldsens Sarg in der Sakristei der Frauenkirche aufgestellt. ${ }^{353}$

Die drei Phasen der Feierlichkeiten zu Thorvaldsens Begräbnis hielt der Kupferstecher Joel Ballin 1844 in einer Zeichnung und einer darauf basierenden Lithografie fest (Abb. 122). Das oberste Bild ist dabei fast identisch mit der vorgestellten Zeichnung von Libert und zeigt den aufgebahrten Thorvaldsen im Antikensaal der Kopenhagener Kunstakademie, gerahmt von seinen eigenen Werken, Canovas Perseus, antiken Statuen und wachenden Zeitgenossen. Durch den weitwinkligen Bildausschnitt sind bei Ballin mehr Skulpturen um Thorvaldsens lit de parade zu sehen als bei Libert, darunter der zweite Engel des Papstgrabmals für Pius VII. Zudem wird der Bildvordergrund von Thorvaldsens 1840 modellierter Statue des von 1588 bis 1648 herrschenden dänischen Königs Christian IV. und seiner Selbstbildnisbüste von 1810 bestimmt (Abb. 31). ${ }^{354}$ Ballins Darstellung dieser beiden Männer sollte möglicherweise als eine Zusammenführung der ersten und der vorerst letzten bedeutenden dänischen Persönlichkeit verstanden werden: Während Christian IV. der erste König war, der Kopenhagens Geschichte städtebaulich und kulturell nachhaltig geprägt hatte, erreichte Thorvaldsen mit seinem Schaffen den Status einer internationalen Berühmtheit, was wiederum auf sein Heimatland zurückstrahlte.

352 Andersen 1845, 73; Thiele 1831-1850, Bd. 4, 223-224; Thiele 1852-1856, Bd. 3, 182; Ravn 1944, 18; Lange, B. 2002, 74; Jørnæs 2011, 248.

353 Thiele 1831-1850, Bd. 4, 225; Thiele 1852-1856, Bd. 3, 188; Otto 1869, 670; Wilckens 1875, 130; Ravn 1944, 19; Gohr 1977b, 92; Jørnæs 2011, 250.

354 Das Gipsmodell des Standbildes von Christian IV. befindet sich heute in Thorvaldsens Museum in Kopenhagen (Inv.-Nr. A152). 


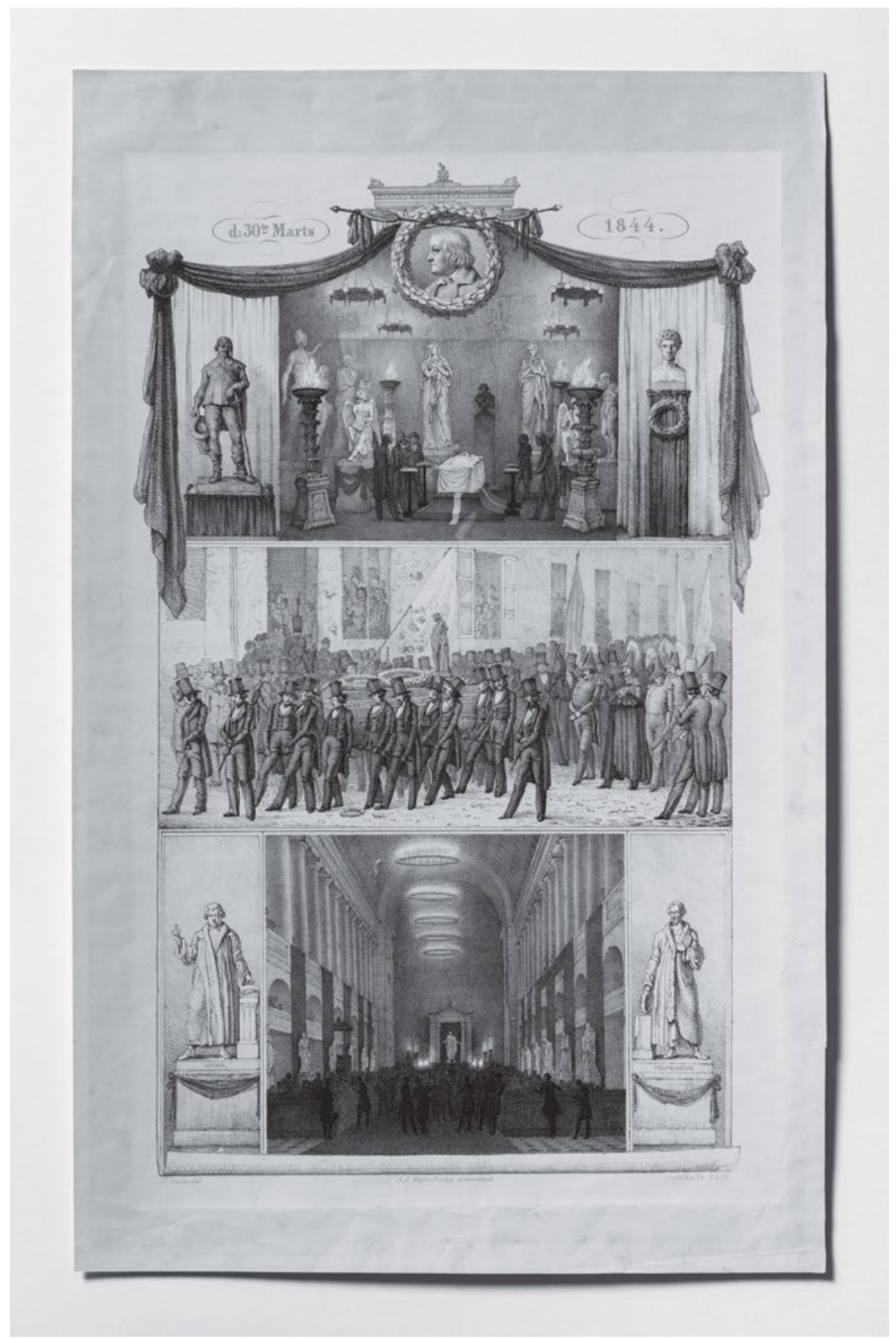

122__Joel Ballin, Thorvaldsens Begräbnisfeierlichkeiten, 1844, Lithografie, $427 \times 226$ mm, Kopenhagen, Thorvaldsens Museum (Inv.-Nr. E2285) 
In der mittleren Szene bei Ballin ist die Prozession durch die dänische Hauptstadt dargestellt, deren Straßen und Fenster mit Schaulustigen gefüllt sind. Die unterste Zeichnung schließlich zeigt das Innere der Kopenhagener Frauenkirche, wo die eigentliche Begräbniszeremonie stattfand. Wie eine Fortführung der Apostel in der Frauenkirche wirken hier Thorvaldsens im linken und rechten Vordergrund dargestellte Statuen der Reformatoren Martin Luther und Philipp Melanchthon. Diese beiden um 1838 bestellten Werke sollten die Vorhalle der Frauenkirche schmücken, wurden jedoch nie in Marmor ausgeführt. ${ }^{355}$

Die Feierlichkeiten zu Thorvaldsens letzter Ehre hatten den Charakter eines Staatsbegräbnisses und wurden über die dänischen Landesgrenzen hinaus rezipiert. Obwohl Thorvaldsens celebrity-Status in der ihm gegenüber nach wie vor kritisch eingestellten französischen Berichterstattung etwa als „patriotische Übertreibung“ bezeichnet wurde, schlugen die Zeitgenossen grundsätzlich versöhnliche Töne an. ${ }^{356}$ In den unzähligen nach Thorvaldsens Tod verfassten Reden und Gedichten wurde der Bildhauer als „Dänemarks Stolz“ und dessen Ableben sowohl als „Nationalunglück“ wie auch als „Trau’r der Welt“ bezeichnet. ${ }^{357}$ Nicht nur war der Tod des „weltberühmten Meisters“ die wichtigste Meldung in den tags darauf erschienenen dänischen Zeitungen, er löste weit über die Landesgrenzen hinaus eine Flut von Veröffentlichungen und symbolischen Ehrerweisungen aus. ${ }^{358}$ Beispielsweise wurde in der Accademia di San Luca die 1824 von Tenerani geschaffene Porträtbüste von Thorvaldsen aufgestellt. Zu diesem Anlass hielt Canina eine Gedenkrede, die zudem in gedruckter Form in Umlauf gebracht wurde. ${ }^{359}$

Thorvaldsens Tod bot schließlich eine letzte Gelegenheit für die Assoziierung des Bildhauers mit der glanzvollsten Epoche der griechischen Antike: So wurde bemerkt, dass seit Perikles' Zeit keinem Künstler eine ähnliche Ehre zuteil geworden sei wie die Begräbnisfeierlichkeiten für Thorvaldsen. ${ }^{360}$ Thiele nahm den Rückblick auf Thorvaldsens Leben indessen zum Anlass, den Bildhauer erneut mit den höheren Mächten des Kosmos zu assoziieren:

355 Die Originalmodelle dieser beiden Statuen befinden sich in Thorvaldsens Museum in Kopenhagen (Inv.-Nr. A160 und A161).

356 De Loménie 1845, 28: „Quand bien même on penserait qu'il y a dans la renommée de Thorwaldsen un peu d'exagération patriotique, il est impossible de ne pas être touché de cette naïve et affectueuse admiration, et l'on doit reconnaître que de tels hommages rendus à un simple artiste honorent le Danemark et son roi tout autant que Thorwaldsen. “ D’Angers 1856, 14-15.

357 Siehe bspw. Andersen 1845, 70 und 73 (nach einem Gedicht von Johan Ludvig Heiberg); Thiele 1831-1850, Bd. 4, 222; Thiele 1852 - 1856, Bd. 3, 180; Wilckens 1875, 127; Schleiden 1890, 90.

358 Zitat: Møller 1844, 3: „verdensberømte Mesters“. Eine ähnliche Formulierung findet sich auch bei Brandt 1844, 3. Zu Thorvaldsens Tod als wichtigster Zeitungsmeldung siehe Jørnæs 2011, 246.

359 Canina 1844; siehe auch Kat. Nürnberg/Schleswig 1991, 538. Das Gipsmodell von Teneranis Porträtbüste von Thorvaldsen befindet sich als Dauerleihgabe der Kopenhagener Ny Carlsberg Glyptothek (Inv.-Nr. MIN 0628) in Thorvaldsens Museum (Inv.-Nr. Dep.30).

360 De Loménie 1845, 25; d’Angers 1856, 14. 
Und wie ruhig und ungestört war doch dabei sein Wirken! Während in demselben Jahrhundert große Umwälzungen die Welt umgestalteten, - während die Erde mit Strömen Blutes getränkt wurde, - bewegte er sich wie ein Himmelskörper in seinem mächtigen Gange über den Unfrieden der Welt dahin, und nie ward er aus seiner Bahn gezogen. Auf demselben Blatte in den Jahrbüchern der Geschichte, welches den späteren Geschlechtern eine der einflussreichsten Epochen der Weltbegebenheiten schildert, wird das stille Künstlerleben Thorvaldsens als die wunderbare Wiedergeburt der Kunst des Alterthums interliniirt zu lesen sein. ${ }^{361}$

Solche Gemeinplätze nährten den Kult um Thorvaldsen über dessen Tod hinaus und sollten die schon früh prophezeite Unsterblichkeit seines Ruhms sicherstellen. ${ }^{362}$ Im größeren Kontext der damaligen celebrity-Kultur ist indessen das von Barfod zusammengestellte und bereits im April 1844, also unmittelbar nach Thorvaldsens Tod, veröffentlichte Thorvaldsensk Album beachtenswert. Barfod schreibt in der Einleitung: „Es ist ein großer Segen für ein Volk, einen welthistorischen Stern ersten Ranges hervorgebracht zu haben. “363 Auch hier kommt die Verbindung von Nationalstolz und Internationalität zum Tragen, die so zentral war für die celebrity-Kultur des frühen 19. Jahrhunderts. Interessant ist zudem die auch in anderen Quellen vorkommende Bezeichnung von Thorvaldsen als Stern (heute würde man von Star sprechen), was seinen Status als gleichsam strahlende Berühmtheit noch unterstreicht. Gleich einem heutigen ,Fanbuch'sammelte Barfod im genannten Album alle möglichen Texte über Thorvaldsen, wie Zeitungsartikel, Gedichte, Reden, Lieder und Briefe. Der zeitliche Schwerpunkt des Albums liegt auf den Jahren zwischen Thorvaldsens erstem Besuch in der Heimat und der damit verbundenen triumphalen Reise durch Europa (1819) und seinem Todesjahr (1844). Dabei ist gerade im Hinblick auf die celebrity-Kultur bezeichnend, dass Barfods Fokus weniger auf dänischen als auf internationalen Publikationen lag. Ebenfalls im April 1844 veröffentlichte der Typo-

graf Johan Møller mit seinen Mindeblomster (Gedenkblumen) eine ähnliche Sammlung von Kleinpublikationen, jedoch spezifisch zu Thorvaldsens Tod.

\section{Letzte Ruhe im Museum}

Wie die Quellen berichten, soll Thorvaldsen an seinem letzten Lebenstag gemeint haben: „Ja, jetzt kann ich sterben, wann ich will, Bindesböll hat mein Grab fertig!“364 Das hier überlieferte Timing erinnert stark an den glücklichen Zufall, dem der Bildhauer mehr als vier Jahrzehnte zuvor seinen künstlerischen Durchbruch mit der Jason-Statue zu verdan-

Just Mathias Thiele, Rede am Stiftungstag der Kopenhagener Kunstakademie, 31. März 1844, zit. nach Thiele 1852 - 1856, Bd. 3, $185-186$.

362 Siehe bspw. Bruun, R.E. 1817, 543; Jacobsen 1820, 96; Ludwig von Bayern (später Ludwig I.) an Bertel Thorvaldsen, 16. Oktober 1822, zit. bei Thiele $1852-1856$, Bd. 2, 94.

363 Barfod 1844, 2: „Det er en stor Velsignelse for et Folk at have frembragt en verdenshistorisk Stjerne af förste Rang."

364 Thiele 1852-1856, Bd. 3, 179. Siehe auch Thiele 1831-1850, Bd. 4, 219. Dieser Ausspruch findet sich in jeweils leicht verschiedenen Wortlauten auch bei Wilckens 1875, 125; Kornerup 1935, 5; Ravn 1944, 8. 
ken hatte: Damals fiel der Besuch des Bankiers Hope in Thorvaldsens Atelier gemäß den Quellen genau auf den Tag, an dem Letzterer Rom hätte verlassen wollen, hätte ihn nicht eine Nachlässigkeit seines Reisegefährten daran gehindert. ${ }^{365}$ Die Parallelen in den beiden Erzählungen lassen vermuten, dass Thiele durch jene zeitlichen Fügungen die Dramatik sowohl von Hopes Besuch in Thorvaldsens Atelier als auch der oben zitierten Aussage des Bildhauers zu seiner Grabstätte steigern wollte.

Mit großer Wahrscheinlichkeit geht die Errichtung von Thorvaldsens Grab im Innenhof seines Museums auf den eigenen, wohl in der ersten Hälfte des Jahres 1840 geäußerten Wunsch des Bildhauers zurück. ${ }^{366}$ Denn während die am 13. November 1839 vom König approbierten Entwürfe für Thorvaldsens Museum an der Stelle der heutigen Grabstätte einen Brunnen zeigen, ist diese auf den Plänen vom August des darauffolgenden Jahres bereits eingezeichnet. ${ }^{367}$ Die Arbeiten an der Grabstätte begannen 1842 und wurden - entgegen der oben zitierten Aussage des Bildhauers - erst im Sommer 1844 abgeschlossen, also einige Monate nach seinem Tod. ${ }^{368}$ Die Wände des traditionelle Trauersymbole aufweisenden Grabes sind nach einem Entwurf von Bindesbøll mit weißen Lilien sowie dunkel- und hellroten Wildrosen auf blauem Grund ausgemalt (Taf. XVII). Der schwarze Boden weist ein ornamentiertes Kreuz und Thorvaldsens Todesjahr in grauer Farbe auf, während an der blauen Decke zwei sich kreuzende Palmzweige dargestellt sind.

Die Integrierung von Thorvaldsens Grab in sein Museum macht Letzteres zugleich zum Mausoleum des Bildhauers. Diese Doppelfunktion stellte damals insofern eine Neuheit dar, als erstens Museum und Mausoleum in ein und demselben Gebäude vereint wurden und es sich zweitens um die Grabstätte eines Zeitgenossen handelte. ${ }^{369}$ Außerdem trugen jene zweifache Funktion des Gebäudes und seine Benennung nach Thorvaldsen wesentlich zu dem auf dessen Nachruhm zielenden Denkmalcharakter des Museums bei. ${ }^{370}$ Wie Birgit Ulrike Münch zusammengefasst hat, bildet ein Grabmal unter anderem „den konkreten Erinnerungsort [...] für den Verstorbenen“ und begünstigt „die persön-

Siehe dazu Kap. I.1.

366 Andersen 1845, 78; Thiele 1831-1850, Bd. 4, 225; Thiele 1852-1856, Bd. 3, 183; Wilckens 1875, 120; Müller, S. 1893, 299; Bott, G. 1981, 346. Bätschmann 1997, 92, vermutet hingegen, dass die Idee für Thorvaldsens Grab im Museum auf Thiele zurückgeht. Auch Trempler 2011, 205, geht davon aus, dass jene Idee von außen an den Bildhauer herangetragen und von diesem lediglich bewilligt wurde. Eine solch passive Sichtweise auf Thorvaldsen scheint sich jedoch schwer mit dessen bewusster Selbstvermarktung und der aktiven Planung seines Nachruhms in Einklang bringen zu lassen.

367 Ravn 1944, 29; Schultz 1948a, 66; Kat. Nürnberg/Schleswig 1991, 705 und 708; With 1998, 129-131; Trempler 2011, 208.

368 Kat. Nürnberg/Schleswig 1991, 708; auch Ravn 1944, 29.

369 In diesen zwei Punkten hebt sich Thorvaldsens Museum/Mausoleum von früheren Beispielen wie dem Museo Canova in Possagno (Kap. IV.1) oder dem Musée des Monuments français in Paris ab; zu Letzterem siehe auch Trempler 2011, 208-209.

370 Siehe auch Bott, G. 1981, 346 und 352; Bätschmann 1997, 42; Henderson 2005, 25; Trempler 2011, 207. 
liche Memoria und damit die Sorge um das Seelenheil des Toten“" ${ }^{371}$ Ein Spezifikum von Künstlergrabmälern ist gemäß Münch, dass sie „sowohl retrospektiv auf das künstlerische Schaffen des Verstorbenen zu dessen eigenen Lebzeiten als auch prospektiv auf das memoriale Weiterleben des Künstlers in der Form [...] seiner Kunstwerke" verweisen. ${ }^{372}$ Dies gilt für Thorvaldsens Grabstätte in seinem eigenen Museum in besonderem Maß. Hier stellt sich gar die Frage, ob es sich bei diesem Gebäude um ein Museum mit einem Künstlergrab oder um ein monumentales Grabmal in Form eines Museums handelt. ${ }^{373}$

Thorvaldsens Museum wurde im Spätsommer 1848 vollendet. Am 6. September jenes Jahres wurde der Sarg des Bildhauers von der Kopenhagener Frauenkirche in einer frühmorgendlichen Prozession zum Museum transportiert, wo er schließlich in die Erde gelassen wurde. ${ }^{374}$ Das kleine Gipsmodell von Thorvaldsens Selbstbildnis mit der Statue der Hoffnung, der von Schulkindern gestiftete silberne Eichenkranz und eine beschriftete Marmortafel wurden mit ins Grab gegeben. ${ }^{375}$ Die Form der Gruft wird im Innenhof des Museums mit einem Rahmen aus schwarzen Granitplatten angezeigt, in die Thorvaldsens Name, Geburts- und Sterbedatum eingraviert sind (Taf. XII, Abb. 123). Dieser Rahmen war ursprünglich mit Rosen bepflanzt; heute wächst dort immergrüner Efeu als Symbol für Thorvaldsens fortwährenden Ruhm. ${ }^{376}$

Das Farbkonzept und die Darstellung von lebensgroßen Palmen, Lorbeersträuchern und Eichen im Innenhof des Museums stammen von H. C. From. ${ }^{377}$ Wesentlich zu dieser 1844 vollendeten polychromen Ausmalung trug auch Thorvaldsens Schüler Scholl bei, der ähnlich wie sein Lehrer das im damaligen Kopenhagener Stadtbild vorherrschende Grau als einen tristen Anblick empfand: In einem Tagebucheintrag vom 30. April 1840 beschrieb er Kopenhagen als eine Stadt, „die nicht übel gebaut [ist], doch durch die vielen Grau angestrichenen Häuser einen einförmigen traurigen Carakter annimmt “.378 Von Scholl stammt der gemalte Fries mit wagenlenkenden Genien, Amphoren und Dreifüßen, der im Innenhof den oberen Wandbereich der Nord- und Südseiten ziert. ${ }^{379}$

Die den Innenhof des Gebäudes schmückenden Motive untermalen die Funktion des Museums als Thorvaldsens Mausoleum: Alle drei dargestellten Pflanzen - Lorbeer, Pal-

371 Münch 2011, 15.

372 Ebd., 17.

373 Eine ähnliche Frage wird bei Trempler 2011, 216, Anm. 5 aufgeworfen.

374 Thiele 1831-1850, Bd. 4, 225-226; Thiele 1852-1856, Bd. 3, 188-189; Wilckens 1875, 130-131; Bruun, C./Fenger 1892, 162; Müller, S. 1893, 299; Kornerup 1935, 7; Ravn 1944, 29; Gohr 1977b, 92; Jørnæs 2011, 250; Trempler 2011, 205.

375 Wilckens 1875, 131; Ravn 1944, 29; auch Müller, S. 1893, 299; Bjarne Jørnæs, in: Helsted 1973, 54; Friborg 2014.

376 Siehe auch Trempler 2011, 215.

377 Bruun, C./Fenger 1892, 109; Trempler 2011, 206.

378 Johann Scholl, 30. April 1840, zit. nach Bott, G. 1991, 149.

379 Siehe auch Bruun, C./Fenger 1892, 109; Bott, G. 1991, 152; Lange, B. 2002, 74; Trempler 2011, 206; Thule Kristensen 2013, 114. 
123_Innenhof von Thorvaldsens Museum mit Bertel Thorvaldsens Grab, Kopenhagen, 2012

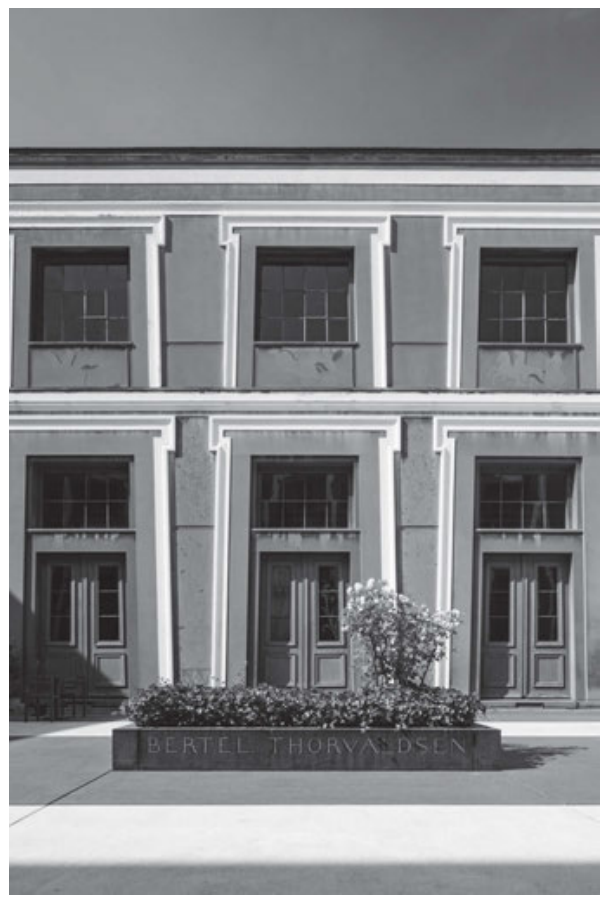

men und Eichen - stehen hier symbolisch für Sieg und ewigen Ruhm. ${ }^{380}$ Während der Palmzweig ein Attribut der Siegesgöttin Nike respektive Viktoria ist, waren aus Lorbeer oder gerade in Skandinavien aus Eichen gebundene Ehrenkränze bei Siegen oder an Begräbnissen übliche Gaben. Die in Scholls Fries dargestellten Amphoren fanden ihrerseits in der Antike oft Verwendung als Grabbeigaben oder Urnen, während wagenlenkende Genien ein verbreitetes römisches Sinnbild für den Lauf des Lebens waren. ${ }^{381}$ Letzteres Motiv hatte - wie die Quadriga auf dem Dach des Museums - seinen Ursprung im Triumphwagen römischer Herrscher. In diesem Zusammenhang ist ferner Stephen Greenblatts Abriss der Entwicklung und Transformation des römischen Triumphwagens über dessen Funktion bei Trauerzügen in der Renaissance bis hin zur schwarzen Limousine in der heutigen Begräbnistradition interessant. ${ }^{382}$ Das Triumphwagen-Motiv dürfte schließlich - gerade in Verbindung mit dem um Thorvaldsens Grab laufenden Circus aus

380 Floryan 1998, 33.

381 Melander 1982, 70-73; auch Hammerich 1876, 153-154; Jørgensen 1972b, 30; Gohr 1977b, 92; With 1998, 132; Lange, B. 2002, 74; Thule Kristensen 2013, 114.

382 Greenblatt 2010b, 15. 
weißen Granitplatten - auf das von Zeitgenossen als Triumphzug bezeichnete Leben des Bildhauers hindeuten.

Das Farbkonzept der dekorativen Gestaltung des Innenhofs geht erneut auf die visuelle Kultur des alten Ägypten zurück. Bezeichnenderweise wurde die altägyptische Kultur im 18. und 19. Jahrhundert stark mit dem Totenkult assoziiert, weshalb sich die ägyptische Formensprache besonders häufig an Grabmälern aus dieser Zeit findet. ${ }^{383}$ Ein oft zitiertes Beispiel dafür - und mögliches Vorbild für Thorvaldsens Museum/Mausoleum - ist Étienne-Louis Boullées Entwurf für ein Kenotaph in Form eines monumentalen Sarkophages von $1781-1793 .{ }^{384}$ Ferner nahm Canova in seinem 1805 ausgeführten Grabmal für die Erzherzogin Marie Christina in der Augustinerkirche in Wien die Form einer Pyramide auf. Abgeschrägte Türrahmen waren außerdem ein verbreitetes Element auf ägyptischen und etruskischen Grabmälern und Urnen, die Bindesbøll zahlreich auf seinen Reisen in den 1830er Jahren skizziert hatte sowie im vatikanischen Museo Gregoriano besichtigen konnte. ${ }^{385}$ Auch Thorvaldsen selbst verwendete dieses Motiv in seinen Grabmonumenten für Papst Pius VII. im Petersdom in Rom (1824-1831) und für Eugène de Beauharnais in der Münchner St.-Michaels-Kirche (1827-1829; Abb. 83).

Die Nähe der Formensprache von Bindesbølls Gebäude zur antiken Sepulkralkunst aus verschiedenen Kulturen verleiht dessen Doppelfunktion als Museum und Mausoleum für Thorvaldsen zusätzliches Gewicht. Erstaunlicherweise wurde in diesem Zusammenhang in der bisherigen Forschungsliteratur nicht auf das archetypische Mausoleum der Geschichte verwiesen, nämlich das Grabmal des karischen Herrschers Maussolos in Halikarnassos, dem heutigen Bodrum in der Türkei. Dieses zu den sieben antiken Weltwundern zählende, im frühen 16. Jahrhundert endgültig zerstörte Bauwerk wurde von Plinius d. Ä. beschrieben. ${ }^{386}$ Dessen Erwähnung eines Säulengangs, einer sich darüber erhebenden Pyramide sowie einer das ganze Bauwerk krönenden Quadriga veranschaulicht plastisch die Kombination von griechischen und ägyptischen Elementen und kann über den Aspekt der kulturellen Übersetzung direkt mit Thorvaldsens Museum/Mausoleum in Verbindung gebracht werden.

\section{Die Sakralisierung von Thorvaldsens Museum und Mausoleum}

Thorvaldsens Grabstätte befindet sich in der Mitte des seinerseits im Zentrum des Museumsbaus gelegenen Innenhofs. Gleichzeitig ist sie auf einer Achse zwischen der großen Vorhalle und dem Christussaal positioniert, in dem der Gang durch das Museum sowohl physisch als auch symbolisch kulminiert. ${ }^{387}$ Bei offener Türe des Christussaals wird er-

384 Paris, Bibliothèque Nationale de France (Inv.-Nr. EST HA-57).

385 Miss 1991, 350 - 351; Lange, B. 2002, 57; auch Bramsen 1959, 87 - 88.

386 Plinius 1992, $30-31$.

387 Siehe auch Gohr 1977b, 91; Traeger 1981, 44; Pieńkos 2011, 336; Trempler 2011, 215. 
sichtlich, dass die geöffneten Arme der von den Apostelfiguren umgebenen ChristusStatue direkt auf die letzte Ruhestätte ihres Schöpfers ausgerichtet sind und diesen zu empfangen scheinen (Taf. XII). ${ }^{388}$ Somit nimmt der Rahmen rund um Thorvaldsens Grabstätte jenen der Aufbahrung und besonders der Begräbniszeremonie nochmals auf: Nachdem der Leichnam auf Charlottenborg ebenso wie in der Frauenkirche von eigenen Werken des Bildhauers umgeben war, scheinen diese nun auf ewig Totenwache zu halten. ${ }^{389}$

Die architektonische Struktur des geosteten Museums mit dem auf den Christussaal ausgerichteten Künstlergrab im Zentrum sakralisiert sowohl den Bildhauer und sein Werk als auch den säkularen Bau insgesamt. Bereits die Zeitgenossen verglichen das $\mathrm{Mu}-$ seum - wie schon Thorvaldsens Ateliers - mit einem Tempel. ${ }^{390}$ So berichtete die Zeitung Berlingske Tidende am Tag nach Thorvaldsens Tod:

Albert Thorvaldsen, König der Künstler, ist tot. [...] Aber er lebt in seinen Werken, in diesen, seiner und Dänemarks Ehre und Größe, wird er stets leben: Im Heiligtum, das für seine Kunstwerke aufgerichtet wird und wo auch sein Staub ruhen soll, wird er unter uns leben! ${ }^{391}$

Wenige Tage nach der Eröffnung des Museums schrieb die Zeitung Flyveposten am 22. September 1848 schließlich: „Einer der allerschönsten Kunsttempel der Welt ist nun in Dänemarks Hauptstadt geöffnet, ein Allerheiligstes des Genies und Geschmacks [...]. “"392 Auch im Christussaal selbst wähnten sich die Zeitgenossen „in einer Kirche“ oder betrachteten ihn als das „Allerheiligste des Museums“. 393 Während dem Autor Meïr Aron

Siehe auch Otto 1869, 671; Bott, G. 1981, 348 - 349.

389 In diesem Zusammenhang sei ferner die Grabstätte des Bildhauers Vincenzo Vela (1820 - 1891) im schweizerischen Ligornetto erwähnt, in der dessen Aufbahrung vor seiner eigenen Ecce Homo-Statue nachgebildet und dadurch verewigt wurde; siehe auch Pieńkos 2011, 333-334.

390 Siehe bspw. Gardthausen 1844, 5; Thorvaldsen og den danske Digtere 1844, 10; Thiele 1831-1850, Bd. 4, 225; Thiele 1852-1856, Bd. 3, 149 und 183. Im Zusammenhang mit der damaligen Erhebung der Kunst zur Ersatzreligion bezeichnet noch Vammen 1994, 14, Thorvaldsens Museum als „Kathedrale des Goldenen Zeitalters" und den Bildhauer als Priester und Papst der Kunst. Zur Sakralisierung von Künstlerateliers und Museen im frühen 19. Jahrhundert siehe auch Maaz 2008, 22.

391 Berlingske politiske og Avertissements-Tidende, 82, 25. März 1844: „Albert Thorvaldsen, Kunstnernes Konge, er død. [...] Men han lever i sine Værker, i disse, hans og Danmarks Hæder og Storhed, vil han stedse leve: i den Helligdom, som er oprejst for hans Kunstværker og hvor hans Støv ogsaa skal hvile, vil han leve blandt os!“ (Hervorhebung im Original.) Siehe auch Møller 1844, 3.

392 „Thorvaldsens Museum“, Flyveposten, 221:4, 22. September 1848, 3: „Et af Verdens allerkjønneste Kunsttempler er nu aabnet i Danmarks Hovedstad, et Geniets og Smagens Allerhelligste, [...].“

393 Zum Vergleich des Christussaals mit einer Kirche siehe Goldschmidt 1848, 272: „Et Sted er der i Museet, hvor man befinder sig som i en Kirke; det er Salen med Christus og Apostlene og Englen med Døbefonden, [...].“ Siehe auch Kat. Kopenhagen 1974, 30 - 31. Zu jenem Saal als dem „Allerheiligsten“ des Museums siehe bspw. Thiele 1831-1850, Bd. 4, 183; Thiele 1852-1856, Bd. 3, 149; Hammerich 1876, 148. 
Goldschmidt die Farben an Thorvaldsens Museum eher missfielen, ging er bei der Hervorhebung von Analogien zwischen dem Museum und einer Kirche vermutlich weiter als alle anderen Zeitgenossen. Durch seine Feststellung, dass die Christus- und Apostel-Statuen „in Wahrheit Gottesdienst“ abhalten, vergöttlichte er Thorvaldsen explizit. Zudem würden in dem Bau „der ganze Mythos der Schöpfung [...] mathematisch bewiesen“ und der „am Menschen und dessen göttlicher Seele“ Zweifelnde versöhnt. ${ }^{394}$

Die Sakralisierung von Thorvaldsens Museum/Mausoleum wird durch seine unmittelbare örtliche Umgebung noch gesteigert: Wie die weiter oben vorgestellten Gemälde von Hansen und Zeuthen zeigen, wird das Museumsgebäude auf der Ostseite von der Kuppel der zu Schloss Christiansborg gehörenden Kapelle überragt (Taf. XI und XII). ${ }^{395}$ Diese Kuppel scheint aus verschiedenen Blickwinkeln Teil des Museumsgebäudes zu sein, was dessen Assoziation mit einem Sakralraum zusätzlich betont. Aleida Assmann hat den heiligen Ort im engen Sinn als „eine Kontaktzone zwischen Gott und Mensch“ definiert. ${ }^{396}$ Zugleich könnten profane Orte aber auch „durch die Präsenz des Toten geweiht“ sein und so zu heiligen Orten werden. ${ }^{397}$ Mit Blick auf Thorvaldsens Museum trifft beides zu: Wie in diesem Buch mehrfach dargelegt wurde, hatte sich um den dänischen Bildhauer bereits zu Lebzeiten ein beispielloser Personenkult gebildet - er wurde verehrt und buchstäblich vergöttert. Insofern stellt sein Museum tatsächlich einen Begegnungsort mit dem als gottgleichem Genie verehrten Künstler dar. Darüber hinaus beherbergt das Museum als Thorvaldsens Mausoleum die Grabstätte des Bildhauers und wird durch diese zu einem "geheiligten Ort“ erhoben, um nochmals eine Formulierung Assmanns aufzunehmen. ${ }^{398}$ Schon der Zeitgenosse Hugh Macmillan bezeichnete Thorvaldsens Museum 1869 als „Schrein dieser bemerkenswerten Heldenverehrung“ und Kopenhagen als „die Stadt von Thorvaldsen - das Mekka der Skulptur“ “. 399 Wenige Jahre später schrieb der Kritiker Clemens Petersen über Thorvaldsens Museum:

Es sieht genau wie ein Kasten aus. Doch seine Umrisse sind so delikat und so nobel in ihrer vollkommenen Einfachheit, dass es nicht ein gewöhnliches Warenlager [wareroom box] sein kann; es muss ein Schrein sein. Und die Monotonie, der Ernst und die Trauer dieses Schreins sind so erhaben, so prachtvoll, so triumphierend, dass es nicht ein gewöhnliches Grab sein kann; es muss ein Mausoleum sein. Und

394 Goldschmidt 1848, 272: „Der holdes i Sandhed Gudstjeneste. [...] men Sjælen har reist disse Mure, denne hele Bygning og fyldt den med Skatte. Hele Mythen om Skabelsen bliver her mathematisk beviist, og kommer Nogen til dette Sted, tynget og træt af Tidens Kamp, tvivlende om Mennesket og dets guddommelige Sjæl, saa gaaer han kvæget og styrket derfra." Siehe auch Kat. Kopenhagen 1974, 30 - 31.

395 Gemäß Krohn 1917a, 10, war es Bindesbølls Absicht, die Kuppel der Schlosskapelle in die Gesamtwirkung des Museumsgebäudes einzubeziehen.

396 Assmann 1999, 303.

397 Ebd., 325.

398 Ebd.

399 Macmillan 1869, 345: „Copenhagen is in fact the city of Thorvaldsen - the Mecca of sculpture. [...] Of course we visited the shrine of this remarkable hero-worship [Thorvaldsens Museum], [...]." 
so ist es. Es ist das einzige Mausoleum auf der Welt. Am Tag, an dem es fertig war, wurden alle anderen Grabmonumente stumm, für den Zweck unzureichend, und vergleichsweise unbedeutend. [...] Aber gibt es irgendein anderes Mausoleum auf der Welt, in dem die Taten des Helden auf seinem Grab stehen, nicht in Versen geschrieben oder in Symbolen verbildlicht, sondern in lebender Präsenz [d.h. als Skulpturen] [...]? Es gibt keines. ${ }^{400}$

\section{Plural temporality, oder: Die Ewigkeit der Vergangenheit}

Die in der Architektur und dekorativen Gestaltung von Thorvaldsens Museum vereinten Einflüsse und Elemente aus verschiedenen Kunst- und Bautraditionen scheinen das lange gepflegte Bild Thorvaldsens als universellem Künstler und internationaler Berühmtheit zu unterstreichen. Wie die historistische Architektur seines Museums veranschaulicht, geht mit dem stilistischen Eklektizismus eine Zusammenführung verschiedener Zeitepochen einher, oder wie Lisbet Balslev Jørgensen es beschrieben hat: „Stilarten waren nicht länger an die Zeit gebunden. Vergangenheit konnte Gegenwart werden. " ${ }^{401}$ In ähnlichen Worten erklären Alexander Nagel und Christopher S. Wood ihr Konzept der plural temporality, wonach Artefakte verschiedene Zeiten in sich vereinen und dadurch die Vergangenheit zu einem Teil der Gegenwart werden lassen können. ${ }^{402}$ In diesem Zusammenhang ist bezeichnend, dass Burke in seinen Untersuchungen zur kulturellen Übersetzung auch die Vergangenheit als ein „fremdes Land“ charakterisiert. ${ }^{403}$ Er argumentiert, dass die Übersetzungsprozesse dieselben seien, ob sie nun Elemente aus anderen Kulturen oder aus anderen Zeitepochen betreffen, denn „Historiker vermitteln zwischen der Vergangenheit und der Gegenwart und begegnen denselben Dilemmas wie andere Übersetzer“ ${ }^{\star 404} \mathrm{Ge}$ mäß Laura Hollengreen ist kulturelle Übersetzung ebenfalls nicht nur in geografischer (from place to place), sondern auch in zeitlicher Hinsicht (from past to present) zu verstehen. ${ }^{405}$ Folglich verwischen Übersetzungsprozesse die „Grenzen von Zeit, Raum, Medium und Kultur“ ${ }^{406}$ Dementsprechend schreibt auch Greenblatt, dass jene Prozesse „kulturelle

Petersen 1893, o. S.: „It looks exactly like a box. Yet its outlines are so delicate and so noble in their utter simplicity, that it cannot be a common wareroom box; it must be a shrine. And the monotony, the gravity and mourning of this shrine are so sublime, so grand, so triumphant, that it cannot be a common tomb; it must be a mausoleum. And so it is. It is the only mausoleum in the world. The day it was finished all other sepulchral monuments became mute, inadequate to the purpose, and comparatively insignificant. [...] But is there any other mausoleum in the world in which the hero's deeds stand on his grave, not written in verses or pictured by symbols, but in living presence, $[\ldots]$ ? There is none." Jørgensen 1989, 178: „Stilarterne var ikke længere bundet til tiden. Fortid kunne blive nutid.“ Nagel/Wood 2005, 403 - 404 und 408; auch Nagel/Wood 2010, 9.

403 Burke 2007, 7 und 35: „[...] the past is a foreign country [...]." Siehe auch Burke 2009, $70-71$. Zur Thematik der kulturellen Übersetzung siehe Kap. IV.2.

404 Burke 2007, 7: „Historians mediate between the past and the present and face the same dilemmas as other translators [...].“ Siehe auch Burke 2009, $70-71$.

405 Hollengreen 2008, XI.

406 Ebd.: „[...] crossing and sometimes blurring boundaries of time, space, medium, and culture[...].“ 
Verbindungen zwischen unerwarteten Zeiten und Orten“ herstellen. ${ }^{407}$ Die Grundlage der plural temporality nach Nagel und Wood sind schließlich bewusst eingesetzte Anachronismen in einem Kunstwerk, das damit nicht nur auf den Moment seiner Entstehung verweist, sondern ebenso Referenzen in die Vergangenheit (im Sinne etwa einer früheren Zeit oder eines älteren Kunstwerks), auf zukünftige Ausstellungs- und Rezeptionssituationen sowie auf außerhalb der messbaren Zeit liegende Ideen wie die Ewigkeit enthält.

In Thorvaldsens Museum als Gesamtkunstwerk basiert die kulturelle Übersetzung ebenfalls auf anachronistischen Elementen, die eine mehrschichtige Zeitlichkeit erzeugen. Anders als in Nagels und Woods Verständnis handelt es sich bei den aus fernen geografischen Regionen oder anderen Zeitepochen entlehnten Motiven jedoch nicht um einen „Ersatz“ (substitution) der jeweiligen Originale. ${ }^{408}$ Durch die Zusammenführung von Motiven aus der ägyptischen, griechischen, etruskischen und römischen Kultur in einem Museumsgebäude für einen zeitgenössischen dänischen Künstler scheint der Zweck der kulturellen Übersetzung hier vielmehr darin zu bestehen, Thorvaldsen in die großen antiken Traditionen einzuschreiben und ihn gleichsam als deren Fortführung zu inszenieren.

Mehr noch: Die Übersetzung fremder Elemente in Thorvaldsens Museum scheint den Bildhauer von spezifischen geografischen und temporalen Bindungen zu lösen und ihn stattdessen zu einem ort- und zeitlosen Künstler zu erheben. Gerade das Mausoleum verweist auf einen Ort und eine Zeitlichkeit jenseits des menschlichen Lebens. In diesem Zusammenhang ist ferner das mit Thorvaldsens Sarg in die Erde gelassene Modell des Selbstbildnisses mit der Statue der Hoffnung von Bedeutung: Wie Friborg gezeigt hat, besitzt die Granatapfelblüte in der Hand der Göttin der Hoffnung eine doppelte Symbolik von Vergänglichkeit und Unsterblichkeit zugleich. ${ }^{409}$ Auf die durch das Museum sichergestellte Unsterblichkeit Thorvaldsens verwies auch Thiele in seiner Rede am Stiftungstag der Kopenhagener Kunstakademie am Tag nach den Begräbnisfeierlichkeiten für den Bildhauer in der Frauenkirche: „Dort [im Museum] soll jetzt das Bild seines unsterblichen Geistes aufbewahrt werden; dort wird er deshalb niemals sterben.“410

Thorvaldsens Museum war - gerade in seiner Doppelfunktion als Museum und Mausoleum - das wichtigste Kulturprodukt, das die zeitgenössische Berühmtheit des Bildhauers in posthumen Ruhm überführen sollte, und bildete damit ein zentrales Instrument der celebrity-Kultur und des Geniekults um ihn. Das Ziel der Förderer des Museums, dieses zu einer ewigen Gedenkstätte für den darin weiterlebenden dänischen Künstler werden zu lassen, hat sich erfüllt. Damit steht es dem Museo Canova diametral gegenüber, um einen

409 Friborg 2014.

410 Just Mathias Thiele, Rede am Stiftungstag der Kopenhagener Kunstakademie, 31. März 1844, zit. nach Thiele 1852-1856, Bd. 3, 186. 
letzten Vergleich mit dem 22 Jahre vor Thorvaldsen verstorbenen italienischen Bildhauer zu ziehen: Myssok sieht den Grund für den schwindenden Ruhm Canovas in der posthumen Wegführung seiner Werke aus Rom ins abgelegene Possagno und der damit einhergehenden, wenngleich ungewollten Degradierung Canovas von einem internationalen zu einem lokalen Künstler des Veneto. ${ }^{411}$ Damit ist nochmals die Problematik von Zentrum und Peripherie angesprochen.

Auch die Errichtung von Thorvaldsens Museum basierte auf einem Transfer von Werken und Sammlungen weg vom kulturellen Zentrum der Zeit in eine periphere Region. Dennoch blieb der Kult um Thorvaldsen in Nordeuropa noch mindestens bis ins frühe 20. Jahrhundert bestehen. Warum ist es in diesem Fall gelungen? Der anhaltende Erfolg von Thorvaldsens Museum im Hinblick auf den Nachruhm des dänischen Bildhauers dürfte sich mit der ganzen Konstellation im Entstehungsprozess dieses Museums erklären lassen: Während die Errichtung des Museums in Possagno faktisch als Alleingang von Canovas Halbbruder Sartori zu deuten ist, fußte Thorvaldsens Museum auf einem kollektiven, von einflussreichen Personen der damaligen dänischen Politik getragenen Vorhaben. Indem diese für die Umsetzung des Plans an das dänische Nationalgefühl appellierten und eine öffentliche Geldsammlung lancierten, ermöglichten sie der gesamten Bevölkerung Dänemarks, aktiv Teil jenes geschichtsträchtigen Ereignisses zu werden. Zugleich fiel die Errichtung von Thorvaldsens Museum in eine Zeit tiefsten gesellschaftlichen und politischen Umbruchs und diente dadurch von Beginn an als Symbol einer neuen Ära. Dies dürfte wiederum den Gemeinschaftssinn und das Nationalbewusstsein der Dänen gestärkt haben, sodass sie jenes Sinnbild der nachrevolutionären Zeit zu einem Ort des kollektiven Gedächtnisses erhoben und diesen - wenngleich nicht mehr in der kultähnlichen Form wie im 19. Jahrhundert - bis heute pflegen. Dadurch wurde Thorvaldsens damalige celebrity tatsächlich in dauerhaften Ruhm verwandelt. 
